
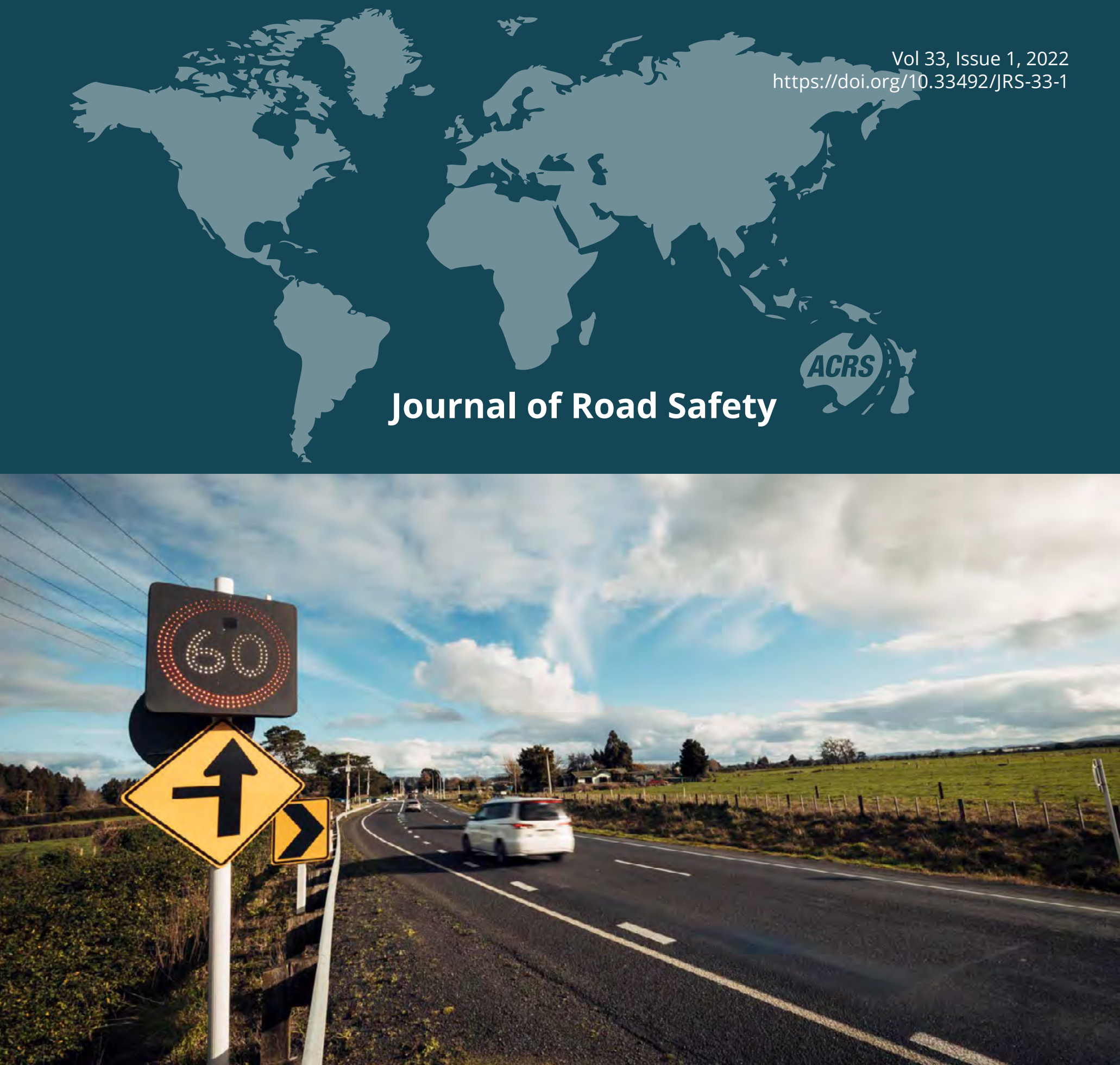

\title{
Peer-reviewed papers
}

Road Safety Evidence Review

- Understanding the role of Speeding and Speed in Serious Crash Trauma: A Case Study of New Zealand

\section{Road Safety Case Studies}

- $\quad$ Adopting a Safe System Approach to Determine Safer Speed Limits: A Case Study from Iran

- Silent, unsafe... and underestimated? Exploring the relationships between life stress and safety issues among Spanish drivers

- Traffic safety climate factors in explaining driving behaviours and traffic crash involvement: comparative study among Male and Female drivers

\section{Contributed articles}

Perspective on Road Safety

- New Deal in Road Safety: Why we need NGOs

\section{Letter to the Editor}

- COVID-19 pandemic, driving test and road safety during outbreak 


\section{Campaign highlights the risks of 'casual speeding'}

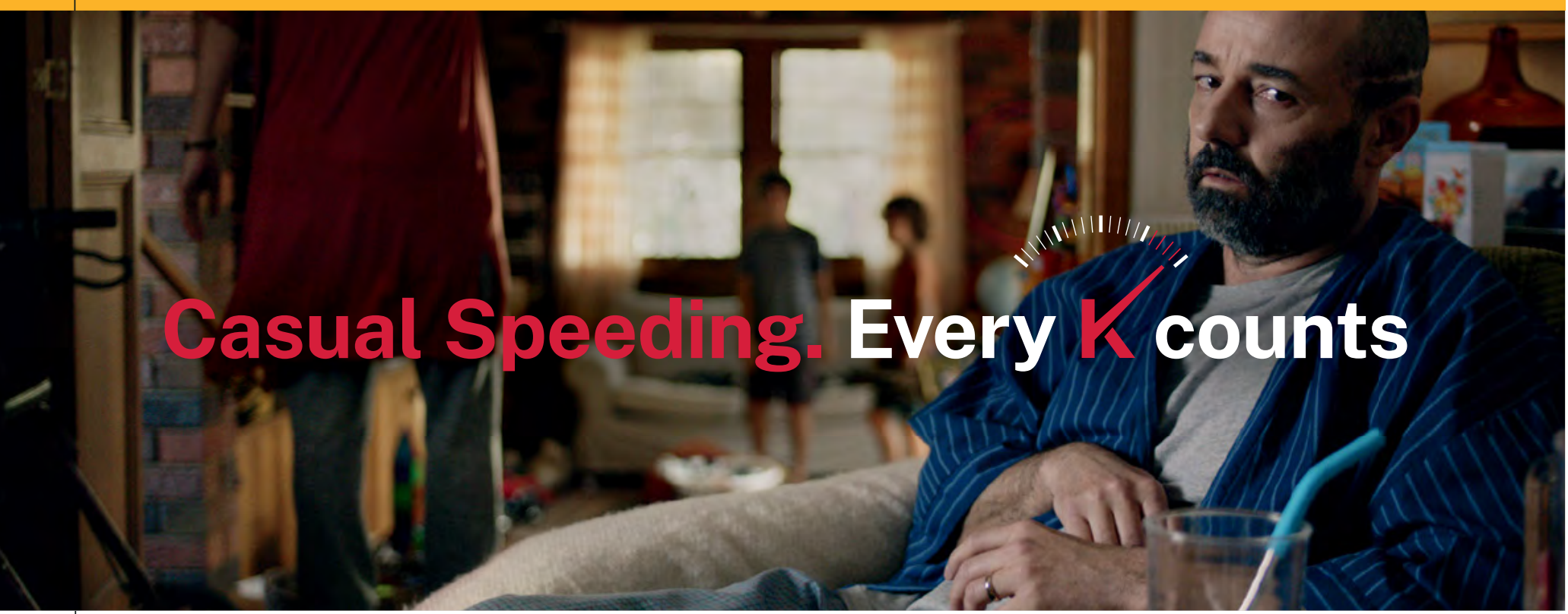

On 31 October, Transport for NSW (TfNSW) launched the 'Casual Speeding. Every K counts' campaign urging motorists to slow down and not to be casual about speeding.

Research commissioned by TfNSW shows many NSW motorists do not believe that 'going a bit over' the speed limit is risky or dangerous and report they commonly engage in this type of speeding.

However, the truth is that speeding at no more than $10 \mathrm{~km} / \mathrm{h}$ over the speed limit is the biggest contributor to deaths and serious injuries on NSW roads.

Evidence shows that small changes in speed can have a big impact on the outcome of a crash:

- Going $5 \mathrm{~km} / \mathrm{h}$ over in a $60 \mathrm{~km} / \mathrm{h}$ zone doubles your risk of having a crash

- Going $10 \mathrm{~km} / \mathrm{h}$ over in a $60 \mathrm{~km} / \mathrm{h}$ zone means you're four times more likely to be injured in a crash.

The 'Casual Speeding. Every K counts' campaign is targeted at all NSW motorists and aims to challenge motorists' casual attitudes towards driving slightly over the speed limit and encourage them to slow down. It demonstrates the real risks and consequences to themselves and others of going 'just a bit' over the speed limit or driving too fast for the conditions.

The campaign comprises:

- TV and cinema advertising

- Radio advertising

- Outdoor advertising

- Digital advertising.

To view the campaign, or for more information, please visit roadsafety.transport.nsw.gov.au/campaigns/speed 


\section{Sign up to the Road to Zero}

newsletter
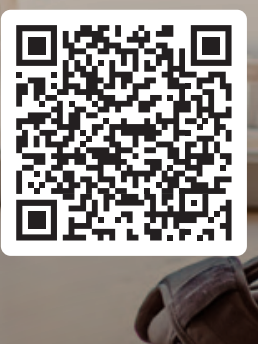

For road safety resources, case studies and more, sign up to the Road to Zero newsletter for the latest news on our. journey to achieve Vision Zero - an Aotearoa New Zealand where no one is killed or seriously injured on our roads.

Sign up at nzta.govt.nz/road-to-zero 


\section{Australasian Road Safety Conference}

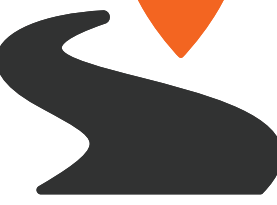

28-30 SEPTEMBER • CHRISTCHURCH, NZ • ONLINE

\section{CHANGING TODAY FOR TOMORROW}

\section{Australasian Road Safety Conference}

The largest road safety-dedicated conference in the Southern Hemisphere

Join Australasia's leading road safety and injury prevention researchers, practitioners and policy makers for the Australasian Road Safety Conference 2022.

ARSC 2022 will be held in conjunction with Trafinz in Christchurch, NZ and online to accommodate delegates from anywhere in the world. This hybrid format will bring together road safety stakeholders and decision-makers from Australasia and international jurisdictions to facilitate collaboration and share information.

Call for abstracts opens in early February 2022.

The theme is Changing Today for Tomorrow with the sub themes:

- Prioritising People

- Implementing Change

- Defining Tomorrow

- Innovation \& Transformation

\section{Brought to you by}
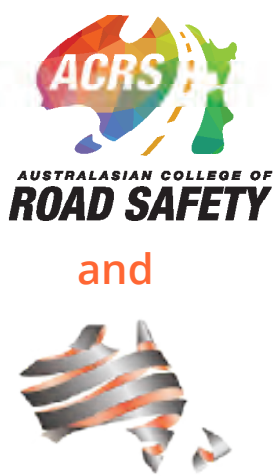

Austroads

In conjunction with

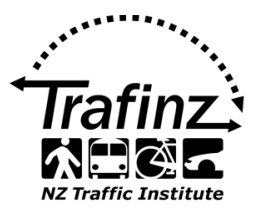

With thanks to Gold \& LMIC Scholarship Sponsor

Australian Government

Department of Infrastructure, Transport, Regional Development and Communications

\section{Registration opening soon}

Plan to be a part of this incredible event - in person or virtually

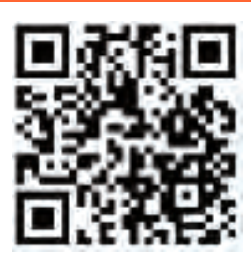




\section{Contents}

\section{Peer reviewed papers}

\section{Road Safety Evidence Review}

Understanding the role of Speeding and Speed in Serious Crash Trauma: A Case Study of New Zealand

- R.F. Soames Job and Colin Brodie

\section{$\underline{\text { Road Safety Case Studies }}$}

Adopting a Safe System Approach to Determine Safer Speed Limits: A Case Study from Iran

- Mansour Ranjbar, Ali Tavakoli Kashani, Mohammad Mehdi Besharati, Moslem Azizi Bondarabadi,

Hormoz Zakeri, Seyedali Hosseinizadeh, Gregory Chambers, Lori Mooren and Ray Shuey

Silent, unsafe... and underestimated? Exploring the relationships between life stress and safety issues among

Spanish drivers

- Francisco Alonso, Mireia Faus and Sergio A. Useche

Traffic safety climate factors in explaining driving behaviours and traffic crash involvement: comparative study among Male and Female drivers.

- Charles Atombo and Chaozhong $\mathrm{Wu}$.....

\section{Contributed articles}

\section{Perspective on Road Safety}

New Deal in Road Safety: Why we need NGOs

- Lotte Brondum, Chika Sakashita, Liz Man, and Valeria Motta

\section{Letter to the Editor}

COVID-19 pandemic, driving test and road safety during outbreak

- Rujittika Mungmngpuntipantip and Viroj Wiwanitkit

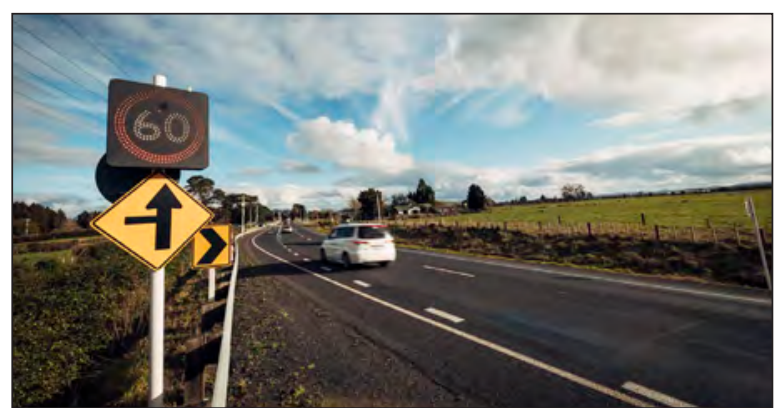

\section{Cover image}

Under-reporting of speeding in crashes contributes to under-appreciation of speeding risk by media, community and decision-makers. See Road Safety Evidence Review article: Job, R.F.S and Brodie, C. (2022). "Understanding the role of Speeding and Speed in Serious Crash Trauma: A Case Study of New Zealand" Journal of Road Safety, 33(1), 5-25. https://doi.org/10.33492/JRS-D-21-00069

Photo kindly provided by Waka Kotahi NZ Transport Agency.

\section{Disclaimer}

Materials (papers, contributed articles, letters, advertisements and editorial) in this journal may not necessarily reflect the opinions of peer reviewers or the Australasian College of Road Safety, who disclaim all liability for any damages that may result from publication of any material and from persons acting on it. 
The Journal of Road Safety (ISSN 2652-4252 (Online); ISSN 2652-4260 (Print); DOI:10.33492/JRS (formerly The Journal of Australasian College of Road Safety (JACRS), ISSN 1832-9497, DOI:10.33492/JACRS between 2005 and 2019 and RoadWise between 1988 and 2004). Published quarterly (February, May, August, November) as an on-line Open Access Journal (https:// acrs.org.au/journals) by the Australasian College of Road Safety.

Managing Editor: Dr Chika Sakashita

Australasian College of Road Safety \& Global Road Safety Solutions Sydney, NSW. journaleditor@acrs.org.au

Editor-in-Chief: Prof Raphael Grzebieta (FACRS)

Emeritus Professor (Road Safety), Transport and Road Safety

(TARS) Research Centre, School of Aviation, UNSW.

Adjunct Professor, Victorian Institute of Forensic Medicine,

Monash University

Associate Editor: Prof Jake Olivier

Professor, School of Mathematics and Statistics, UNSW

New South Wales, Australia

Deputy Director, Transport and Road Safety (TARS)

Research Centre, School of Aviation, UNSW

\section{Advertising and sponsorship}

Advertising rates and, specifications are on the College website at http://acrs.org.au/publications/journals/advertising/ or available by email to faa@acrs.com.au. Discounts are available for prepaid advertising booked to run for more than one issue. The College also welcomes sponsorship of the Journal. For more information about becoming a Journal sponsor, please contact the Managing Editor.

\section{Editorial Policy}

The Journal of Road Safety (JRS) is an international, scholarly, cross-disciplinary, peer-reviewed and open-access journal purely focused on road safety. The JRS accepts papers from any country or region and aims to publish a diverse range of high quality papers on road safety from researchers, policy makers, program implementers and other road safety experts.

All papers submitted to the JRS undergo a peer-review process, unless the paper is submitted as a Contributed Article or Correspondence (Letter to the Editor). Peer-review Papers and Contributed Articles can take the form of the following articles types: Original Road Safety Research; Road Safety Data, Research \& Evaluation Methods; Road Safety Policy \& Practice; Road Safety Case Studies; Road Safety Evidence Review; Road Safety Best Practice Guidance; Road Safety Theory; Road Safety Media Review; Perspective on Road Safety.

All submissions are assessed on the basis of quality and importance for advancing road safety, and decisions on the publication of the paper are based on the value of the contribution the paper makes in road safety. Once a paper is submitted, the Editor-in-Chief and/or Managing Editor initially review the submission. Authors are notified if their paper is judged to be outside of the JRS' scope or lacks originality or message that is important to the readers of the JRS.

Peer-review submissions that pass the initial screening process will be sent out to a minimum of three peer reviewers selected on the basis of expertise and prior work in the area. Additional peer reviewers may be called on at the discretion of the Editor(s), e.g. in the case of a disagreement between referees' opinions. The names of the reviewers are not disclosed to the authors.

Based on the recommendations from the peer-reviewers, the Editorin-Chief makes a decision, in consultation with the Managing Editor and/or Editorial Board when needed, to accept or reject a manuscript, or to request revisions from the author/s in response to the comments from the reviewer/s. Authors are informed of the decision after the first round of review. Revised submissions are sent out for a second round of review and authors are again notified of the decision based on the recommendations from the peerreviewers.
Contributed Article submissions that pass the initial screening process will be reviewed in detail by the Managing Editor and an additional reviewer may be called on at the discretion of the Editor(s) or the paper may be subject to peer-review, e.g. in the case of contentious contents that need expert assessment. The Managing Editor makes a decision, in consultation with the Editor-in-Chief and/or Editorial Board when needed, to accept or reject a manuscript, or to request revisions from the author/s in response to the comments from the reviewer/s. The names of the reviewers are not disclosed to the authors. Authors are informed of the decision after the first round of review.

As a rule of thumb, manuscripts can undergo only one major revision. Any editorial decisions regarding manuscript acceptance by the Editor-in-Chief and Managing Editor are final and further discussions or communications will not be entered into in the case of a submission being rejected. For both peer-review and contributed articles, one or more of the reviewers may require a major revision or reject the paper because of content that may otherwise be of general interest to readers but is not at the level expected of a caliber of a scientific journal paper.

\section{Author responsibility}

Authors are responsible for complying with all the requirements (including Article formatting, References, Ethics in publishing, Originality \& plagiarism, Author declaration) before submitting their papers. Authors must write entirely original works, and appropriately cite the work and/or words of others to ensure originality and avoidance of plagiarism. Authors of original road safety research articles should present an accurate account of the work performed as well as objective discussion of the findings and their significance. Submission of an article implies that the work described has not been published previously (except in the form of an abstract or as part of a published lecture or academic thesis or as an electronic preprint), that it is not under consideration for publication elsewhere, and that, if accepted, it will not be published elsewhere in the same form, in English or in any other language, including electronically without the written consent of the copyright-holder.

If excerpts from other copyrighted works are included, the author(s) must obtain written permission from the copyright owners and credit the source(s) in the article. Authors are obliged to promptly notify the Managing Editor and cooperate with the Editor to retract or correct the paper when an author discovers significant errors in their own published works. Statements of compliance are required if the work involves chemicals, procedures or equipment that have any unusual hazards inherent in their use. Research involving human subjects, human material, human tissues, or human data, authors must provide a statement including the project identification code, date of approval, and name of the ethics committee or institutional review board cited in the Methods section of the article. Any conflicts of interest must be declared. Authors are to comply with the Guidelines issued by the Committee on Publication Ethics (COPE)

\section{ACRS office contact details}

Dr Ingrid Johnston, Chief Executive Officer ceo@acrs.org.au for inquiries regarding membership and College activities.

Dr Chika Sakashita, Managing Editor, journaleditor@acrs.org.au for inquiries regarding submissions, current and back issues, advertising and sponsorship for the Journal.

Contact admin@acrs.org.au for inquiries regarding Journal subscriptions and changes of postal address.

Mailing address: PO Box 198, Mawson, ACT 2607 Australia

Phone: (02) 62902509

Head office: Pearce Centre, Collett Place, Pearce ACT Australia 


\section{Editorial Board}

The JRS Editorial Board consists of diverse road safety experts from highly credentialed academics to highly experienced practitioners in road safety delivery. Some are ex-academics with many years of practical experience in road safety.

\begin{tabular}{|c|c|c|}
\hline Editorial Board & Affiliation & Country/State \\
\hline Dr Rebecca McLean & $\begin{array}{l}\text { Senior Lecturer Fellow, Dept Preventive and Social Medicine, } \\
\text { Dunedin School of Medicine, University of Otago }\end{array}$ & New Zealand \\
\hline Prof Judith Charlton & Director, Monash University Accident Research Centre & Victoria, Australia \\
\hline Dr Judy Fleiter & Visiting Fellow, Centre for Accident Research and Road Safety & $\begin{array}{l}\text { Queensland, } \\
\text { Australia }\end{array}$ \\
\hline Prof Rebecca Ivers & Head of School, Public Health \& Community Medicine, UNSW & $\begin{array}{l}\text { New South Wales, } \\
\text { Australia }\end{array}$ \\
\hline Dr Soames Job (FACRS) & CEO, Global Road Safety Solutions & $\begin{array}{l}\text { New South Wales, } \\
\text { Australia }\end{array}$ \\
\hline A/Prof Michael Keall & $\begin{array}{l}\text { Research Associate Professor, Department of Public Health, } \\
\text { University of Otago Medical School }\end{array}$ & New Zealand \\
\hline Dr Nadine Levick & Director, Objective Safety LLC & Israel \\
\hline Prof Andrew McIntosh & $\begin{array}{l}\text { Director, McIntosh Consultancy \& Research } \\
\text { Adjunct Professor, ACRSIP FedUni } \\
\text { Adjunct Associate Professor, } \\
\text { Monash University Accident Research Centre }\end{array}$ & Victoria, Australia \\
\hline Prof Lynn Meuleners & $\begin{array}{l}\text { Director, School of Population and Global Health, } \\
\text { University of Western Australia }\end{array}$ & $\begin{array}{l}\text { Western Australia, } \\
\text { Australia }\end{array}$ \\
\hline Prof Jake Olivier & Professor, School of Mathematics and Statistics, UNSW & $\begin{array}{l}\text { New South Wales, } \\
\text { Australia }\end{array}$ \\
\hline $\begin{array}{l}\text { A/Prof George } \\
\text { Rechnitzer }\end{array}$ & $\begin{array}{l}\text { Adjunct Associate Professor, Transport and Road Safety (TARS) } \\
\text { Research Centre, UNSW }\end{array}$ & $\begin{array}{l}\text { New South Wales, } \\
\text { Australia }\end{array}$ \\
\hline $\begin{array}{l}\text { Prof Michael Regan } \\
\text { (FACRS) }\end{array}$ & $\begin{array}{l}\text { Emeritus Professor, Research Centre for Integrated Transport Innovation } \\
\text { (rCITI), School of Civil and Environmental Engineering, UNSW }\end{array}$ & $\begin{array}{l}\text { New South Wales, } \\
\text { Australia }\end{array}$ \\
\hline Dr Ray Shuey & $\begin{array}{l}\text { Principal and Founder, Strategic Safety Solutions Pty Ltd. } \\
\text { President/Chairman, International Safety Foundation (NFP Charity) }\end{array}$ & Victoria, Australia \\
\hline Prof Gordon Smith & $\begin{array}{l}\text { Stuart M. and Joyce N. Robbins Distinguished Professor, } \\
\text { School of Public Health, West Virginia University } \\
\text { Adjunct Professor, University of Maryland School of Medicine }\end{array}$ & $\begin{array}{l}\text { West Virginia \& } \\
\text { Maryland, USA }\end{array}$ \\
\hline A/Prof Richard Tay & VC Senior Research Fellow, RMIT University & Victoria, Australia \\
\hline Dr Blair Turner & Senior Transport Specialist, Global Road Safety Facility & $\begin{array}{l}\text { Washington DC, } \\
\text { USA }\end{array}$ \\
\hline Dr Shane Turner & $\begin{array}{l}\text { Technical Director, Road Safety, Abley. } \\
\text { Adjunct Senior Fellow, Department of Civil and Natural Resources } \\
\text { Engineering, University of Canterbury }\end{array}$ & New Zealand \\
\hline $\begin{array}{l}\text { Prof Barry Watson } \\
\text { (FACRS) }\end{array}$ & Adjunct Professor, CARRS-Q, Queensland University of Technology & $\begin{array}{l}\text { Queensland, } \\
\text { Australia }\end{array}$ \\
\hline Prof Fred Wegman & Emeritus Professor of Traffic Safety, Delft University of Technology & The Netherlands \\
\hline $\begin{array}{l}\text { Prof Ann Williamson } \\
\text { (FACRS) }\end{array}$ & Director, Transport and Road Safety (TARS) Research Centre, UNSW & $\begin{array}{l}\text { New South Wales, } \\
\text { Australia }\end{array}$ \\
\hline
\end{tabular}

We welcome questions and suggestions to continue to improve the Journal of Road Safety.

Please contact Managing Editor journaleditor@acrs.org.au 


\section{Peer-reviewed papers}
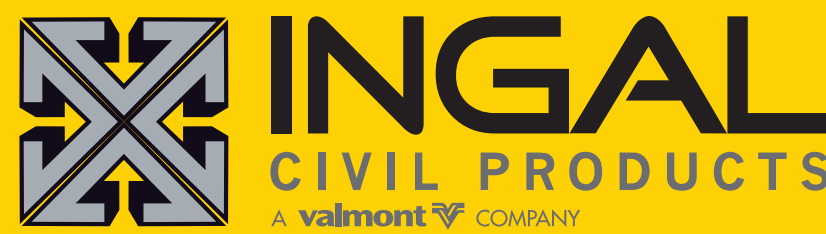

C I VIL PRODUCTS

A valmont $\sqrt{ }$ COMPANY

\section{Australia's leading manufacturer of road safety barriers since 1933.}

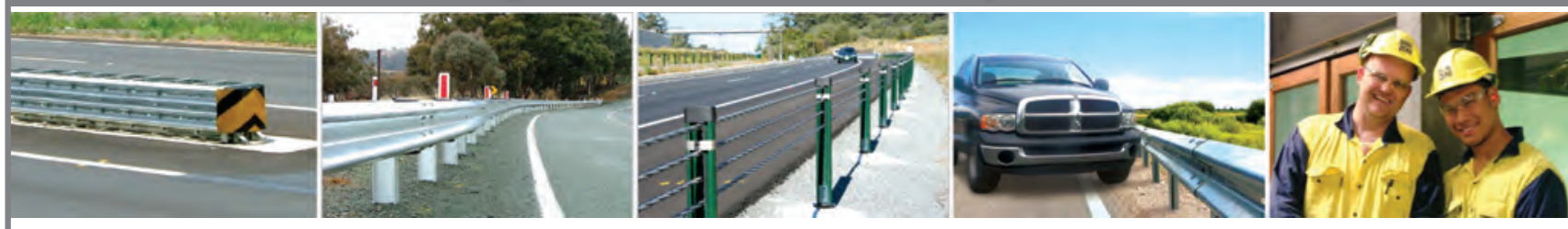

GUARDRAIL • WIREROPE SAFETY BARRIER • CRASH CUSHIONS • CARPARK BARRIERS • EZY GUARD BARRIER

HEAD OFFICE: 57-65 Airds Road, Minto NSW 2566 


\title{
Road Safety Evidence Review
}

\section{Understanding the role of Speeding and Speed in Serious Crash Trauma: A Case Study of New Zealand}

\author{
R.F. Soames Job ${ }^{1}$ and Colin Brodie ${ }^{2}$ \\ ${ }^{1}$ CEO, Global Road Safety Solutions, Sydney, Australia \\ ${ }^{2}$ Director, Colin Brodie Consulting Ltd, Tauranga, New Zealand \\ Corresponding Author: Soames Job, Global Road Safety Solutions, soames.job@gmail.com
}

\section{Key Findings}

- Speeding is substantially under-estimated as a factor in serious crashes in New Zealand's crash data, and elsewhere

- Under-reporting of speeding in crashes contributes to under-appreciation of speeding risk by media, community and decision-makers

- Combining data sources indicates that speeding is involved in around $60 \%$ of fatal crashes in New Zealand

- $\quad$ Speeding kills more people each year in New Zealand than homicides

- Different data sources on speed and crashes appear inconsistent because they address different questions

\begin{abstract}
Multiple sources of evidence address the contribution of speed and speeding in crashes: police crash reports, in-depth crash investigations, studies of speed and serious crash risk, assessments of survival and injury rates for various impact speeds, and evaluations of the safety outcomes of speed management interventions. These sources of evidence all indicate that speed is a major factor in crash trauma, but appear to differ in estimates of the extent of the role of speed. This paper employs New Zealand as a country case study, undertaking a targeted assessment of data from the different sources to better determine the roles of speed and speeding in serious crashes. We find that apparent mismatches of estimates of the role of speed from different sources largely arise for two reasons. First, the studies vary in methodology and thus validity, and second the data from the different sources provide answers to fundamentally different questions, which are then incorrectly subsumed into the general question of the role of speed. Finally, we answer the question: 'What is the extent of the role of speed in crashes, and particularly deaths and serious injuries?' by providing answers to the different ways of couching these questions. Depending on the question, correct answers range from $20 \%$ to $100 \%$ of serious crashes. By combining evidence from different sources, we estimate that speeding is involved in around $60 \%$ of fatal crashes in New Zealand, and that speeds above New Zealand's Safe and Appropriate Speeds are involved in around 71\% of injury crashes.
\end{abstract}

\section{Keywords}

Speeding, Under-reporting of speeding, Speeding and crashes, Speed and crashes, Speed and injury, Speed management

\section{Introduction}

Speed is fundamental to road safety, with many sources of evidence pointing to the profound role of speed in road crashes, injuries, and deaths. The nine key sources of evidence identified and considered in this paper are: (1) Analyses of the probability of survival for different impact speeds for various road users (pedestrians, vehicle occupants); (2) Meta-analyses of the relationships between average travel speeds and fatal, injury, and crash occurrences; (3) Evaluations of speed management interventions in terms of lives, injuries and crashes saved; (4) Analyses of Police based crash data; (5) In-depth crash investigations; (6) Application of safe system principles;

Received: 19/12/2021; Received in revised form: 06/01/2022; Accepted: 11/01/2022; Available online: 09/02/2022

Copyright: (C) The Author(s). 2021 This is an open access article distributed under the terms of the Creative Commons Attribution (CC BY)_license, which permits unrestricted use, distribution, and reproduction in any medium, provided the original author(s) and the source are credited.

Suggested citation: Job, R.F.S and Brodie, C. (2022). "Understanding the role of Speeding and Speed in Serious Crash Trauma:

A Case Study of New Zealand”. Journal of Road Safety, 33(1), 5-25. https://doi.org/10.33492/JRS-D-21-00069 
(7) Application of 'Safe and Appropriate Speeds' or similar policy positions; (8) Naturalistic Driving Studies; and (9)

Combined data sources. The purposes of this paper are to:

1. Review these sources of evidence in order to estimate the role of speed in road safety. New Zealand is employed as a case study in order to allow comparison of data from different sources (along with collection of additional data) for the one country. For issues where data are not available directly for New Zealand, the applicability of evidence from elsewhere is considered and employed when suitable, with the rationale for applicability provided. In the absence of a focus on a single country or state, differences in estimates of the role of speed may simply reflect real differences between the various countries from which the data were collected.

2. In addition, it is worthwhile to consider the extent to which the expansive global body of evidence applies to a particular country, because the claim from each country that they are unique and thus somehow the evidence on the importance of speed does not apply to them is ubiquitous: Such claims are common in discussions of road safety in many countries including from Ministers at the Third Global Ministerial Conference on Road Safety, Stockholm 2020 (and for discussion see Delaney, Ward, Cameron \& Williams, 2005; Shoukrallah, 2008; Turner, Job \& Mitra, 2021, p.4-5).

3. It is important to appreciate the role of speed in serious crashes, not just the role of speeding. This review and analysis considers both speed and speeding. For this purpose, these terms are explicitly defined.

Speeding is taken here to refer to travelling at a speed above the legal limit, including limits which may apply to the particular driver (such as a learner driver) or vehicle (such as a truck or bus). In some countries the offence of speeding may also apply for driving at a speed which is excessive for the conditions. This is not a point of focus in the present paper because police in many countries, including New Zealand, have informed us (personal communication) that this is quite rare or never applied, though other charges may be applied. Speed refers simply to the occurrence of movement measures as distance/ time, such as kilometres per hour $(\mathrm{kmh})$. Thus, analyses of the role of speed in crashes relate to changes in risk with changes in speed independent of the speed limit.

Ongoing challenges in the management of speed for road safety are the primary reasons for undertaking this review and analysis. First, speed management is the most contested area of road safety policy and practice (Mooren, Grzebieta \& Job, 2014), with speeding identified as the most commonly disobeyed law (Grabar, 2021) and common media resistance to speed management (Litras \& Spits, 2010, and in New Zealand, Matthew, 2019). Second, many effective evidence-based policy settings are established yet mostly not adopted, including speed limiting of vehicles or intelligent speed adaptation, speed limits set to safe speeds (Job \& Sakashita, 2016; Wambulwa \& Job, 2019) and effective use of speed enforcement (OECD, 2006; Job, 2018), including covert speed cameras (Keall, Povey \& Frith, 2001). Third, it is vital to assess the various sources and the evidence they provide, because just one source (police based crash data) dominates both professional and media considerations of the role of speeding and often the role of speed as well (e.g., OECD, 2006; Grabar, 2021; and in New Zealand, Matthew, 2019). Finally, the diverse sources of evidence are rarely compared or combined, which may provide opportunities to advance our knowledge of the roles of speed and speeding in road trauma.

\section{Multiple Roles of Speed in Crashes}

Speed increases both the risk of a crash as well as its severity. Speed increases crash risk and severity through more mechanisms of action than are generally appreciated. The mechanisms are listed below, separated for effects on crash occurrence and crash severity:

\section{Crash occurrence:}

1. As speed increases so too does the distance the vehicle travels in the time the driver (henceforth including rider) takes to see a problem ahead, judge what to do, and react (e.g., brake to a stop), because the vehicle is traveling faster for that available time. Thus, the vehicle is closer to any problem situation identified even before the driver has judged the need to stop and moved to brake;

2. Once the brakes are applied the vehicle takes longer to stop from higher speeds;

3. The driver is less likely to see a hazard in a busy road environment when traveling at higher speed simply because the driver has less time to scan the environment on approach;

4. Drivers may be less inclined to stop and give way when they are travelling at higher speeds due to increased braking and then acceleration afterwards required to return to their original speed. Research shows a linear relationship between driver approach speed and failing to yield to pedestrians at unsignalized crosswalks: at $20 \mathrm{mph}$ around $75 \%$ of drivers yield, but at just $10 \mathrm{mph}$ higher speed only $40 \%$ of drivers yield to pedestrians (Bertulis \& Dulaski, 2014).

5. At night even moderate speed in a poorly lit urban environment can mean the vehicle is travelling at a speed which results in a combined judgement, reaction time, and stopping distance that make it impossible to stop within the distance illuminated by the headlights. Thus, a crash with a pedestrian on the 
road or hazard may be unavoidable by the time it is visible (for example, see Grzebieta 2019);

6. At higher speed the driver is less able to manoeuvre and stay in control of the vehicle to get around a problem and avoid a crash;

7. At higher speed the vehicle is less able to negotiate a curve or corner without losing control and running off the road or crossing to the wrong side of the road, risking a head on crash. This is not a rare form of head on crash on rural roads, with studies of headon crashes showing that curves are associated with more head-on crashes (e.g., Hosseinpour, Yahaya, \& Sadullah, 2014), and that head-on crashes are mostly not associated with overtaking (which was involved in less than $8 \%$ of head on crashes even on rural roads, with these crashes more commonly caused by driving 'too fast for the conditions': Garder, 2006). The figure is similar for New Zealand with only $7 \%$ of overtaking fatal and serious injury crashes involving overtaking (New Zealand Transport Agency Waka Kotahi, 2011).

8. Higher speeds reduce the time from when a risk becomes visible to the driver to when evasive action is required, based on the topography of the road. For example, the speed limit may be low because of curves limiting vision for intersections or junctions just beyond the curve and thus the speed limit is set to allow enough time for entering or crossing drivers (or pedestrians) to do so safely in the time they have before a vehicle which is just out of view behind the curve would reach them, and enough time for a vehicle travelling along the road with the curve to see, judge, and stop. However, a speeding vehicle can reach the intersection too quickly causing a crash. The same logic applies to other road features such as crests of hills which limit vision ahead;

9. Even if in view, other road users may reasonably expect an approaching vehicle to take a certain time to reach them at the prevailing speed limit allowing them time to cross, yet a speeding vehicle may reach them sooner. (This is especially true for older pedestrians who tend to (miss)judge a safe crossing gap by the distance to the approaching vehicle more than the speed of the vehicle: Job, Haynes, Prabhakar, Lee, \& Quach, 1998).

\section{Crash severity:}

10. The higher the speed the higher the energy and thus the forces in a crash. Speed is the toxin in crashes, with higher speeds delivering exponentially more energy into the crash (IIHS, n.d.). Speed has this especially powerful (exponential) effects on crash severity because the kinetic energy of a vehicle is not just proportional to its speed but to the square of its speed or velocity. For example, when impact speed increases from 30 to $50 \mathrm{kmh}$ (a 67 percent increase), the energy increases by 178 percent. ;
11. Safety features of the road, such as crash barriers, are located, designed and built to provide protection up to the speed limit (New Zealand Transport Agency Waka Kotahi, 2021), but may become ineffective if hit at speeds above the limit. Thus, as speed increases road features designed to manage crash forces and/ or prevent the vehicle from a more severe crash - for example over a cliff or into oncoming traffic (such as crash barriers, medians, and impact attenuators) are less able to perform their safety function effectively. It is no simple matter to build all barriers, medians, etc. to withstand high speeds: this costs more limiting funds available for other road safety work, and may not be possible with the space available on many roads.

12. As speed increases active vehicle safety features such as automatous braking are less able to stop in time to avoid a crash or less able to reduce speed to safe levels of impact by the time the impact occurs;

13. As speed increases, the passive protective features of vehicles are increasing likely to fail: the integrity of the vehicle body may fail crushing the occupants and leaving little survival room; restraint systems (i.e., airbags, seat belts) may be unable to minimize higher levels of force sufficiently to avoid severe injury or death.

\section{Applying the Evidence on Speed and Speeding to New Zealand}

This paper presents a case study of New Zealand, which like all countries, has a particular combination of features and challenges in relation to road safety. The uniqueness of countries and regions is often asserted as a reason for not adopting evidence on road safety from other countries (see Turner et al., 2021). There is clearly a case for not simply generalizing the processes which delivered road safety from other countries to New Zealand in instances such as messaging for attitude change which are highly reliant on existing social values, beliefs, and religions. Thus, distinctiveness, local attitudes and existing beliefs must be considered in applying some aspects of speed management. On the other hand evidence from various country has regularly been applied successfully in other countries including New Zealand, including the successes of speed cameras and speed managing infrastructure (Delaney at al., 2005; Turner et al., 2021; Wilson et al., 2010).

In road safety we have more in common than we have that distinguishes us. This is especially true for many but not all elements of speed and road safety. Most critically, the universal laws of physics, the universal vulnerability of the human body to force, and the similarity of human reaction times, mean that the toxic exponential effects of speed on crash risk and crash severity apply the same way in all countries. Thus, universally with other things being equal, higher speeds increase both crash risk and severity and interventions which reduce speeds will reduce 


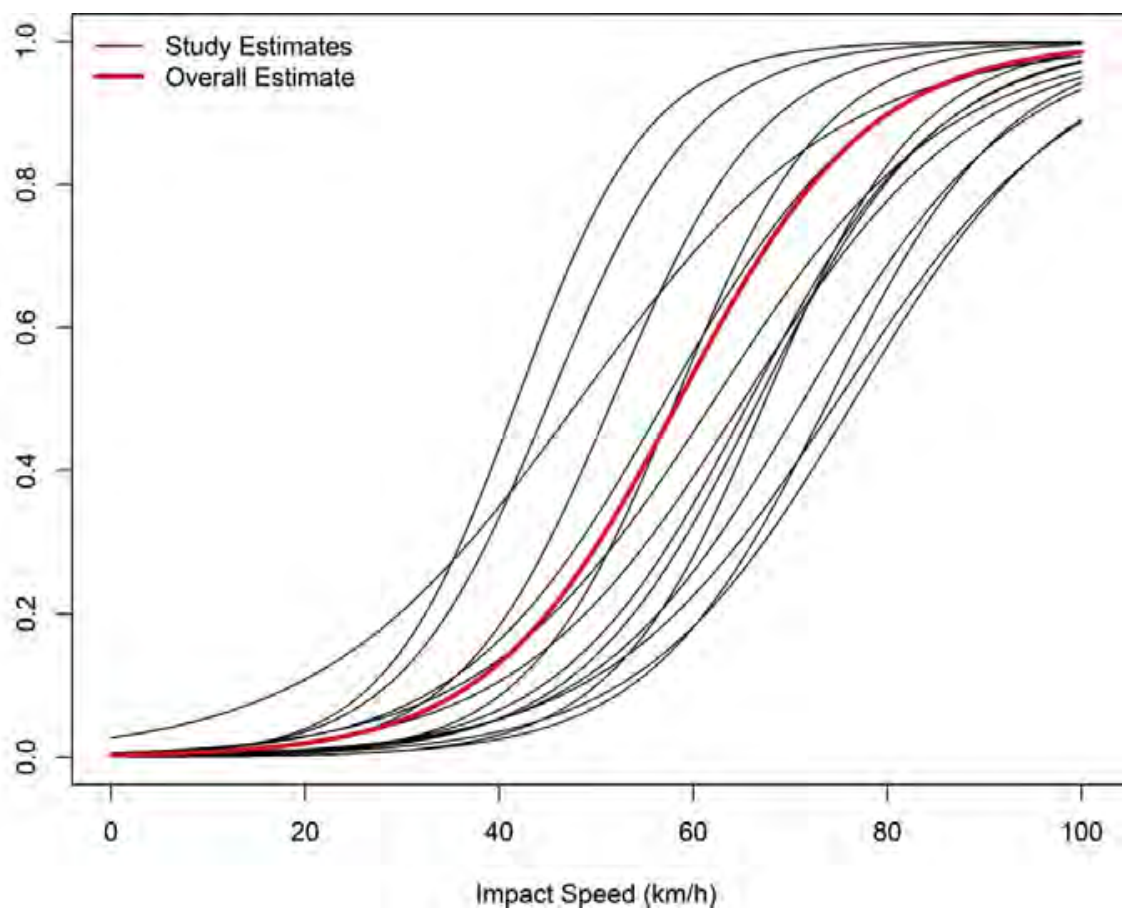

Fig. 5. Plot for S-shaped curves for pedestrian fatality risk by impact speed.

Figure 1. The relationship between pedestrian death risk and the impact speed of vehicles (Source: Hussain et al., 2019)

fatal and serious injury crashes. For this reason, research findings on the effects of speed are especially transferable from one country to another, with an appreciation of some differences in consequence. For example, older cars and those with less effective passive safety (effective seatbelts, effective and fullest set of airbags, etc.) will have lower New Car Assessment Program safety star ratings and will allow severe injuries at lower impact speeds than the best safety rated cars (Van Ratingen et al., 2016). Vehicle fleet age is relevant for New Zealand, because the average age of the fleet is older than many of the high-income countries in which relevant research has been conducted (in New Zealand 14.4 years versus USA 11.6 years, Australia 10.1 years, Europe 7.4 years: Ministry of Transport, 2020). Thus, if anything, severe injuries may occur at slightly lower speeds in New Zealand due to slightly less protection afforded by the vehicles.

\section{Sources of Evidence on the Role of Speed}

In addition to the fundamental laws of physics, an expansive and irrefutable body of evidence exists showing the critical role of speed in both crash occurrence and severity (for reviews and meta-analyses see: Elvik, Vadeby, Hels, \& van Shagen, 2019; Global Road Safety Partnership, 2008; Job \& Sakashita, 2016; Nilsson, 2004; OECD, 2006; Turner, Job, \& Mitra, 2021; Wilson, Willis, Hendrikz, Le Brocque, \& Bellamy, 2010; World Health Organization,
2017). For studies of New Zealand see Accident Rehabilitation \& Compensation Insurance Corporation \& Land Transport Safety Authority (New Zealand) (2000), Keall, Povey \& Frith (2001), and Makwasha \& Turner, (2013). This includes several different approaches to determining the role of speed, each of which is described and briefly reviewed in this section.

Source 1: Analyses of the probability of survival for different impact speeds for various road user types (pedestrians, vehicle occupants) and for different crash configurations

Impact speed refers to the speed of the vehicle (relative to the person or object struck) at the instant of collision.

Data from New Zealand: Several meta-analyses of probability of death for each impact speed have been undertaken. These meta-analyses require the data from many studies combined to produce the best global estimates. Thus, there are no such meta-analyses for New Zealand per se, and the 15 studies accepted as methodologically rigorous by Hussain, Feng, Grzebieta, Brijs \& Olivier (2019) the most recent of these studies, do not include any from New Zealand. However, because (1) the laws of physics apply in every country, (2) human bodies have similar frailties across the globe, and (3) these data do not involve social/psychological aspects (which do vary across countries in relation to speed and safety) we can be confident that these findings apply in New Zealand. 
In addition, the countries covered in the 15 studies employed by Hussain et al. (China, Germany, Japan, Korea, UK, and USA) represent a range of vehicle fleets. In addition, the analysis of speed and serious injury risk by Jurewicz, Sobhani, Woolley, Dutschke \& Corben (2016) does focus on Australia and New Zealand.

The initial analysis of fatality probability by impact speed was presented by Wramborg (2005) and is commonly reproduced (e.g., Global Road Safety Partnership, 2008). More recently, Hussain et al. (2019) reported a more exacting analysis including studies undertaken since Wramborg's analysis. Their curve for pedestrian impact crashes (reproduced in Figure 1) show a highly similar shape to that of Wramborg, but the curve is slightly shifted to higher speeds for the same fatality risk. These curves highlight the vital role of speed, with dramatic increases in risk of death as impact speeds increase. For example, Hussain et al. (2019) found that each $1 \mathrm{~km}$ increase in impact speed produced an 11 percent increase in the likelihood of a pedestrian fatality and a $7 \%$ increase for serious injury. Jurewicz et al.'s (2016) analysis of serious injury risk and impact speed reveals a similarly powerful effect of speed on risk. Finally, a recent study by Doecke, Baldock, Kloeden \& Dutschke (2020) accessed more current technology to assess the speed- serious injury relationship, employing speed data from vehicle event data recorders from crash involved vehicles. This study confirmed the powerful effects of speed on the risk of serious injury.

\section{Source 2: Meta-analyses of the relationships between average travel speeds and fatal, injury, and crash probabilities}

Many studies allow an assessment of the relationship between mean speeds of travel and outcomes: reported crashes, injuries, and deaths. These individual studies may cover changes in speed and safety with meta-analyses of many studies allowing more reliable identification of the speed-safety relationships across a large range of speeds. As in Source 1, shared human physical vulnerability to force and the laws of physics mean that these findings apply in New Zealand. In addition, the countries covered in these meta-analyses are wider because relevant studies have been reported from more countries, including research from New Zealand, for example in Elvik's analyses considered below.

Nilsson reported the first detailed meta-analysis of the relationship between changes in speed and fatal, serious injury and all injury crashes, based on many international studies. Subsequent re-analyses and follow-up research evaluations led by Elvik validate these fundamental influences of speed on safety, including finding that the effects of speed are even stronger than indicated in Nilsson's initial research (Elvik, 2013; Elvik et al., 2009; Elvik et al., 2019), though the effects of speed may be larger on rural roads than in urban environments (Cameron
\& Elvik, 2010). The best fit for the relationship between speed and serious crash risk appears to be exponential across the full range of speed changes.

These meta-analyses show the power of small changes in speed in producing powerful changes in crash trauma. Changes in speed has even greater impacts on higher severity crash outcomes with small changes in speed having dramatic impacts on fatal outcomes; each $1 \%$ increase in travel speed results in around a $4 \%$ increase in deaths. The most critical refinement of these estimates from Elvik's comprehensive analyses is that the nature of the mean change in speed matters- that is, the way the distribution of speeds changes matters. Elvik (2019) showed that, for example, if the mean speed change is largely due to reducing the speeds of the higher level speeders then the safety value is substantially greater. This is particularly important, because this is exactly what speed cameras tend to achieve (see Elvik 2019; Montella, Imbriani, Marzano, \& Mauriello, 2015 also found reduced variance in speeds with speed cameras; and in New Zealand, Keall, Povey \& Frith, 2001 found greater reductions in higher level speeds with more effective speed enforcement). Finally, these meta-analyses consistently show more powerful effects of speed on more serious crashes (fatal, to injury to non-injury) establishing the importance of speed for both crash severity and crash occurrence. However, the exact extent of the role of speed in occurrence is difficult to determine, because the research is based on reported crashes and crash severity influences the probability that a crash will be reported (see Hauer, 2006).

\section{Source 3: Evaluations of speed management interventions in terms of lives, injuries and crashes saved}

Many evaluations have been reported of the speed and safety effects of different types of speed cameras, other interventions to promote general deterrence of speeding (such as campaigns and changes in penalties or processes) various forms of road engineering to reduce speeds, lower speed limits, and vehicle based technologies to manage speed (Delaney et al., 2005; and for reviews see Turner et al, 2021; Wilson et al., 2010).

Several relevant studies have been undertaken in New Zealand, and are reviewed here. For example, Makwasha \& Turner (2013) evaluated the implementation of gateway treatments designed to slow traffic entering urban areas. They found a statistically significant $23 \%$ reduction in serious outcome crashes due to the gateways. However, they do not report the exact level of speed reduction. Thus, it is not possible to determine the speed-crash relationship from this study. For the purpose of assessing the power of speed in determining safety outcomes, the most relevant examples for New Zealand include measures of speeds as well as safety outcomes. 
Keall, Povey \& Frith (2001) included comprehensive measures of changes in speed, crashes, injuries, and deaths in evaluating the addition of covert mobile speed camera enforcement to ongoing high visibility mobile camera enforcement. Two sets of results allow examination of the power of speed in changing crash outcomes in New Zealand. First, the effects of covert enforcement were evaluated over the rural road network of the region being treated. Results showed a $1.6 \mathrm{kmh}$ (also a $1.6 \%$ reduction) net speed reduction which produced a net $19 \%$ reduction in casualties (injuries and deaths). According to Nilsson's relationship this speed reduction will generate a $5 \%$ to $6 \%$ reduction in deaths and serious injuries combined. Keall et al. also assessed effects at camera enforcement locations, finding a $3.1 \mathrm{kmh}(3.2 \%)$ net reduction in speed resulting in a $29 \%$ reduction in casualties. Nilsson's relationship suggests an $11 \%$ to $12 \%$ reduction in casualties. Thus, in both cases, if New Zealand is to be considered different, these results indicate that speed matters even more to road safety in New Zealand than the global findings. However, Keall et al. found that higher level speeds were reduced more than mean speeds (evident from larger reductions in $85^{\text {th }}$ percentile and higher percentile speeds than in mean speeds). As noted earlier, Elvik's (2019) more detailed analysis of distributions of speeds shows that this pattern should produce a stronger safety benefits. Keall et al's results are consistent with this pattern, though even with the adjustment for the larger reduction in high level speeds, these results in New Zealand suggest an especially powerful role for speed in crash trauma.

A strong evaluation was also conducted of the implementation of traffic activated variable speed limit signs at 10 intersections in New Zealand (Mackie, Brodie, Scott, Hirsch, Tate, Russell \& Holst, 2017). In this intervention traffic on side roads joining main roads was electronically detected on approach, and the variable speed limit signs on the main road were activated reducing the speed limit to $70 \mathrm{kmh}$. This reduced speeds by around $7-9 \mathrm{kmh}$ on average and this resulted in a dramatic reduction in crash trauma: fatal and serious injury crashes were reduced in net by $79 \%$ and total crashes by $51 \%$. This study included control intersections and the (much smaller) reductions in crashes at those locations were subtracted from the total reductions at the treated intersections to control for any general improvement effects. The authors conclude that these safety gains are so large that they indicate other benefits of the treatment beyond speed reductions, such as increased alertness. Based on metaanalyses of speed-crash relationships, just under a 50\% reduction in fatal crash might be expected with slightly less reduction for serious injury crashes. An added beneficial effects such as alertness (Mackie et al., 2017) is not an unreasonable speculation. However, there is no direct evidence for this account, leaving open the possibility that these large benefits are simply due to speed being a key factor in intersection crashes in high speed limit zones (in New Zealand).

\section{Source 4: Analyses of Police based crash data}

Perhaps the most obvious readily available and most used in the media (e.g., Margeit, 2021; Matthew, 2019; Meredith, 2017) source of data on the role of speed in crash trauma are crash data, which in New Zealand and almost everywhere arise from Police reports of crashes. This relates specifically to the role of speeding (travelling at a speed above the legal limit). Typically, police estimated data on the involvement of speeding in crashes increase in proportion from property damage only crashes to injury crashes, and rise again for fatal crashes. For serious injury and fatal crashes, the proportion for which speeding is identified as a factor typically ranges around $20 \%$ to $35 \%$ across countries and states (for example: IRTAD, 2019; Michigan Department of State Police, 2013). One of the clearest signs that there is something wrong with these statistics comes directly from police themselves: In Brazil official statistics are in the usual $20-35 \%$ range for speeding in fatal crashes, yet police officers report that believe that the real number is around $80 \%$ (Job, Lancelot, Gauthier, de Melo e Silva, Howard, Ledesma \& Carneiro, 2015). In NSW, the under-reporting of speeding in fatal crashes is so well recognized by the NSW Centre for Road Safety and NSW Police that added criteria are employed at the stage of data entry to identify speeding in crashes with the aim of at least partly correcting this under-reporting (NSW Centre for Road Safety, 2017). Thus, official crash statistics in the state of New South Wales (NSW) provide a higher proportional involvement of speed- usually around 40\% (NSW Centre for Road Safety, 2012, 2020). Recognition of under-reporting of speeding as a crash factor goes beyond police, with commentaries highlighting

Table 1: The role of speeding in crashes arising from Police-based crash data by severity in New Zealand, and in Auckland (Sources: Present analysis of 5 years of crash data in New Zealand: 2016-2020). Note: These numbers are corrected later and should not be taken as a guide to the role of speed

\begin{tabular}{|l|c|c|}
\hline Crash Severity & $\begin{array}{c}\text { \% involving } \\
\text { speeding from } \\
\text { Police-based } \\
\text { crash data } \\
\text { New Zealand }\end{array}$ & $\begin{array}{c}\text { \% involving } \\
\text { speeding from } \\
\text { Police-based } \\
\text { crash data } \\
\text { Auckland }\end{array}$ \\
\hline Fatal Crash & 29.7 & 36.4 \\
\hline $\begin{array}{l}\text { Serious Injury } \\
\text { Crash }\end{array}$ & 20.6 & 19.6 \\
\hline $\begin{array}{l}\text { Minor Injury } \\
\text { Crash }\end{array}$ & 16.4 & 16.0 \\
\hline Non-injury & 12.4 & 10.2 \\
\hline $\begin{array}{l}\text { All reported } \\
\text { crashes }\end{array}$ & 14.0 & 12.0 \\
\hline
\end{tabular}


the issue (Job, 2020) and data demonstrating the problem (Doecke, \& Kloeden, 2014).

New Zealand is experiencing exactly the same situation: Police report-based crash statistics indicate speeding is a factor in a typical cascading sequence of more involvement in more serious crashes (see Table 1). Auckland is considered on its own, due to indications that the influence of speed in crash occurrence and severity may not be as powerful in urban environments as it is on rural roads (Cameron \& Elvik, 2010). New Zealand Police officers have informed the authors (personal communications) that speeding is substantially under-represented in the data compared with reality. This is explored further later in this paper.

\section{Source 5: In-depth crash investigations}

In-depth crash investigations, including crash reconstruction, allow more comprehensive processes for determining the role of different factors in a crash than can be identified by police in 'normal' crash investigation processes, including more accurate determination of the role of speed (Grzebieta, Rechnitzer \& McIntosh, 2013). Such investigations are beyond the scope of normal police investigations (Doecke, \& Kloeden, 2014), as well as beyond levels of resourcing available for Police. In reality there may be three levels of crash investigation: the initial assessment and crash data recording by Police normally at the crash scene soon after the crash; a further more detailed investigation by Police for certain serious crashes; and a comprehensive in-depth investigation/reconstruction undertaken for research purposes or for legal cases (Grzebieta, 2019; Grzebieta et al., 2013).

Several relevant in-depth crash investigation studies have been reported by the Centre for Automotive Safety Research. Two studies employed in depth analysis of crashes in urban and in rural environments to more accurately determine the role of speed including comparisons with speeds of control (non-crash involved) vehicles travelling through the crash locations (Kloeden, McLean \& Glonek, 2002; Kloeden, Ponte \& McLean, 2001). These studies both revealed powerful effects of speed. For example, in the urban environment traveling just $5 \mathrm{kmh}$ above the speed limit resulted in a doubling of serious (injury or fatal) crash risk.

Doecke \& Kloeden (2014) employed evidence on the role of speeding in 144 crashes which occurred in South Australia obtained from crash reconstructions to validate (or not) the recording of speeding as a factor in crashes applying the methods employed in NSW, and standard reporting processes based on police reports of contributing errors. They found that speeding (the error of 'excessive speed') as recorded according to the NSW criteria lacked strong accuracy in identifying crashes where a vehicle was speeding. However, this method was more accurate than simply relying on speeding as recorded based on Police reporting. Thus, crash investigations shows that Police reporting for exceeding the speed limit is poor, but other simple methods applied when entering data are better for overall representation of the proportion of crashes which involve speeding, but are not strongly accurate for individual crashes.

This important and rare study also highlights the alarming level of under-reporting in Police data. Based on calculations from the raw data provided in the paper, the traditional data recording based on police identifying speeding as contributing to the crash resulted in an under-estimate of speeding as factor by $94.9 \%$. While accuracy on a crash by crash bases was still weak, the NSW method resulted in a much closer match on actual proportion of crashes involving speeding, though still with an under-estimate of $10.3 \%$. The generalizability of this study is limited by the representativeness of the crashes investigated. However, it nonetheless highlights the high level of under-reporting of speeding in police crash reports.

Finally, in Thailand, an in-depth crash investigation study found that $68 \%$ of crashes investigated involved speedingmuch higher than expected from police data (Klinjun, Kelly, Praditsathaporn \& Petsirasan, 2021).

\section{Source 6: Application of safe system principles}

Safe System principles (sometimes also called Vision Zero) include the vision of (and mechanisms for achieving) zero road deaths and serious injuries (for details see: Belin, 2016; Job, 2017; Larsson, Dekker \& Tingvall, 2010). These principles are the basis of influential global road safety strategies and guides (Bliss \& Breen, 2013; ITF, 2016; OECD, 2006; Wambulwa \& Job, 2019), including both the 2011-2020 and the 2021-2030 global plans developed by the United Nations and the World Health Organization (WHO, 2011; WHO \& United Nations Regional Commissions, 2021); and are demonstrably successful in Sweden (Belin, 2016) and beyond (Marsh, De Roos \& Webster, 2016; Mooren, Grzebieta, Job \&Williamson, 2011). Safe System has been adopted repeatedly by the New Zealand Government in road safety strategies (New Zealand Government, 2019; Ministry of Transport, 2010).

Fundamental within the safe system principles is that road safety will never be solved by expecting imperfect people to behave perfectly on the road: humans make mistakes, and should not die for momentary lapses of concentration or misjudgements. Thus, the forces to which the human body is exposed in the event of a crash must be managed down to level which are survivable. If the roads and roadsides (barriers, etc.) combined with the level of protection offered by vehicles cannot manage the forces down to this level, then the speed is too high for safe system. As a guide safe system principles indicate speed limits and operating speeds to be achieved to deliver safe system $(30 \mathrm{kmh}$ to protect pedestrians, cyclists, and motorcyclists; $50 \mathrm{kmh}$ where side impact crashes are 
possible; and, 70kmh where head-on crashes are possible: for example, in New Zealand, see Frith, 2012). However, more fundamentally, the principles indicate that wherever a death or serious injury occurs by default the speeds involved in the crash were too high for the level of crash force and the force mitigation (protection) available in the crash. Thus, application of the safe system principles dictates that speed is a contributing factor in all deaths and serious injuries. This position is often explicitly articulated: "Speed is a contributing factor in all RTAs [road traffic accidents]." (Moore, 2020); or stated as speed being a factor in severity of all crashes (OECD, 2006); including by experts in New Zealand: "The speed component of a Safe System involves the development of road typologies to eliminate fatal and serious injury crashes by avoiding speeds above critical thresholds." (Frith, 2012).

\section{Source 7: Application of 'Safe and Appropriate Speeds'}

New Zealand's current and previous road safety strategies adopt safe system principles with the ultimate aim of delivering zero deaths. As part of the journey to this objective, New Zealand has identified 'Safe and Appropriate Speeds' for the road network determined using the New Zealand Speed Management Guide (New Zealand Transport Agency Waka Kotahi, 2016). Analyses identify that $87 \%$ of the country's road network has speeds which do not match the safe and appropriate limits, with $86 \%$ having limits higher than the safe and appropriate levels (Ministry of Transport, 2019; New Zealand Government, 2019). In this respect, New Zealand's approach aligns with most high income countries on speed limits, with the best performing road safety countries increasingly adopting $30 \mathrm{kmh}$ urban limits to protect vulnerable road users though with $50 \mathrm{kmh}$ limits on some urban roads, and rural limits which increasingly approach safe system levels (Weijermars \& Wegman, 2011).

With the above information and data on the distributions of travel speeds relative to speed limits in New Zealand, it is possible to estimate the proportion of fatal and serious injury crashes which involve speeds which are above safe and appropriate speeds. This can be achieved by determining what proportions of drivers are travelling at speeds above or within Safe and Appropriate Speeds.

The Steps below and Table 2 show how this can be done for the three different road groups based on Safe and Appropriate Speeds. The calculations for each step are presented in Table 2.

\section{Step 1-Define the driving speeds which are above or} within the Safe and Appropriate Speed, for the roads: This is achieved by determining the difference between the speed limit and the Safe and Appropriate Speed, and by considering those who are speeding by amounts which would be above the Safe and Appropriate Speeds. As a conservative (conservative here means making estimates which are more likely to under-estimate the crash risk contributed by driving above the safe and appropriate speed, rather than over-estimate it) guide to the difference between existing speed limits and safe and appropriate limits, for the $86 \%$ of roads where the limit is higher than the Safe and Appropriate level, the lowest possible difference is $10 \mathrm{kmh}$ (because speed limits are set in $10 \mathrm{kmh}$ increments). For any cases where the prevailing limit is $20 \mathrm{kmh}$ or more above the safe and appropriate speed, the present calculations will be highly conservative. We also assume on a similar basis that for the small proportion for roads $(1 \%)$ with limits below the safe and appropriate levels, the limit is $10 \mathrm{kmh}$ below the safe and appropriate level.

Step 2 - Determine the proportions of drivers travelling in relevant categories of speeding or at speeds below the limit: To achieve this we must estimate the distribution of travel speeds relative to the limit in New Zealand, for which we have two sources. The first source is Mackie et al. (2017, Figure 4) for the $70 \mathrm{kmh}$ limit (in 2016 when the changes have had time to settle in for motorists) noting that this does not assume that $70 \mathrm{kmh}$ is above the safe and appropriate speed, but rather uses the distribution of actual speeds as a guide to travel speeds relative to speed limits in New Zealand. This distribution indicates that around $48 \%$ of drivers are above the limit of $70 \mathrm{kmh}$ averaging (conservatively) around $75 \mathrm{kmh}$, a further $42 \%$ are travelling between 61 and $70 \mathrm{kmh}$ averaging around $66 \mathrm{kmh}$, with the remaining approximately $10 \%$ travelling at or below $60 \mathrm{kmh}$, averaging conservatively around $58 \mathrm{kmh}$. The second source is additional analyses undertaken for this paper of speed surveys on New Zealand Roads from 2014 and 2015 (the latest available). These indicate that the proportion of vehicles above the speed limit, averaged for rural and urban roads, is $40 \%$, slightly lower than in the distribution from Mackie. These surveys also show that $2.5 \%$ of drivers are exceeding the speed limit by more than $10 \mathrm{kmh}$, while Mackie's data indicate a higher percentage. Because the speed surveys are more representative with both urban and rural roads, and because the distribution from Mackie is for a variable speed limit sign which is not typical, these are adopted, the calculations below are based on the present analysis of New Zealand speed surveys. Thus, the following relevant percentage of travel speeds are adopted: (1) $2.5 \%$ of drivers are exceeding the speed limit by more than $10 \mathrm{kmh},(2)$ $40 \%$ of drivers are above the speed limit (including those exceeding by more than $10 \mathrm{kmh}$ ), (3) $50 \%$ are within $10 \mathrm{~km}$ below the speed limit, and (4) $10 \%$ are below the speed limit by $10 \mathrm{kmh}$ or more.

Step 3-Determine the relative speeds of each of the categories of speed which are above the Safe and Appropriate Speed: This is achieved by calculating the percentage difference in speed from the speed limit. From the detail of Mackie's speed distributions and the speed survey distributions from the 2014 and 2015 speed surveys 
we are able to estimate the mean difference between the speeds of each of these categories of travel speed and the speed limit (taken as a base for risk). Those exceeding the limit by over $10 \mathrm{kmh}$ are averaging $14 \mathrm{kmh}$ above the speed limit, those above the speed limit are averaging $6 \mathrm{kmh}$ above the average, those within $10 \mathrm{~km}$ below the speed limit are averaging $4 \mathrm{kmh}$ below the limit, and those below the speed limit by $10 \mathrm{kmh}$ or more are averaging $12 \mathrm{kmh}$ below the limit. As an average to represent rural and urban speed limits, a limit of $70 \mathrm{kmh}$ is adopted for these calculations. Thus, those exceeding the limit by over $10 \mathrm{kmh}$ are averaging $20 \%$ above the speed limit, those above the speed limit are averaging 9\% above the average, and those within $10 \mathrm{~km}$ below the speed limit are averaging $6 \%$ below the limit.

Step 4-Calculate the relative serious crash risk of each of these categories of speed, above and below the Safe and Appropriate Speed: This is achieved by applying the evidence from Source 2 (Meta-analyses of speed and crash risk) to the percentage differences in speed calculated at Step 3.

Applying the estimated increase in fatal and serious injury crashes risk from the wealth of data in Source 2 above (each $1 \%$ increase in speed results in $3.5 \%$ increase in serious crash risk) means that those travelling $20 \%$ above the limit have an average risk per vehicle which is $70 \%$ (20\% times 3.5\% increase in risk) higher than if travelling at the speed limit. These calculations, all made by apply the $3.5 \%$ for each percentage difference, are presented in Table 2.

Step 5-Assign the relative risks calculated at Step 3 to the proportions of drivers in each speed category: This amounts to determining net risk by combining exposure (proportion of drivers) and risk (relative crash risk determined by differences in travel speed).

Step 6-Calculate contribution to injury crashes: This is calculated by distributing net risk for each category of drivers above the Safe and Appropriate Speed to the known contribution to serious crashes for each category of road. The distributions of injury crashes on the three categories of road are: $50.7 \%$ on roads with speed limits above the Safe and Appropriate Speed, $45.7 \%$ on roads with speed limits equal to the Safe and Appropriate Speed, and 3.6\% on roads with speed limits below the Safe and Appropriate Speed (Ministry of Transport, 2019).

Step 7- Calculate the proportion of injury crashes contributed by drivers above the Safe and Appropriate Speed, but not speeding: One group of drivers are travelling at speeds above the Safe and Appropriate Speed but not speeding: The drivers travelling within the speed limit but not more than $10 \mathrm{kmh}$ below the limit on the roads for which the speed limit is above the Safe and Appropriate Speed. Their risk contribution is calculated in Table 2, last row.
A study in New Zealand by Mackie et al., (2017a) finds results which validate this analysis. Mackie et al. (2017a) investigated 100 fatal crashes and 200 serious injury crashes that occurred across 2015/16 to understand what system failures may have contributed to the crash and the severe outcomes. The analysis was based on safe system boundary conditions, some of which were derived for similar assessments in Sweden (Stigson, 2011) and South Australia (Wundersitz, 2014). For speed the triggers for system failure were that the travel speed or the speed limit were above the recognised Safe and Appropriate Speed for the road, the travel speed was above the advisory speed (typically for curves) or the section of road was identified as being a priority for speed management work. Based upon these criteria, Mackie et al. (2017a) found that the speed system failure contributed to the crash and outcomes in $75 \%$ of the fatal crashes and $70 \%$ of the serious injury crashes. It is noteworthy that speeding (exceeding the speed limit) or driving too fast for the conditions, were not included in these percentages, but were assigned to a behavioural failure category. Thus, with speeding adding more to these numbers, these percentages will be higher. With serious injuries being much more common than deaths, the average from Mackie's study will be slightly above $70 \%$, compared with $71.8 \%$ from the present analysis. Thus, these two quite different sources of data provide well aligned answers.

Source 8: Naturalistic Driving Studies. In naturalistic driving studies cohorts of drivers agree to be continuously tracked with video and/or other recordings of their driving. Despite the value of these studies in many aspects of road safety, they are not reviewed in detail here, because few such studies exist assessing speeding and crash risk, and because of the methodological risks associated with drivers knowing they are being monitored and so possibly reducing their speeding and other behaviours. While these studies do show that people become used to the monitoring and appear to return to normal driving, the full extent of this return to how they would have driven without any monitoring is not established, because pre-monitoring behavioural records are not available.

Even with these limitations a clear relationship between speeding and increased crash risk is still observed in naturalistic driving studies (Kamrani, Arvin \& Khattak, 2019). This finding is to be expected even within the noted limitations, because even if speeding is less common than it would otherwise be, the risk it brings remains. Thus, the methodological limitations do not influence the identification of a speeding-crash risk relationship, though the limitations do influence the estimation of speeding crash prevalence.

Other analyses of speed behaviour from naturalistic driving studies do not directly assess speed and crash risk of the drivers in the study, but employ the speeds chosen by drivers in the study to assess road features. For example, 
Table 2: The logic for determining the proportion of drivers in various categories of speed above and below Safe and Appropriate Speeds

\begin{tabular}{|c|c|c|c|}
\hline & $\begin{array}{l}\text { Road for which } \\
\text { the speed limit is } \\
\text { above the Safe and } \\
\text { Appropriate Speed }\end{array}$ & $\begin{array}{l}\text { Road for which the } \\
\text { speed limit is equal } \\
\text { to the Safe and } \\
\text { Appropriate Speed }\end{array}$ & $\begin{array}{l}\text { Road for which } \\
\text { the speed limit is } \\
\text { below the Safe and } \\
\text { Appropriate Speed }\end{array}$ \\
\hline $\begin{array}{l}\text { From Step 1: } \\
\text { Speed cut off point defining Safe and } \\
\text { Appropriate Speed }\end{array}$ & $\begin{array}{l}10 \mathrm{kmh} \text { below the } \\
\text { speed limit }\end{array}$ & The speed limit & $\begin{array}{l}10 \mathrm{kmh} \text { above the } \\
\text { speed limit }\end{array}$ \\
\hline $\begin{array}{l}\text { From Step 1: } \\
\text { Defining those above the Safe and Appropriate } \\
\text { Speed }\end{array}$ & $\begin{array}{l}\text { Speeding Drivers } \\
\qquad+ \\
\text { Drivers who are } \\
\text { travelling within } \\
\text { 10kmh of the limit }\end{array}$ & Speeding Drivers & $\begin{array}{l}\text { Drivers speeding by } \\
\text { at least } 10 \mathrm{kmh} \text { above } \\
\text { the limit }\end{array}$ \\
\hline $\begin{array}{l}\text { From Step 2: Calculated \% above and below } \\
\text { the Safe and Appropriate Speed }\end{array}$ & $40 \%+50 \%$ & $40 \%$ & $2.5 \%$ \\
\hline $\begin{array}{l}\text { From Step 3: Average speeds of each of the } \\
\text { categories of speed relative to speed limit, } \\
\text { above and below the Safe and Appropriate } \\
\text { Speed }\end{array}$ & 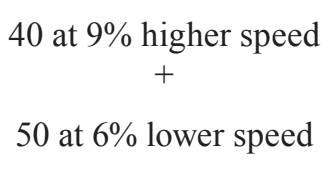 & 40 at $9 \%$ higher speed & $\begin{array}{l}2.5 \text { at } 20 \% \text { higher } \\
\text { speed }\end{array}$ \\
\hline $\begin{array}{l}\text { From Step 4- Calculate the relative serious } \\
\text { crash risk of each of these categories of speed, } \\
\text { above and below the Safe and Appropriate } \\
\text { Speed }\end{array}$ & $\begin{array}{l}40 \text { at } 31.5 \% \text { higher } \\
\text { risk }+ \\
50 \text { at } 21 \% \text { lower risk }\end{array}$ & $\begin{array}{l}40 \text { at } 31.5 \% \text { higher } \\
\text { risk }\end{array}$ & 2.5 at $70 \%$ higher risk \\
\hline $\begin{array}{l}\text { From Step 5-Net risk determined by assigning } \\
\text { relative risks calculated at Step } 4 \text { to the } \\
\text { proportions of drivers in each speed category } \\
\text { (= risk * exposure) }\end{array}$ & $\begin{array}{c}\begin{array}{c}40 * 1.315=52.6 \% \text { of } \\
\text { risk }+\end{array} \\
50 * .79=39.5 \% \text { of risk } \\
\text { Total }=92.1 \% \text { of risk }\end{array}$ & $\begin{array}{l}40 * 1.315=52.6 \% \text { of } \\
\text { the total risk on these } \\
\text { roads }\end{array}$ & $\begin{array}{l}2.5 * 1.70=4.25 \% \text { of } \\
\text { the total risk on these } \\
\text { roads }\end{array}$ \\
\hline $\begin{array}{l}\text { From Step 6-Contribution to injury crashes, } \\
\text { determined by distributing net risk for each } \\
\text { category of above or below the Safe and } \\
\text { Appropriate Speed for the known contribution } \\
\text { to serious crashes for each category of road }\end{array}$ & $\begin{array}{l}92.1 \% \text { of the } 50.7 \% \\
\text { of injury crashes }= \\
47.6 \% \text { of all injury } \\
\text { crashes in NZ }\end{array}$ & $\begin{array}{l}52.6 \% \text { of the } 45.7 \% \\
\text { of injury crashes }= \\
24.0 \% \text { of all injury } \\
\text { crashes in NZ }\end{array}$ & $\begin{array}{l}4.25 \% \text { of the } 3.6 \% \% \\
\text { of injury crashes }= \\
0.2 \% \text { of all injury } \\
\text { crashes in NZ }\end{array}$ \\
\hline $\begin{array}{l}\text { TOTAL of injury crashes in New Zealand } \\
\text { contributed to by travel speeds above the Safe } \\
\text { and Appropriate Speed for the road }\end{array}$ & \multicolumn{3}{|c|}{$47.6 \%+24.0 \%+0.2 \%=71.8 \%$} \\
\hline $\begin{array}{l}\text { TOTAL of injury crashes in New Zealand } \\
\text { contributed to by travel speeds above the } \\
\text { Safe and Appropriate Speed by drivers not } \\
\text { travelling above the speed limit. }\end{array}$ & \multicolumn{3}{|c|}{$\begin{array}{l}50 \% \text { of drivers on roads for which the speed limit is above the Safe and } \\
\text { Appropriate Speed, with a risk } 21 \% \text { lower than the speed limit. } \\
50 \% \text { of drivers } * .79 \text { risk } * 50.7 \% \text { of injury crashes }=20.0 \%\end{array}$} \\
\hline
\end{tabular}


Dhahir \& Hassan (2019) used this method and found that the speed reduction parameters of curves (assessed through the chosen speeds of drivers in the study) are more significant variables in predicting crash frequency than all curve geometric parameters. This adds weight to the vital importance of managing speed on curves which is more important than the risk features of the curves.

\section{Apparently Inconsistent Results}

The above eight sources of evidence on speed and speeding are not as directly comparable as they may appear to be (see below), but are commonly seen as indicating different levels of importance to speed (often misinterpreted as solely speeding) in road safety. For example, at the extreme ends Police-reported crash data indicate that speeding is involved in around $30 \%$ fatal crashes and $20 \%$ of serious injury crashes in New Zealand, while the estimate developed above indicates that $71 \%$ of fatal and serious injury crashes involve vehicles travelling above safe and appropriate speeds, whereas safe system principles produces a figure of $100 \%$ of serious crashes involve speed as a factor. Leaving aside small variations in the data collected within any of the different sources, there are two more fundamental reasons (each reviewed below) for the apparently different answers derived from the different sources:

1. The results from these data sources are influenced by methodological issues and the quality of data available

2. These data sources really address different questions, yet these different questions have gone almost entirely unnoticed, resulting in misinterpretations and use of the data to address core questions, for which the data are unsuitable.

\section{Influences of Methodological Issues and Data Quality/Information Availability}

Results of various sources are influenced by both methodological issues and fundamental data quality/ availability.

\section{Methodological issues}

Several methodological issues can be expected to influence the speed-serious crash risk relationships observed. These have been considered elsewhere (Job submitted; Wilson et al, 2010) and so are only briefly considered here, for their implications for the present focus. Relevant methodological issues include: differences in in the definitions of a serious injury (for examples see Table 1 in Hussain et al., 2019); small numbers of for example fatal crashes due to small lengths of road included in studies allowing larger impacts of random variations; the absence of control groups or control locations (Job, submitted); the lack of comprehensive crash investigations/crash reconstructions noted above; confounding factors which may arise due to other road safety related changes during evaluations (see Keall et al., 2001 for an example which is likely to have caused on under-estimate of the benefits of the covert enforcement being evaluated in New Zealand); failures of other elements of deterrence, such as penalties which are insufficient to significantly deter, which will weaken the effects of speed enforcement (see Job, submitted); and some challenges with employing data from Event Data Recorders, as described below in the paper.

These are variations across studies, and not reasons to dismiss the breadth of evidence for the powerful role of speed in crash occurrence and outcomes. In addition, many systematic reviews and meta-analyses as cited above, control for such methodological factors by rigorously selecting the best studies, and find powerful effects of speed and speed management. The highly consistent finding, that speed is a powerful determiner of serious crash risk, cannot be explained by these variations. However, the range of findings in evaluations of speed enforcement appears to largely arise from these variations (Job, submitted). Without them, a smaller range of findings is logically expected.

\section{Fundamental data quality/availability issues}

Data quality and availability issues are most likely to apply to police-based crash data in New Zealand, and in every country. Most fundamentally, many even serious crashes are simply not recorded in police based crash systems or even in medical/health-based systems, with low-income countries missing $84 \%$ of deaths in their official data (Job \& Wambulwa, 2020), and even high income countries missing many serious injury crashes from police based crash data systems (Watson, Watson \& Vallmuur, 2015). Furthermore, the missing data reflect systematic biases to certain crashes types (those involving vulnerable road users, single vehicle crashes) and certain locations (remote and regional) being more likely to be omitted in police based crash data (Wambulwa \& Job, 2019; Watson et al., 2015). These limitations of crash data systems also influence other forms of evaluation, and may result in an underestimate of the role of speeding in crashes if omitted crash types and locations are more likely to involve speeding than other crashes.

This is not a criticism of police, but rather and acknowledgement of the major challenges faced in their crash reporting task. For example, in a single vehicle crash on a remote road the driver may be motivated not to report the crash and risk penalties including loss of licence. For reported crashes, there are major challenges in attempting to determine the causes of a crash after the event, with limited resources available to police for most crashes and with most surviving drivers inevitably motivated to present their behaviour as lawful, rather than admitting to faults such as speeding. In the view of most motorists there is not a lot that a police officer can do to determine speeding at a crash scene, and indeed they are largely 
correct in this view. Of course, there are exceptions with independent witnesses, or for example a crash in which a modern car has hit a pole and torn in half in $50 \mathrm{kmh}$ zone clearly involved forces well beyond those possible from impact at $50 \mathrm{kmh}$. However, police face an unenviable task when attending a fatal pedestrian crash where there are no uninvolved witnesses. The pedestrian is dead and thus unable to provide his/her account of events, whereas the driver is likely to be uninjured, though shocked, and able to provide his/her account. The driver is most unlikely to admit that he/she was speeding or distracted, and likely to claim that the pedestrian darted out (Job, 2020). While police may doubt the account, proving it wrong is deeply challenging, especially in countries which do not undertake detailed crash reconstruction. Without crash reconstruction which may uncover factors such as speeding the driver is unlikely to be charged and thus the crash will not be recorded as speeding. Many such crashes do involve speeding yet few will be recorded as such. In New Zealand, speed is reported as being a contributing factor in only $8 \%$ of pedestrian fatalities. Across the majority of attended crashes in New Zealand which do not involve a Serious Crash Analyst, speed will only be reported by police as a factor if it is obvious from the circumstances and/or there are witness or offender accounts to support speed as a factor. Thus, in many systems police may not report any known error factor or contributing factor for some even serious crashes, because it is not possible to determine these in without extensive crash reconstruction and even then the nature of the error (speeding, fatigue, distraction) cannot be determined in every case.

Finally, Police based databases may suffer from another source of missing speeding as a factor. In some cases of serious crashes identified by police as involving speeding, police may not charge the driver with speeding, preferring to apply a more serious charge such as 'dangerous driving' which may include driving a vehicle recklessly or at a speed or in a manner which is dangerous to the public (Doecke \& Kloeden, 2014). Thus, because a 'dangerous driving' charge may or may not involve speeding, speeding may not be recorded as a factor in the database.

\section{Source 9: Estimating the real role of speeding in crash causality by combining data sources to correct police based crash data}

An important question arises from the above evidence that in crash databases, including in New Zealand, speeding (travelling at speeds above the limit) is missed as a factor in many crashes: This being the case, what is a best estimate of the real extent of speeding in crash causality in New Zealand? Note that this question is particular to crash causality, not the mechanisms of injury, which are almost universally not considered by police in crash reporting, with systems which do not have a formal variable or system/criteria for this, including in New Zealand.
Data from our analysis of 5 years of data from the New Zealand crash data system were provided in Table 1. As noted earlier, clear indications, including from New Zealand Police, are that the role of speeding in crashes is under-estimated. It is possible to make reasonable estimates of the extent of this under-reporting in New Zealand from several sources of related evidence. This may be achieved from two forms of analysis: (1) studies of the safety benefits of eliminating or greatly reducing speeding; (2) Crash investigation studies which employ more rigorous sources of data to determine the role of speeding, compared with police data on the role of speeding.

The safety benefits of eliminating or greatly reducing speeding: The best was to determine the role of a particular causal factor in crashes is not to conduct post-event analyses with unreliable sources or unavailable data, but to eliminate the causal factor and observe to what extent the crashes are reduced. Speed cameras offer the closest opportunity to this, if changes in the extent of speeding are known. Job \& Sakashita (2016) noted that the evaluation of the first 28 speed cameras installed in NSW resulted in an $89 \%$ reduction in fatal crashes, a $20 \%$ reduction in injury crashes, and a $19.7 \%$ reduction in all crashes, arising from a $71 \%$ reduction in speeding. However, crash data in NSW (NSW Road Safety Strategy Branch, 2003: with the year selected to be in the time of the evaluation) indicate the following involvements of speeding: $43 \%$ for fatal crash, $16 \%$ for injury crashes, and $17 \%$ for all crashes, including the additional criteria employed in NSW to identify speeding related crashes (see NSW Road Safety Strategy Branch, 2003). On the basis that the speed cameras do not treat other causes of crashes, the camera evaluation data indicate the following involvements of speeding: $89 \%$ for fatal crash, $20 \%$ for injury crashes, and $19.7 \%$ for all crashes. Comparing the results of largely eliminating speeding at speed camera locations, with the official data indicates the following levels of underestimate of the role of speeding: $52 \%$ for fatal crash, $25 \%$ for injury crashes, and $14 \%$ for all crashes. Other factors deserve noting: These percentages may be an over-estimate on the basis of factors such as regression to the mean, and these locations not being representative. Balancing these issues, these may be an under-estimate of speeding involvement in serious crashes because reductions were achieved without eliminating all speeding.

The most comprehensive study of a speed enforcement intervention in New Zealand is by Keall et al. (2001) however, it reports changes in mean speed but not the extent of elimination of speeding. Thus, the results reported cannot be used to estimate the role of speeding in New Zealand, applying the same logic as above on the evaluation of speed cameras in NSW.

More rigorous sources of data to determine the role of speeding in crashes: Elsegood, Doecke, \& Ponte (2021) employed speed data from vehicle Event Data Recorders to 
assess the extent of speeding in crashes in South Australia. They found that speeding was involved in $24.5 \%$, and $37.8 \%$ for free speed vehicles (vehicles not slowed by other traffic in front of them). This was in a sample with only one fatal crash and 3.6\% hospitalized injury crashes, with $82 \%$ of crashes occurring in metropolitan areas, thus also under-representing single vehicle crashes, which are much more likely to involve speeding. For example, Doecke, Elsegood \& Ponte (2021) found that the rate of speeding in single vehicle crashes was twice that of rear-end crashes, and more than twice that of intersection crashes. Finally, speeds from event recorders were taken for one vehicle not all vehicles in multi-vehicle crashes: the rear vehicle in rear end crashes, and the vehicle which has right of way in intersection crashes. Strangely, this means that if the vehicle with right of way is not speeding but the vehicle which fails to give way is speeding in an intersection crash, then this crash which clearly involved speeding will not be recorded as a speeding crash. Thus, based on the sample, these data offer a reasonable guide to the role of speeding in high income countries in non-injury crashes in metropolitan areas only, except for the issue of speeding only being assessed for one vehicle.

Doecke, Elsegood \& Ponte (2021) reported a study of speeding in fatal and serious injury crashes, again based on sound data from vehicle event data recorders. However, the authors apply two further statistical treatments to estimate the role of speeding in South Australia. First, various weightings were applied with the aim of better representing crashes in South Australia. Second, for each crash, a theoretical (and generally empirically reasonable) set of calculations were made, attempting to assess what would have happened if the speeding vehicle had been travelling at the speed limit, with assumed reaction times, braking distances, and survival rates for impact speeds, etc. to calculate the new impact speed and survivability. Thus, it is critical to appreciate that their conclusion that speeding contributes to $18 \%$ of fatal and serious road trauma in South Australia, does not mean that speeding was only involved in $18 \%$ of fatal and serious injury crashes. Rather, it means that for some speeding-involved fatal crashes a re-calculation of the speeds and forces involved assuming that the speeding vehicle was travelling at the speed limit may mean that the crash forces are still severe. Thus, some fatal crashes for example which did involve speeding will not be in the $18 \%$ because the calculations indicate that the crash forces would still have been fatal even if the speeding vehicle had been travelling at the speed limit. However, considering the multiple mechanisms by which speeding could contribute to the error (such as failing to have time to scan and detect), it is difficult adjust for these errors and thus be confident of this re-calculation process. Thus, the best answer from this study to the question: 'what proportion of fatal and serious injury crashes involved speeding?' is available from the raw data provided before these weighting for South Australia representativeness and crash survivability calculations were applied. The raw data were provided (Doecke et al., 2021), and show that for fatal crashes 50\% involve speeding, and for hospitalized injury crashes $33 \%$ involve speeding.

For both studies, the use of vehicle event data recorders has the advantage of allowing for an objective assessment of speeds immediately prior to a crash. However, this also presents significant disadvantages which may underestimate the role of speeding. Most critically, these recorders are more prevalent in more modern vehicles with requirements for them being gradually rolled out over many recent years in various manufacturing countries (UNECE, 2021; US Government, 2008), which biases the sample both of vehicles and drivers. Not only are more modern vehicle more likely to have the recorder, but also these were required in more advanced countries earlier than less safe vehicle manufacturing countries. Thus, the vehicles with the recorders tend to be newer and safer vehicles which afford more protection in a crash, meaning that the data in these studies comes from safer-than-average vehicles reducing the risk of fatality or serious injury. Second, as a consequence of the roll-out of requirements over time and over different countries in which the vehicles are produced, vehicles with a recorder on average cost more to purchase. Thus, drivers of these vehicles will tend to be older - with more money- and safer. Third, it is also possible that no data can be recovered from a data recorder and indeed cases were dropped for this reason in these studies. This may occur in more serious crashes which involve loss of electrical power early in the crash, with regulations setting impact speeds which the event recorder is required to survive (e.g., 50mph: US Government, 2008). Thus, crashes at higher speeds (more likely to involve speeding) are more likely to be omitted from the study due to loss of data. Fourth, the methodological issue described above for the Elsegood et al. study relating to assessing speeding only for one vehicle in multi-vehicle crashes, apply in both these studies. Based on the above methodological concerns, the real rate of speeding involvement in fatal crashes is over the $50 \%$ estimate and the real rate of speeding involvement in serious injury crashes is over the $33 \%$ estimate by Doecke et al (2021). Police based crash data from South Australia estimate that speeding is involved in only around $25 \%$ of fatal crashes $(24 \%$ in 2018 and $26 \%$ in 2017: see Table 2 of Department of Planning, Transport \& Infrastructure, 2019). Speeding involvement data are not provided for other crashes or in more specific detail. Thus, the more rigorous data from Doecke et al. (2021) indicate that the police based estimate is missing as many fatal crashes in which speeding is involved, as are being reported $(50 \%$ versus $25 \%$ ).

Crash Data from New Zealand: Table 3 provides the police based estimates of speeding involvement in crashes (from present analyses) with corrections applied based on the level of error revealed in the studies from NSW (Job \& Sakashita, 2016) and SA (Doecke, 2021), 
Table 3: The role of speeding in crashes from Police-based crash data in New Zealand and in Auckland, with the correction factors calculated above applied (Sources: present analysis of 5 years of crash data in New Zealand; analysis of data above to develop correction factors)

\begin{tabular}{|c|c|c|c|c|c|c|}
\hline $\begin{array}{c}\text { Crash } \\
\text { Severity }\end{array}$ & $\begin{array}{l}\text { \% involving } \\
\text { speeding } \\
\text { from Police- } \\
\text { based crash } \\
\text { data } \\
\text { New Zealand }\end{array}$ & $\begin{array}{c}\text { \% involving } \\
\text { speeding from } \\
\text { Police, corrected } \\
\text { for estimated } \\
\text { under-reporting } \\
\text { from speed } \\
\text { camera study } \\
\text { (Job \& Sakashita, } \\
\text { 2016)* }\end{array}$ & $\begin{array}{l}\text { \% involving } \\
\text { speeding } \\
\text { from Police, } \\
\text { corrected for } \\
\text { estimated } \\
\text { under- } \\
\text { reporting } \\
\text { from } \\
\text { Event Data } \\
\text { Recorder } \\
\text { study } \\
\text { (Doecke et } \\
\text { al., 2021)* }\end{array}$ & $\begin{array}{c}\% \text { involving } \\
\text { speeding } \\
\text { from Police- } \\
\text { based crash } \\
\text { data } \\
\text { Auckland }\end{array}$ & $\begin{array}{l}\text { \% involving } \\
\text { speeding } \\
\text { from Police, } \\
\text { corrected for } \\
\text { estimated } \\
\text { under- } \\
\text { reporting } \\
\text { from speed } \\
\text { camera study } \\
\text { (Job \& } \\
\text { Sakashita, } \\
\text { 2016)* }\end{array}$ & $\begin{array}{c}\text { \% involving } \\
\text { speeding } \\
\text { from Police, } \\
\text { corrected for } \\
\text { estimated } \\
\text { under- } \\
\text { reporting } \\
\text { from } \\
\text { Event Data } \\
\text { Recorder } \\
\text { study } \\
\text { (Doecke et } \\
\text { al., 2021)* }\end{array}$ \\
\hline Location & \multicolumn{3}{|c|}{ NEW ZEALAND } & \multicolumn{3}{|c|}{ AUCKLAND } \\
\hline Fatal Crash & 29.7 & 61.9 & 59.4 & 36.4 & 75.8 & 72.8 \\
\hline $\begin{array}{l}\text { Serious Injury } \\
\text { Crash }\end{array}$ & 20.6 & NA & NA & 19.6 & NA & NA \\
\hline $\begin{array}{l}\text { Minor Injury } \\
\text { Crash }\end{array}$ & 16.4 & 21.9\# & NA & 16.0 & 21.3\# & NA \\
\hline Non-injury & 12.4 & NA & NA & 10.2 & NA & NA \\
\hline $\begin{array}{l}\text { All reported } \\
\text { crashes }\end{array}$ & 14.0 & 16.3 & NA & 12.0 & 14.0 & NA \\
\hline
\end{tabular}

*The correction factor applied arises from directly from the estimated police data misses of speeding. Thus, if the police data miss $50 \%$ of speeding cases, then the correction is to double the reported percentage.

\#In NSW crash data, serious and minor injuries are not separated. The correction factor for all injuries is applied here only to minor injuries because most injuries are minor.

analysed immediately above. The correction factors from these studies are applied to New Zealand based on similar police reporting procedures, and thus similar rates of missing speeding in crashes. The in-depth crash investigation study by Doecke \& Kloeden (2014) provides a much higher correction factor: that police reporting misses $94.9 \%$ of speeding crashes. In addition, crash data specific to Auckland (the largest city in New Zealand) are included in order to allow a guide to speeding as a factor in metropolitan environments, and because of concerns noted above that the data from Doecke et al. may over-represent metropolitan crashes.

The results in Table 3 highlight that the under-estimation of speeding in crashes is more substantial for fatal crashes than for other crashes. The correction factors show close consistency from the two sources for fatal crashes, and indicate that in New Zealand around $59 \%$ to $62 \%$ of fatal crashes involve speeding (henceforth, simplified to around $60 \%$ ).

\section{What Question are These Different Data Sources Answering?}

The extent of the role of speed in crashes is addressed in multiple ways with data answering critically different questions all fitting within the general rubric of speed and crashes. These questions vary in terms of the outcome variable: typically fatalities (or fatal crashes), serious injuries, minor injuries, or all crashes. Less obviously, they also differ in terms of the independent variable: impact speed, travel speed, speed, and speeding. In addition, different changes in individual speeds producing the same change in mean speed also produce different effects (Elvik et al., 2019). The different data sources described above answer different questions. It is vital to appreciate this, because evidence from the different sources, but especially police based crash data are often misinterpreted as essentially addressing the question: To what extent is speeding contributing to serious crashes? 
Table 4: The questions which are addressed within the rubric of the role of speed in road safety, the data sources which best answer them, and best estimates of the answers

\begin{tabular}{|c|c|c|c|}
\hline The question & $\begin{array}{l}\text { Best source of data to answer } \\
\text { this question }\end{array}$ & $\begin{array}{l}\text { Example References for } \\
\text { the Source }\end{array}$ & $\begin{array}{l}\text { Best Estimate of } \\
\text { the Answer for New } \\
\text { Zealand }\end{array}$ \\
\hline $\begin{array}{l}\text { To what extent is travel } \\
\text { speed a major determiner of } \\
\text { fatal crash risk }\end{array}$ & $\begin{array}{l}\text { Source 2: Meta-analyses of } \\
\text { speed and fatal crash risk } \\
\text { Source 3: Evaluations of speed } \\
\text { management interventions in } \\
\text { terms of lives, injuries and } \\
\text { crashes saved }\end{array}$ & $\begin{array}{l}\text { Cameron \& Elvik, 2010; } \\
\text { Delaney et al., 2005; } \\
\text { Elvik, 2013; Elvik et al., } \\
\text { 2009; Nilsson, 2004; } \\
\text { Turner et al, 2021; Wilson } \\
\text { et al., } 2010\end{array}$ & $\begin{array}{l}\text { Each } 1 \% \text { increase in } \\
\text { speed produces a } 4 \% \\
\text { increase in deaths }\end{array}$ \\
\hline $\begin{array}{l}\text { To what extent is travel } \\
\text { speed a major determiner of } \\
\text { serious injury crash risk }\end{array}$ & $\begin{array}{l}\text { Source 2: Meta-analyses of } \\
\text { speed and serious injury crash } \\
\text { risk } \\
\text { Source 3: Evaluations of speed } \\
\text { management interventions in } \\
\text { terms of lives, injuries and } \\
\text { crashes saved }\end{array}$ & $\begin{array}{l}\text { Cameron \& Elvik, 2010; } \\
\text { Delaney et al., 2005; } \\
\text { Elvik, 2013; Elvik et al., } \\
\text { 2009; Nilsson, 2004; } \\
\text { Turner et al, 2021; Wilson } \\
\text { et al., } 2010\end{array}$ & $\begin{array}{l}\text { Each } 1 \% \text { increase in } \\
\text { speed produces a } 3.5 \% \\
\text { increase in serious } \\
\text { crashes }\end{array}$ \\
\hline $\begin{array}{l}\text { To what extent is impact } \\
\text { speed a major determiner of } \\
\text { fatality risk }\end{array}$ & $\begin{array}{l}\text { Source 1: Analyses of the } \\
\text { probability of survival for } \\
\text { different impact speeds }\end{array}$ & $\begin{array}{l}\text { Hussain et al., 2019; } \\
\text { Wramborg, } 2005\end{array}$ & $\begin{array}{l}\text { Each } 1 \mathrm{~km} \text { increase in } \\
\text { impact speed produces } \\
\text { an } 11 \% \text { increase in } \\
\text { the likelihood of a } \\
\text { pedestrian fatality. }\end{array}$ \\
\hline $\begin{array}{l}\text { To what extent is impact } \\
\text { speed a major determiner of } \\
\text { serious injury risk }\end{array}$ & $\begin{array}{l}\text { Source 1: Analyses of the } \\
\text { probability of survival for } \\
\text { different impact speeds }\end{array}$ & $\begin{array}{l}\text { Doecke et al., 2020; } \\
\text { Jurewicz et al., } 2016\end{array}$ & $\begin{array}{l}\text { Each } 1 \mathrm{~km} \text { increase in } \\
\text { impact speed produces } \\
\text { a } 7 \% \text { increase in the } \\
\text { likelihood of pedestrian } \\
\text { serious injury. }\end{array}$ \\
\hline $\begin{array}{l}\text { What proportion of fatal } \\
\text { crashes involve speeding } \\
\text { as a factor? }\end{array}$ & $\begin{array}{l}\text { Source 9: Combining data } \\
\text { sources to correct Source 4: } \\
\text { police based crash data under- } \\
\text { estimations, employing } \\
\text { Sources } 3 \text { and } 5\end{array}$ & $\begin{array}{l}\text { Analyses from the present } \\
\text { paper. }\end{array}$ & Around $60 \%$ \\
\hline $\begin{array}{l}\text { What proportion of serious } \\
\text { injury crashes involve } \\
\text { speeding as a factor? }\end{array}$ & $\begin{array}{l}\text { Source 9: Combining data } \\
\text { sources to correct Source 4: } \\
\text { police based crash data under- } \\
\text { estimations, employing } \\
\text { Source } 3 \text { and } 5\end{array}$ & $\begin{array}{l}\text { Analyses from the present } \\
\text { paper. }\end{array}$ & NA \\
\hline $\begin{array}{l}\text { What proportion of fatal } \\
\text { crashes involve speeds } \\
\text { above Safe and Appropriate } \\
\text { Speeds? }\end{array}$ & $\begin{array}{l}\text { Sources 7: Application of 'Safe } \\
\text { and Appropriate' speed limits }\end{array}$ & $\begin{array}{l}\text { New Zealand Transport } \\
\text { Agency Waka Kotahi, } \\
\text { 2016; New Zealand } \\
\text { Government, } 2019\end{array}$ & \multirow{2}{*}{$\begin{array}{l}\text { Available from present } \\
\text { analyses for fatal } \\
\text { and serious injury } \\
\text { combined: } \\
71 \%\end{array}$} \\
\hline $\begin{array}{l}\text { What proportion of serious } \\
\text { injury crashes involve speed } \\
\text { above Safe and Appropriate } \\
\text { Speeds? }\end{array}$ & $\begin{array}{l}\text { Sources 7: Application of 'Safe } \\
\text { and Appropriate' speed limits }\end{array}$ & $\begin{array}{l}\text { New Zealand Transport } \\
\text { Agency Waka Kotahi, } \\
\text { 2016; New Zealand } \\
\text { Government, } 2019\end{array}$ & \\
\hline $\begin{array}{l}\text { What proportion of fatal } \\
\text { crashes involve speed above } \\
\text { safe system in principle } \\
\text { speeds? }\end{array}$ & $\begin{array}{l}\text { Source 6: Application of safe } \\
\text { system principles }\end{array}$ & $\begin{array}{l}\text { Belin, 2016; Job, 2017; } \\
\text { OECD, } 2006\end{array}$ & $100 \%$ \\
\hline
\end{tabular}




\begin{tabular}{|l|l|l|l|}
\hline The question & $\begin{array}{l}\text { Best source of data to answer } \\
\text { this question }\end{array}$ & $\begin{array}{l}\text { Example References for } \\
\text { the Source }\end{array}$ & $\begin{array}{l}\text { Best Estimate of } \\
\text { the Answer for New } \\
\text { Zealand }\end{array}$ \\
\hline $\begin{array}{l}\text { What proportion of serious } \\
\text { injury crashes involve } \\
\text { speed above safe system in } \\
\text { principle speeds? }\end{array}$ & $\begin{array}{l}\text { Source 6: Application of safe } \\
\text { system principles }\end{array}$ & $\begin{array}{l}\text { Belin, 2016; Job, 2017; } \\
\text { OECD, 2006 }\end{array}$ & $100 \%$ \\
\hline $\begin{array}{l}\text { In what proportion of } \\
\text { fatal crashes are police } \\
\text { confident that speeding } \\
\text { was factor implying that } \\
\text { the driver (if alive) would } \\
\text { be charged with speeding } \\
\text { and that speeding could } \\
\text { be legally defended to be a } \\
\text { factor on the basis of police } \\
\text { investigation? }\end{array}$ & $\begin{array}{l}\text { Source 4: Analyses of Police } \\
\text { based crash data }\end{array}$ & $\begin{array}{l}\text { Table 1 in the present } \\
\text { paper; NSW Centre for } \\
\text { Road Safety, 2017 }\end{array}$ & $29.7 \%$ \\
\hline $\begin{array}{l}\text { In what proportion of } \\
\text { serious injury crashes } \\
\text { are police confident that } \\
\text { speeding was factor } \\
\text { implying that the driver } \\
\text { (if alive) would be charged } \\
\text { with speeding and that } \\
\text { speeding can be legally } \\
\text { proven to be a factor in } \\
\text { crash causation, on the basis } \\
\text { of police investigation? }\end{array}$ & $\begin{array}{l}\text { Source 4: Analyses of Police } \\
\text { based crash data }\end{array}$ & $\begin{array}{l}\text { Table 1 in the present } \\
\text { paper; NSW Centre for } \\
\text { Road Safety, 2017 }\end{array}$ & $20.6 \%$ \\
\hline $\begin{array}{l}\text { Do drivers who are } \\
\text { prepared to have their } \\
\text { driving continuously } \\
\text { monitored still speed while } \\
\text { being monitored }\end{array}$ & $\begin{array}{l}\text { Source 8: Naturalistic driving } \\
\text { studies }\end{array}$ & $\begin{array}{l}\text { Dhahir \& Hassan, 2019; } \\
\text { Kamrani et al., 2019 }\end{array}$ & Yes \\
\hline $\begin{array}{l}\text { Does the speeding of drivers } \\
\text { being constantly knowingly } \\
\text { monitored still increase } \\
\text { crash risk? }\end{array}$ & $\begin{array}{l}\text { Source 8: Naturalistic driving } \\
\text { studies }\end{array}$ & Kamrani et al., 2019 & Yes \\
\hline
\end{tabular}

(e.g., Grabar, 2021; and in New Zealand, Matthew, 2019). This interpretation is quite understandable due to the presentation of the data in crash databases as answering this question, meaning that the fault may really lie with the databases, the visibility of these sources, and the weaker accessibility of other information. Table 4 provides the various questions which fit within the broader rubric of the role of speed in crashes, with the outcome variable limited to fatal crashes and serious injury crashes in order to keep focus on the most costly crashes in all respects: human loss, grief, suffering, and economic costs (see Wambulwa $\&$ Job, 2019). Table 4 also connects these questions with the various data sources, and provides a best estimate of the answer to these questions based on the present review and analysis for New Zealand.

\section{Discussion and Conclusions}

This paper reviewed the data providing information relevant to assessing the role of speed in crashes, in terms of their relevance and validity. New Zealand was adopted as a case study in order to focus results in one country as far as possible, to avoid differences which simply arise from country variations. This review identifies many distinct data sources. Detailed analysis of the different sources revealed that apparent inconsistencies can be resolved by (1) appreciating that the different sources address fundamentally different questions, (2) observing the differences in the methodologies and data availability for the different sources, and (3) combining sources to answer some of the key questions on the roles of speed in serious crashes. Least appreciated in terms of the nature of 
the questions addressed is the importance of the different aspects of speed which are measured: mean travel speed, mean crash impact speed, speed, and speeding.

The various sources of data are consistent in showing the vital role of speed in serious crashes, and in showing that the effects of speed are more profound for fatal crashes than for injury crashes, with non-injury crashes less influenced. This is true for sources 1, 2, 3, 4, 5, and 9, with other sources providing less explicit data on this issue.

For New Zealand, Police reports entered into Waka Kotahi, NZ Transport Agencies Crash Analysis System (CAS) provide the lowest estimate of the role of speeding in crashes, but are well recognized (including by Police) in New Zealand as in many countries, to be a substantial under-estimate of the role of speeding in serious crashes. Police based crash data are significantly limited by the focus on speeding not speed as a factor, particularly in relation to what are well recognised as unsafe speed limits; necessarily adopting a more legalistic criterion for the involvement of speeding; and, missing key evidence through being retrospective assessments at crash scenes with limited resources for comprehensive crash investigations in many cases. Correction factors for the under-estimation of speeding as a factor were developed here by combining data from more rigorous sources of evidence of speeding in crashes. Present analyses indicate that speeding is a vital and substantially under-estimated factor in fatal crash in New Zealand, and that the large majority of fatal and injury crashes involve speeds above New Zealand's designated safe and appropriate speeds.

There are limitations to the additional calculation methods employed here to determine real role of speeding in crashes, and to determine the contribution of speeds above Safe and Appropriate Speeds to crash trauma in New Zealand. First, the results of these calculations are influenced by crash data limitations such as crashes not being reported. Second, the estimates made may vary slightly with assumptions made, noting that assumptions made here may under-estimate the role of speeding and speed in serious crashes. Third, the test-retest reliability of these estimates is not known because this is the first time such estimates have been made. However, there are indicators of reliability. Two separate studies were employed to generate corrections to police under-reporting, yet these correction factors align well, resulting in for example estimates of speeding in fatal crashes of 59.4\% and $61.9 \%$. Similarly, an independent sources of evidence for the extent of speeds above safe and appropriate speeds in injury crashes, also align well with the estimate calculated here: $70 \%$ and $71.8 \%$.

The finding that speeding is involved in around $60 \%$ of fatal crashes is of profound importance. It highlights that speeding is the primary and indeed majority behavioural factor in serious crashes. It also allows an estimate of the number of lives lost in New Zealand in speeding crashes.
Over the years 2018-2021, crash deaths averaged 355 per year. The presently calculated estimate that $60 \%$ involved speeding, means that on average 213 people were killed each year in speeding related road crashes. By contrast, over many years, homicides (murders plus manslaughter) in New Zealand averaged 67 per year (New Zealand Police Headquarters, 2019). Three times as many people die due to speeding than die in homicides in New Zealand each year, yet speeding is treated relatively lightly, and commonly viewed as not particularly serious (Mooren et al., 2014).

\section{Recommendations}

The following recommendations are made, which are applicable in New Zealand in particular but also in most countries:

1. Speeding (speeds above the legal speed limit) involves the problem of speed. However, speed is an issue in many cases of death and injury which do not involve speeding. Based on the present analyses, the core but distinct issues of speed and speeding are both critical in road safety and both must remain points of focus for saving lives and avoid serious injuries.

2. Speeding kills more than three times more people each year in New Zealand than homicides, and deserves more resourcing and aggressive management through road design and engineering to reduce speeds, promotion and expansion of effective enforcement and creation of stronger general and specific deterrence.

3. Speed (not just speeding) also deserves more effective management for improved safety. Bringing existing speed limits in New Zealand into alignment with Safe and Appropriate Speeds combined with strong compliance will save many lives and avoid many serious injuries. Developing and promoting speed limits to evidence based policies more closely aligned with safe system principles will save many lives and injuries globally.

4. The clear evidence for under-estimation of speeding in police reports highlights that estimations of the role of speed in crash trauma in New Zealand should not be based on police based crash data.

5. It is worthwhile to consider how the crash data can be presented to highlight the under-reporting of speeding and thus avoid the erroneous message in them that speeding is a much smaller factor than it really is in serious crashes.

6. While acknowledging the under-reporting of speeding in police reports, police should not be expected to simply fix this. This is not a fault with New Zealand police officers or police globally, but a consequence of inherent limitations to post-hoc 
investigation processes as well as the functional focus on legal prosecution, a core role for police.

7. It is not clear from this analysis that increased resourcing in crash investigation is cost effective compared with a continued focus on a safe systems approach to saving lives and injuries.

8. However, the important role of police based crash data in the management of road safety, in community understanding of road safety and in advocacy must be acknowledged. Thus improvements to the system should be explored to, in part, address the underreporting problem. To assist police, in consultation with police, it is worthwhile to consider revising police criteria for speeding as a factor and to consider separating the need for better estimation of this factor from the burden of proof. This could involve accepting the experience and expertise of police by providing uniform guidance and separate fields for police to identify (1) when speeding is clearly not involved, (2) when speeding is suspected as a potential contributing factor, and (3) when the more usual criterion of proof of speeding is met. Implications of the use of these data in legal cases will need to be considered.

9. Revise processes for the interpretation and use of crash data in relation to speeding by adopting and explaining correction factors for the under-estimation of the role of speeding in crash data.

10. Discuss these issues with the community, the media, and decision makers. The conversation on speed may be valuably increased in sophistication, to encapsulate the role of speed in trauma not just the role of speeding.

11. There may be value in undertaking more research directly in New Zealand to more precisely establish correction factors for under-estimation in police based data. However, more than sufficient evidence exists to support improved speed management being implemented without delay.

There will be value in other countries undertaking the correction processes presented herein to better determine the role of speed and speeding in serious crashes, to better guide road safety priorities and communications with the community and decision makers.

\section{Acknowledgements}

The authors thank many people who were critical in obtaining relevant crash and other data for this paper. The work of Marina Palalagi (Auckland Transport) and Victor Cauty (Waka Kotahi) were vital on crash data, as was the contribution of Paul Graham (Waka Kotahi) on speed surveys. New Zealand Police (Peter Jones \& Peter McKennie) provided most helpful inputs. This paper was also improved by the detailed reviews of three peerreviewers, who are gratefully acknowledged.
Funding: This work was supported by the New Zealand Transport Agency Waka Kotahi \& Auckland Transport. The funders sought a scientific account of the role of speed in fatal and serious injury crashes, particularly in New Zealand, in order to guide road safety policy with rigorous analysis. The findings of the authors were not revised by the funders, allowing independence of analysis and conclusions.

\section{References}

Accident Rehabilitation \& Compensation Insurance Corporation \& Land Transport Safety Authority (New Zealand) (2000). Down with speed: A review of the literature and the impact of speed on New Zealanders. Land Transport Safety Authority, Wellington. ISBN 0478108869

Belin, M. (2016). Vision zero as a new way of thinking. Journal of the Australasian College of Road Safety, 27(3), 60-62.

Bertulis, T. \& Dulaski, D.M. (2014). Driver approach speed and its impact on driver yielding to pedestrian behavior at unsignalized crosswalks. Transportation Research Record, 2464(1), 46-51.

Bliss T. \& Breen, J. (2013). Road Safety Management Capacity Reviews and Safe System Projects Guidelines Updated Edition. Washington, DC, USA: Global Road Safety Facility.

Cameron, M.H., \& Elvik, R. (2010). Nilsson's Power Model connecting speed and road trauma: Applicability by road type and alternative models for urban roads. Accident Analysis \& Prevention, 42(6), 1908-1915.

Delaney, A., Ward, H., Cameron, M., \& Williams, A. F. (2005). Controversies and speed cameras: lessons learnt internationally. Journal of Public Health Policy, 26(4), 404-415.

Department of Planning, Transport \& Infrastructure (2019). Towards Zero together: 2018 Road Fatalities and Serious Injuries in South Australia. Adelaide, Australia: Department of Planning, Transport and Infrastructure. Retrieved from https://dpti.sa.gov.au/_data/assets/pdf_ file/0005/524669/2018_End_of_Year.pdf

Doecke, S. D., Baldock, M. R., Kloeden, C. N., \& Dutschke, J. K. (2020). Impact speed and the risk of serious injury in vehicle crashes. Accident Analysis \& Prevention, 144, 105629.

Doecke, S., \& Kloeden, C. N. (2014). The accuracy of determining speeding directly from mass crash data and using the NSW Centre for Road Safety method. Journal of the Australasian College of Road Safety, 25(1), 35-41.

Doecke, S. D., Elsegood, M. E., \& Ponte, G. (2021). The contribution of various levels of speeding to fatal and serious road trauma (CASR189). Adelaide: Centre for Automotive Safety Research.

Dhahir, B., \& Hassan, Y. (2019). Using horizontal curve speed reduction extracted from the naturalistic driving study to predict curve collision frequency. Accident Analysis \& Prevention, 123, 190-199. 
Elsegood, M. E., Doecke, S. D., \& Ponte, G. (2021). Collection and analysis of EDR data from crash-involved vehicles: 2019-20 summary report (No. CASR 170). Adelaide: Centre for Automotive Safety Research

Elvik, R. (2010). A restatement of the case for speed limits. Transport Policy, 17(3), 196-204.

Elvik, R. (2013) A re-para-meterisation of the power model of the relationship between the speed of traffic and the number of accidents and accident victims. Accident Analysis \& Prevention, 50, 854-60.

Elvik, R. (2019). A comprehensive and unified framework for analysing the effects on injuries of measures influencing speed. Accident Analysis \& Prevention, 125, 63-69.

Elvik, R., Høye, A., Vaa, T., \& Sørensen, M. (2009). The handbook of road safety measures. Bingley. UK: Emerald Group Publishing Limited.

Elvik, R, Vadeby, A, Hels, T \& van Schagen, I. (2019) Updated estimates of the relationship between speed and road safety at the aggregate and individual levels, Accident Analysis \& Prevention, 123, 114-122

Frith, B. (2012). Economic evaluation of the impact of safe speeds: literature review. Report No. 505. Wellington: NZ Transport Agency.

Gårder, P. (2006). Segment characteristics and severity of head-on crashes on two-lane rural highways in Maine. Accident Analysis \& Prevention, 38(4), 652-661.

Global Road Safety Partnership (2008). Speed Management: A Road Safety Manual for decision makers and practitioners. Geneva, Switzerland: World Health Organisation/Global Road Safety Partnership (WHO/ GRSP), 2008.

Grabar, H (2021). The American Addiction to Speeding. Slate News \& Politics, December 15, 2021. Retrieved from The speed limit is America's most broken law. Why can't we fix it? (slate.com)

Grzebieta R.H. (2019). Safe Speed Limits, Trauma Week 2019 symposium, Pedestrians - Staying Safe, Royal Australasian College Surgeons, Melbourne, $13^{\text {th }}$ Feb. Retrieved from https://www.surgeons.org/-/media/Project/RACS/ surgeons-org/files/trauma-verification/17-r-grzebietasafe-speed-limits.pdf?rev=be72114dc4ef45689dc3ffa5ede 40052\&hash=3994BB422E7973A805FBA4C7C061D479

Grzebieta, R., Rechnitzer, G., \& McIntosh, A. S. (2013). Traffic accidents investigation, analysis and reconstruction. In I. Freckelton, \& H. Selby (Eds.), Expert Evidence (Vol. 69, 5 ed.). Australia: Thomson Reuters Australia. Retrieved from http://legalonline.thomson.com.au/static/alo/images/154/ COMM.FK SUMM70.pdf

Hauer, E. (2006). The frequency-severity indeterminacy. Accident Analysis \& Prevention, 38(1), 78-83.

Hosseinpour, M., Yahaya, A. S., \& Sadullah, A. F. (2014). Exploring the effects of roadway characteristics on the frequency and severity of head-on crashes: Case studies from Malaysian Federal Roads. Accident Analysis \& Prevention, 62, 209-222.
Hussain, Q., Feng, H., Grzebieta, R., Brijs, T., \& Olivier, J. (2019). The relationship between impact speed and the probability of pedestrian fatality during a vehicle-pedestrian crash: A systematic review and meta-analysis. Accident Analysis \& Prevention, 129, 241-249.

IIHS (2021). Speed. Insurance Institute for Highway Safety. Retrieved from www.iihs.org/topics/speed.

IRTAD (2019). Road Safety Annual Report 2019: Canada. Paris: ITF. https://www.itf-oecd.org/sites/default/files/canadaroad-safety.pdf

ITF (2016). Zero Road Deaths and Serious Injuries: Leading a Paradigm Shift to a Safe System. Paris, France: OECD Publishing.

Job, R.F.S. (2017). Re-invigorating and refining Safe System advocacy. Journal of the Australasian College of Road Safety, 28(1), 64-68.

Job, RFS (2018). Safe Speeds Part 1: Political Decisions and the Limited Adoption of Speed Management for Road Safety. Journal of the Australasian College of Road Safety, 29 (3), 65-69.

Job, R.F.S. (2020). Policies and Interventions to Provide Safety for Pedestrians and Overcome the Systematic Biases underlying these Failures. Frontiers in Sustainable Cities, 25 June 2020 | https://doi.org/10.3389/frsc.2020.00030

Job, R.F.S. (Submitted). Evaluations of Speed Camera Interventions can deliver a Wide Range of Outcomes: Causes and Policy Implications. Submitted to Sustainability.

Job, R.F.S., Haynes, J., Prabhakar, T., Lee, S.H.V., \& Quach, J. (1998). Pedestrians at traffic light controlled intersections: Crossing behaviour in the elderly and non-elderly. In K. Smith, B.G. Aitken, R.H. Grzebieta (Eds.), Proceedings of the Conference on Pedestrian Safety. (pp. 3-11). Canberra: Australian College of road Safety \& Federal Office of Road Safety.

Job, S., Lancelot, E., Gauthier, G., de Melo e Silva, F., Howard, E., Ledesma, R., and Carneiro, E. (2015) Federative Republic of Brazil: National Road Safety Management Capacity Review. (Report No: AUS13128) November 2015. Washington, DC: GRSF World Bank.

Job, R.F.S. \& Wambulwa, W.M. (2020). Features of Low-Income and Middle-Income Countries making Road Safety more Challenging. Journal of Road Safety, 31(3), 79-84. https:// doi.org/10.33492/JRS-D-20-00258

Jurewicz, C., Sobhani, A., Woolley, J., Dutschke, J., \& Corben, B. (2016). Exploration of vehicle impact speed-injury severity relationships for application in safer road design. Transportation Research Procedia, 14, 4247-4256.

Kamrani, M., Arvin, R., \& Khattak, A. J. (2019). The role of aggressive driving and speeding in road safety: Insights from SHRP2 naturalistic driving study data (No. 19-01980). Paper presented at the Transportation Research Board 98th Annual Meeting, January 2019, Washington DC, United States.

Klinjun, N., Kelly, M., Praditsathaporn, C., \& Petsirasan, R. (2021). Identification of Factors Affecting Road Traffic Injuries Incidence and Severity in Southern Thailand Based 
on Accident Investigation Reports. Sustainability, 13(22), 12467. https://doi.org/10.3390/su132212467

Kloeden CN, McLean AJ, Glonek G (2002) Reanalysis of travelling speed and the risk of crash involvement in Adelaide South Australia (CR207). Australian Transport Safety Bureau, Canberra.

Kloeden CN, Ponte G, McLean AJ (2001) Travelling speed and the risk of crash involvement on rural roads (CR204). Canberra: Australian Transport Safety Bureau.

Larsson, P., Dekker, S. W., \& Tingvall, C. (2010). The need for a systems theory approach to road safety. Safety Science, 48(9), 1167-1174.

Litras P, \& Spits S. (2010) Mark Webber attacks 'nanny state.' Sydney Morning Herald, March 29, 2010. Retrieved from https:/www.smh.com.au/sport/motorsport/mark-webberattacks-nanny-state-20100328-r585.html

Mackie, H., Brodie, C., Scott, R., Hirsch, L., Tate, F., Russell, M., \& Holst, K. (2017). The signs they are a-changin': Development and evaluation of New Zealand's rural intersection active warning system. Journal of the Australasian College of Road Safety, 28(3), 11-21.

Mackie, H. W., P. Gulliver, R. A. Scott, L. Hirsch, S. Ameratunga \& J. de Pont (2017a). Serious injury crashes: How do they differ from fatal crashes? What is the nature of injuries resulting from them? Auckland, New Zealand: Mackie Research, The University of Auckland, and TERNZ prepared for the AA Research Council.

Makwasha, T., \& Turner, B. (2013). Evaluating the use of ruralurban gateway treatments in New Zealand. Journal of the Australasian College of Road Safety, 24(4), 14-20.

Margeit, R (2021) Speed cameras are nothing more than cynical revenue raisers. Drive, 15 April 2021. Retrieved from https://www.drive.com.au/caradvice/speed-cameras-arenothing-more-than-cynical-revenue-raisers/

Marsh, F., De Roos, M., \& Webster, R. (2016). Qatar's school safety program: applying Safe System principles. Journal of the Australasian College of Road Safety, 27(3), 11-21.

Matthew, C. (2019). Speed limits do not alter behaviour. Otago Daily Times, 22 July 2019. Retrieved from Speed limits do not alter behaviour | Otago Daily Times Online News (odt. co.nz)

Meredith, S. (2017). There's a speed camera that's generating enough money to rival the average business. CNBC European News, 4 January, 2017. Retrieved from https:// www.cnbc.com/2017/01/04/a-speed-camera-generatesenough-money-to-rival-the-average-business.html

Michigan Department of State Police (2013). Michigan Traffic Crash Facts - A summary of traffic crashes on Michigan roadways in calendar year 2013. Lansing, USA: Michigan Office of Highway Safety Planning.

Ministry of Transport [New Zealand] (2010). Safer Journeys. New Zealand's Road Safety Strategy 2010-2020. Wellington, NZ: New Zealand Government.
Ministry of Transport [New Zealand] (2019). Road Safety Strategy -Speed Reference Group Outcomes Report. Wellington, NZ: New Zealand Government.

Ministry of Transport [New Zealand] (2020). Vehicle age. Wellington: Ministry of Transport. https://www.transport. govt.nz/statistics-and-insights/fleet-statistics/sheet/vehicleage

Moore, J. (2020). Road traffic safety in Canada from 20032017 Doctoral dissertation, University of Split. School of Medicine. Forensic Medicine.

Mooren, L., Grzebieta, R., \& Job, R.F.S. (2014). Speed-the biggest and most contested road killer. Journal of the Australasian College of Road Safety, 25(1), 13-18.

Mooren, L, Grzebieta, R., Job, R.F.S. Williamson, A. (2011) Safe System - International Comparisons of this Approach. A Safe System- making it happen: Proceedings of the Australasian College of Road Safety Conference, Melbourne, 2011.

Montella, A., Imbriani, L. L., Marzano, V., \& Mauriello, F. (2015). Effects on speed and safety of point-to-point speed enforcement systems: Evaluation on the urban motorway A56 Tangenziale di Napoli. Accident analysis \& prevention, $75,164-178$.

Nilsson, G. (2004). Traffic Safety Dimension and the Power Model to describe the Effect of Speed on Safety. Lund, Sweden: Lund Institute of Technology.

NSW Centre for Road Safety (2012). Road traffic casualty crashes in New South Wales: Statistical statement for the year ended 31 December 2011. Chippendale, Australia: Transport for NSW.

NSW Centre for Road Safety (2017). Speed related trauma trendsReport. Chippendale, Australia: Transport for NSW.

NSW Centre for Road Safety (2020). Road traffic casualty crashes in New South Wales: Statistical statement for the year ended 31 December 2019. Chippendale, Australia: Transport for NSW.

NSW Road Safety Strategy Branch (2003). Road Traffic Accidents in NSW - 2001 Statistical Statement: Year Ended 31 Dec6ember 2001. Sydney, NSW: Roads and Traffic Authority.

New Zealand Government (2019). Road to Zero: New Zealand's Road Safety Strategy 2020-2030. Wellington, NZ: New Zealand Government.

New Zealand Police Headquarters (2019). Police Statistics on Homicide Victims in New Zealand 2007 - 2017. Wellington, NZ: New Zealand Police Headquarters. https://www.police. govt.nz/sites/default/files/publications/homicide-victimsreport-2018.pdf

New Zealand Transport Agency Waka Kotahi (2016). Speed Management Guide (First Edition). Wellington, NZ: New Zealand Transport Agency.

New Zealand Transport Agency Waka Kotahi (2022). SafetyRoad deaths. NZTA Website. Retrieved from https://www. transport.govt.nz/statistics-and-insights/safety-road-deaths/ provisional-road-deaths 
OECD (Organisation for Economic Co-operation \& Development)/International Transport Forum (ITF) (2008). Towards Zero: Ambitious Road Safety Targets and the Safe System Approach. Paris, France: OECD.

OECD (2006). Speed management. Paris, France: OECD.

Shoukrallah, R. (2008). Road safety in five leading countries. Journal of the Australasian College of Road Safety, 19(1), 9-12.

Stigson, H., A. Kullgren \& M. Krafft (2011). Use of car crashes resulting in injuries to identify system weaknesses. Paper presented to 22nd International Conference on the Enhanced Safety Vehicles (ESV).

Turner, B., Job, S. \& Mitra, S. (2021). Guide for Road Safety Interventions: Evidence of What Works and What Does Not Work. Washington, DC., USA: World Bank. UNECE (United Nations Economic Commission for Europe) (2021). UN Vehicle Regulation will increase road safety thanks to "Black-box" collecting information on crashes. UNECE, 15 October, 2021. https://unece.org/media/transport/VehicleRegulations/press/361071.

US Government (2008). Federal Register / Vol. 73, No. 9 / Monday, January 14, 2008 / Rules and Regulations. https:// www.govinfo.gov/content/pkg/FR-2008-01-14/pdf/E8-407. pdf\#page $=12$

Van Ratingen, M., Williams, A., Lie, A., Seeck, A., Castaing, P., Kolke, R., ... \& Miller, A. (2016). The European new car assessment programme: a historical review. Chinese journal of traumatology, 19(2), 63-69.

New Zealand Transport Agency Waka Kotahi (2011). High-risk rural roads guide. Wellington, NZ: New Zealand Transport Agency.

New Zealand Transport Agency Waka Kotahi (2021). Specification \& Guidelines for Road Safety Hardware \& Devices. Wellington: Waka Kotahi NZ Transport Agency. https:// www.nzta.govt.nz/assets/resources/road-safety-barriersystems/docs/m23-road-safety-barrier-systems-appendix-a. pdf
Wambulwa, WM. \& Job, S. (2019). Guide for Road Safety Opportunities and Challenges: Low- and Middle-Income Countries Country Profiles. Washington, DC., USA: World Bank. http://documents.worldbank.org/curated/ en/447031581489115544/pdf/Guide-for-Road-SafetyOpportunities-and-Challenges-Low-and-Middle-IncomeCountry-Profiles.pdf

Watson, A., Watson, B., \& Vallmuur, K. (2015). Estimating underreporting of road crash injuries to police using multiple linked data collections. Accident Analysis \& Prevention, 83, $18-25$.

Weijermars, W. \& Wegman, F. (2011) Ten years Sustainable Safety in the Netherlands; an assessment. Journal of the Transportation Research Board, 2213, 1-8.

Wundersitz, L., M. Baldock \& S. Raftery (2014). The relative contribution of system failures and extreme behaviour in South Australian crashes. Accident Analysis \& Prevention 73, 163-169.

WHO (2011). Global Plan for the Decade of Action on Road Safety 2011-202. Geneva, Switzerland: WHO.

WHO \& United Nations Regional Commissions (2021). Global Plan Decade of Action for Road Safety 2021-2030. Geneva, Switzerland: WHO.

Wramborg, P. (2005). A new approach to a safe and sustainable road structure and street design for urban areas. Paper presented to Road safety on four continents conference, 2005, Warsaw, Poland. Linkoeping, Sweden: Swedish National Road and Transport Research Institute (VTI). 


\title{
Road Safety Case Studies
}

\section{Adopting a Safe System Approach to Determine Safer Speed Limits: A Case Study from Iran}

Mansour Ranjbar ${ }^{1}$, Ali Tavakoli Kashani²,3, Mohammad Mehdi Besharati ${ }^{3}$, Moslem Azizi Bondarabadi ${ }^{3}$, Hormoz Zakeri ${ }^{4}$, Seyedali Hosseinizadeh ${ }^{4}$, Gregory Chambers ${ }^{5}$, Lori Mooren ${ }^{6}$ and Ray Shuey ${ }^{7}$

${ }^{1}$ NCD and Mental Health Unit Head, WHO Country Office, Tehran, Iran

${ }^{2}$ School of Civil Engineering, Iran University of Science and Technology, Tehran, Iran

${ }^{3}$ Road Safety Research Center, Iran University of Science and Technology, Tehran, Iran

${ }^{4}$ Iranian National Roads Safety Commission secretariat, Ministry of Roads and Urban Development, Tehran, Iran

${ }^{5}$ Context 3 sixty, Melbourne, Australia

${ }^{6}$ Safety and Communications, Sydney, Australia

${ }^{7}$ Strategic Safety Solutions, Melbourne, Australia

Corresponding Author: Gregory Chambers, 28 Freshfield Avenue, Wantirna 3152, +61 419872938

\section{Key Findings}

- The Safe System Approach provides a valuable framework to review speed limits on duplicated rural highways and freeways

- The framework assists with quantifying safety risk and setting safer speed limits

- The framework provides evidence-based justification to reduce current speed limits

- $\quad$ Modelled framework-based speed limits generally reduce end-to-end travel times

\begin{abstract}
Speed management is one of the main dimensions of the Safe System Approach for reducing both the risk of crash involvement as well as injury severity. This study proposes a practical framework for setting safer speed limits on duplicated rural highways that has been applied to six pilot corridors (total carriageway length of approximately 1,250 km) in Iran. The safer speed limits determined from the proposed framework have been compared with the currently posted speed limits using several indicators and showed a considerable reduction in the total number of changes in speed limits while having very limited impact on reducing the mean travel speed and increase travel time along the study corridors. The study of the pilot corridors establishes that a clear approach and documented guidelines for setting speed limits provides a basis for quantifying engineering judgments about road hazards and determining more consistent speed limit values for similar conditions across Iran's rural highway network, legitimising speed limit reductions aimed at saving lives.
\end{abstract}

\section{Keywords}

Safe System Approach, Speed limit setting, Demonstration Project, Freeways, Multilane highways

\section{Introduction}

Road traffic fatalities and injuries are a major public health problem worldwide, especially in developing countries (WHO, 2018). This has led pioneer countries to move toward adopting a Safe System Approach (SSA) for reducing traffic crash fatalities and serious injuries (OECD, 2008). The SSA is central to reducing road crash trauma internationally, as emphasised in the Stockholm Declaration at the Third Global Ministerial Conference

Received: 21/07/2021; Received in revised form: 09/12/2021; Accepted: 09/12/2021; Available online: 09/02/2022

Copyright: (C) The Author(s). 2021 This is an open access article distributed under the terms of the Creative Commons Attribution (CC BY)_license, which permits unrestricted use, distribution, and reproduction in any medium, provided the original author(s) and the source are credited.

Suggested citation: Ranjbar, M., Kashani, A.T., Besharati, M.M., Bondarabadi, M.A., Zakeri, H., Hosseinizadeh, S., Chambers, G., Mooren, L.and Shuey, R. (2022). “Adopting a Safe System Approach to Determine Safer Speed Limits: A Case Study from Iran” Journal of Road Safety, 33 (1), 26-35. https://doi.org/10.33492/JRS-D-21-00045 
on Road Safety in February 2020. The Declaration also identified speed management as being vital to reduce road traffic deaths and injuries.

The SSA aims to create a road transport system in which human mistakes do not result in serious injury or fatality (Steinmetz, et al. 2015, Doecke, et al. 2018) and is increasingly becoming the foundation of road safety strategies in the developed countries (Hughes, et al. 2015), such as Sweden (Larsson, et al. 2010), United Kingdom (Department for Transport 2000), and Australia (Australian Transport Council, 2011).

These strategies provide a comprehensive overview of all the key components of a safe transportation system primarily with safer vehicles, safer road infrastructures, safer road users, and safer speeds (Hughes, et al. 2015). As vehicle speed is known to be an influential factor on both the likelihood of crash occurrence and the severity of injuries (Evans 1994, Kloeden, et al. 1997, Rosen, et al. 2011, Elvik 2013, Mackenzie, et al. 2015, Doecke, et al. 2018), "speeds must be managed so that humans are not exposed to impact forces beyond their physical tolerance." (WHO, 2018).

Reassessing the speed limits is considered an effective measure to align travel speeds with a safer environment and improve road safety. Speed limit changes have been shown to influence travel speed (Elvik, et al. 2004, Musicant, et al. 2016), which in turn is related to the number of fatal and injury crashes (Farmer 2017). As an example, Elvik, et al. 2004, found that when the speed limit is reduced by $10 \mathrm{~km} / \mathrm{h}$ and no other action taken, the mean speed generally reduces by approximately $2.5 \mathrm{~km} / \mathrm{h}$.

These findings have influenced road transportation authorities to reassess speed limits on the road transport network. As a clear example, $110 \mathrm{~km} / \mathrm{h}$ speed zones were reduced in South Australia with speed limits reduced to $100 \mathrm{~km} / \mathrm{h}$ on $1,100 \mathrm{~km}$ of road in 2003 and a further 723 $\mathrm{km}$ in 2011 (Dua, et al. 2013). A follow up evaluation study indicated that the number of crashes in the after period was $27.4 \%$ lower than would have been expected if the higher speed zones had been maintained (Mackenzie, et al. 2015). Results also showed a $31 \%$ reduction in the number of injuries admitted to hospitals due to crashes on the subject road segments.

\section{Background}

\section{Project Background}

To facilitate formulation of SSA in the national road safety system of member states, the World Health Organization Regional Office for the Eastern Mediterranean (WHO EMRO) has developed a "Road Safety System Framework for the Eastern Mediterranean Region" and Iran has been nominated to demonstrate an applicable SSA-based model in the Region. With EMRO support a project has been launched jointly by WHO Iran Country Office and Iran's National Road Safety Commission (NRSC) in collaboration with national partners to demonstrate enhanced Safety Model Corridors focusing on speed management.

The project aims to demonstrate an effective SSA-based model for EMRO member states focusing on speed management, with the potential to extend over time to other SSA pillars and is structured around the UN's Results-Based Management approach.

\section{Speed Management Background}

Historically, the $85^{\text {th }}$ percentile of the travelling speeds in a road segment has been used globally for setting the speed limit. Similarly, the following criteria is being used in Iran for setting speed limit:

1. $85^{\text {th }}$ percentile speeds of free-flowing traffic

2. Roadway geometric characteristic (i.e., horizontal curve radius, sight distance, etc.)

3. Roadside prevailing land-use

However, studies have shown that the drivers' speed choice may not always be rational as drivers do not foresee all the potential road hazards (Elvik, et al. 2004). These hazards include unprotected guardrail ends, unsafe access points along a rural road, unsafe U-turns and unexpected pedestrian exposures. Indeed, preventing road users from being killed or severely injured due to traffic crashes should become the very first criterion for setting the speed limit. This provides a legitimate basis for limiting the freedom of speed choice and reassessing appropriate safer speed limits based on a more structured and scientific approach.

A review of the literature reveals that previous studies have focused on setting 'safe' speed limits based on the SSA (Jurewicz and Hall 2009, Doecke, et al. 2018). However, these studies have proposed safe speed limits based on only the tolerance threshold of the human body, and do not provide a practical tool for setting safer speed limits based on both the likelihood as well as severity of different potential crash types.

Therefore, the question remains as to "how to identify and set a safer speed limit that suits the road infrastructure and environmental conditions?" The aim of this paper is to document a framework for quantifying the potential safety issues on a road segment and setting safer speed limits along the road segment. The proposed framework is then applied to six corridors in Iran to assess its merits and demerits compared to the speed limits currently posted on these corridors. 


\section{Method}

The study is part of a pilot project aimed at speed management based on the SSA, recognising its holistic nature and central role in reducing road crash trauma internationally ${ }^{1}$.

To determine safer speed limits and associated road engineering treatments on pilot road segments, the following steps were followed: identification and adoption of pilot segments of road, collection of base pilot segment information, adoption of a speed limit setting framework, and application of the speed limit setting framework on the pilot segments.

\section{Pilot segments}

Potential pilot corridors were identified according to the following criteria:

1. the corridors having a primary role in the road network (movement, function and traffic volume),

2. the provinces having adequate capacity to conduct the project (budget allocation and experienced safety professionals),

3. the corridors having a relatively poor road crash and injury history.

The final six corridors in three Provinces were selected by Iran's National Road Safety Commission (NRSC) in consultation with Provincial authorities.

\section{Base information}

Base information collected for each of the six road corridors comprised traffic volumes, speed data from speed cameras and traffic detectors, as well as speed violations data. The information was provided by Provincial agencies from existing data sources, supplemented by some additional project-related data collection. Base information for the pilot corridors is included in Appendix 1.

\section{Speed limit setting framework}

The speed limit setting framework incorporated elements of "movement and place" to determine speed limits consistent with the function of the road (movement) and the human environment and activities that surround the road (place). The "safe system" principles were then incorporated to identify speed limits and associated road engineering treatments that prevent crashes resulting in serious injury or death having undertaken severe injury risk analysis.
Application of the framework involved the following steps: road safety inspection, importing the collected data on each corridor's map, identifying road segments with uniform environmental and safety conditions, scoring an "exposure-risk-severity" matrix, and identifying safer speed limits and associated road engineering treatments for each road segment.

A team of National specialists worked with Provincial counterparts to apply the framework on each of the pilot corridors, both providing consistency across all corridors and developing capacity at Provincial level. Progress evaluations were conducted to assess viability, benefits and potential outcomes of the framework.

\section{Framework Application}

This section describes how the SSA speed limit setting framework was applied to the pilot corridor segments to determine safer speed limits.

\section{Road safety inspection}

Road safety inspections of existing roads provide a mechanism to identify existing road and speed management characteristics that can influence crash likelihood and injury severity (WHO, 2018). In this first step, a team of experienced road safety engineers inspected the pilot corridors (total carriageway length of approximately $1,250 \mathrm{~km}$ ) and documented the current condition by capturing geo-tagged videos ([Figure 1).

\section{Mapping of road safety inspection information}

In this step, the captured videos were reviewed in the office, and all the data corresponding to each segment were located on a corridor map. Data elements included location and type of signs, road access points, roadside hazards, culverts, pavement condition and abutting development.

A total of 3,240 points were pinned and labelled on the maps, allowing the road safety engineering team to analyse the spatial distribution of road infrastructure, road hazards and safety issues along the corridors. This analysis identified a total of 148 road lengths with uniform safety and environmental conditions across the six pilot segments. An example of identified safety risk is shown in Figure 2

\section{Evaluating serious injury risk}

The road safety engineering team used an "ExposureLikelihood-Severity" matrix based on the Austroads Safe System Assessment Framework (Austroads, 2016)

1 Although methodologies such as iRAP can be used to identify speed limits that will improve the safety along road corridors, Iran has limited experience with such methodologoes beyond the application of iRAP to improve pedestrian safety at a limited number of schools.

See https://irap.org/2020/07/new-star-rating-for-schools-case-study-tehran-mashhad-iran/ 


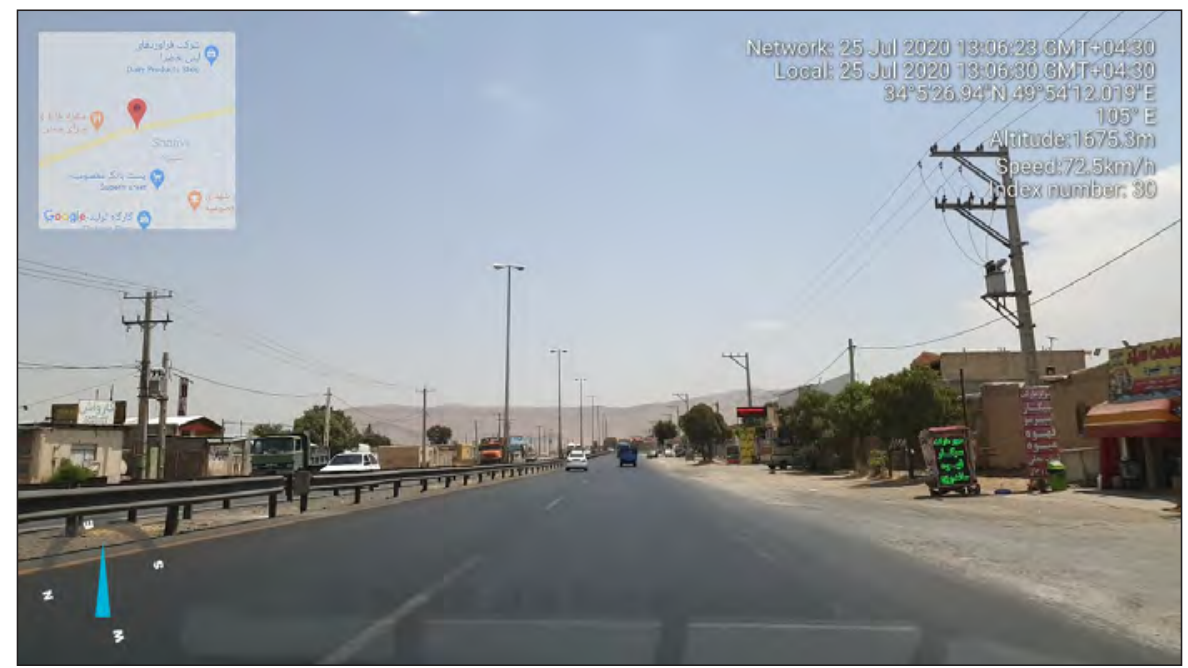

Figure 1. GPS tagged video captured from pilot road (Arak-Salafchegan Hwy)

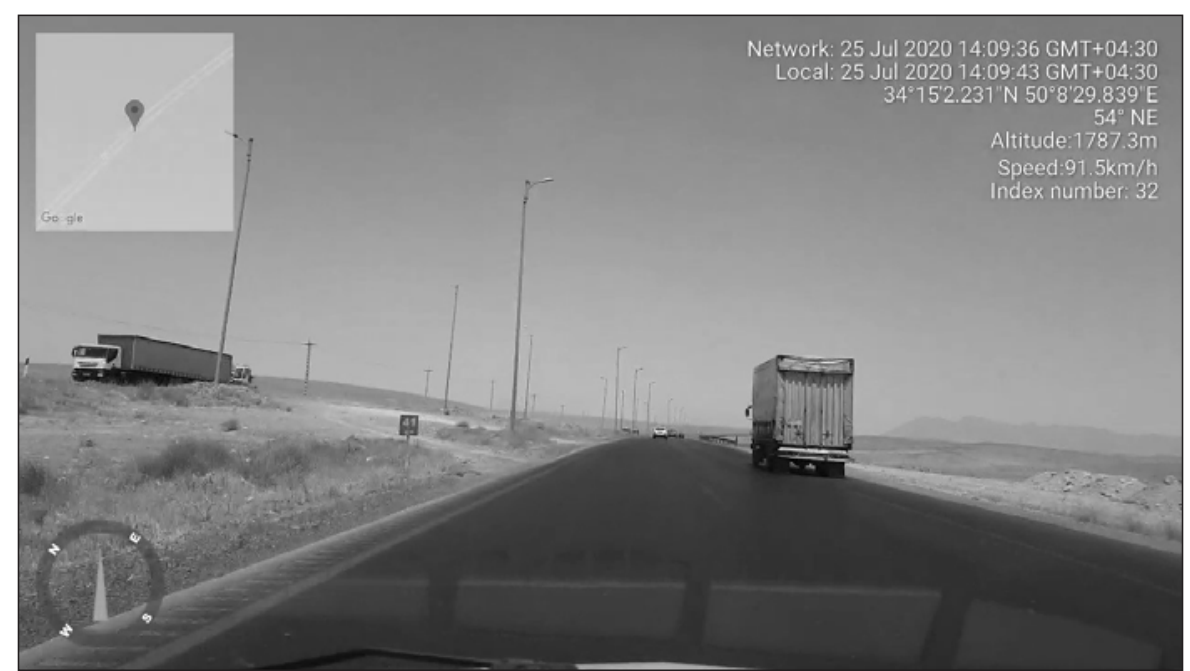

Figure 2. Identified safety risk (unsafe U-turn)

to produce a quantified safety risk score for each uniform road length identified in the previous step. ‘Road User Exposure, Crash Likelihood, and Crash Severity were scored on a scale of 0 to 4 for major potential crash types: Run-off-Road (ROR), Head-on (HO), Intersection (INT), Pedestrian (PED), Bicycle (CYC), Motorcycle (M/C), and other crash types (OTHER). An example of "ExposureLikelihood-Severity" matrix completed for one of the pilot road segments is presented in Table 1.

\section{Determining Safer Speed Limits}

After quantifying the risk scores for each of the road segment, a Safer Speed Limit (SSL) was determined for each segment. These SSLs are the safer speed limits determined for each road segment based on the current safety condition of the segment.

The closer the safety risk score is to zero, the more the segment in question is in alignment with Safe System principles. However, as stated in the Austroads Safe System Assessment Framework, the scoring system should not be interpreted as a linear scale in which, for example, twice the score means twice the risk (Austroads, 2016). For this reason, the risk scores were divided into 5 ranges, 0 , 1-100, 101-136, 137-170, and above 170. These ranges were determined by qualitatively checking and comparing the risk scores calculated for all the segments and identifying typical road segments based on safety conditions. Next, an SSL value was assigned to each score range.`Table 2 shows the maximum safer speed limits identified for the safety risk score ranges. As seen in the second row of Table 2, for any unsafe condition (i.e., risk score being more than zero) the maximum safer speed limit was limited to $90 \mathrm{~km} / \mathrm{h}$.

Moreover, recognising that the Table 2 SSLs are not necessarily appropriate to all functional road types, the road safety engineering team considered Movement and Place principles to determine the maximum SSLs for functional road types in Table 3.This is inspired by the 
Table 1. Exposure-Likelihood-Severity matrix template

\begin{tabular}{|c|c|c|c|c|c|c|c|}
\hline & \multicolumn{7}{|c|}{ Crash Type } \\
\hline & ROR & HO & INT & OTHER & PED & CYC & $\mathrm{M} / \mathrm{C}$ \\
\hline $\begin{array}{l}\text { Road User } \\
\text { Exposure } \\
(0-4)\end{array}$ & $\begin{array}{l}\text { High } \\
\text { volume } \\
\text { (4) }\end{array}$ & $\begin{array}{l}\text { High volume } \\
\text { (4) }\end{array}$ & $\begin{array}{c}\text { Not } \\
\text { applicable } \\
(0)\end{array}$ & $\begin{array}{l}\text { High volume } \\
\text { (4) }\end{array}$ & $\begin{array}{l}\text { With } \\
\text { pedestrian } \\
\text { volumes } \\
(2)\end{array}$ & $\begin{array}{l}\text { With } \\
\text { cyclist } \\
\text { volumes } \\
\text { (2) }\end{array}$ & $\begin{array}{l}\text { with } \\
\text { motorcyclist } \\
\text { volumes } \\
\text { (4) }\end{array}$ \\
\hline $\begin{array}{l}\text { Crash Likelihood } \\
\qquad(0-4)\end{array}$ & $\begin{array}{l}- \\
(0)\end{array}$ & $\begin{array}{c}\text { Divided, } \\
\text { wide/ raised } \\
\text { median } \\
(0)\end{array}$ & $\begin{array}{c}\text { Not } \\
\text { applicable } \\
(0)\end{array}$ & $\begin{array}{l}\text { slow moving } \\
\text { entering/ } \\
\text { leaving traffic } \\
\text { (4) }\end{array}$ & $\begin{array}{l}\text { No } \\
\text { crossing } \\
\text { facilities } \\
\text { (4) }\end{array}$ & $\begin{array}{c}\text { No } \\
\text { Shoulder } \\
\text { No lighting } \\
\text { (4) }\end{array}$ & $\begin{array}{c}\text { Mix of vehicles, } \\
\text { some heavies } \\
\text { (4) }\end{array}$ \\
\hline $\begin{array}{c}\text { Crash } \\
\text { Severity } \\
(0-4)\end{array}$ & $\begin{array}{l}\text { High speed } \\
\text { (4) }\end{array}$ & $\begin{array}{l}\text { High speed } \\
\text { (4) }\end{array}$ & $\begin{array}{c}\text { Not } \\
\text { applicable }\end{array}$ & $\begin{array}{l}\text { High speed } \\
\text { (2) }\end{array}$ & $\begin{array}{c}\text { High speed } \\
\text { (4) }\end{array}$ & $\begin{array}{c}\text { High speed } \\
\text { (4) }\end{array}$ & $\begin{array}{l}\text { High speed } \\
\text { (4) }\end{array}$ \\
\hline $\begin{array}{l}\text { Crash Type } \\
\text { Product } \\
\text { (Out of 64) }\end{array}$ & 0 & 0 & 0 & 32 & 32 & 32 & 64 \\
\hline $\begin{array}{l}\text { Safety Risk Score } \\
\text { (Sum out of } 448 \text { ) }\end{array}$ & & & & 160 & & & \\
\hline
\end{tabular}

Table 2. Safer speed limits based on safety risk scores

\begin{tabular}{|c|c|}
\hline Safety Risk Score & Safer Speed Limit $\mathbf{( k m / h )}{ }^{(1)}$ \\
\hline 0 & $\begin{array}{c}\text { Max. speed limit based on } \\
\text { road type }\end{array}$ \\
\hline $1-100$ & 90 \\
\hline $101-136$ & 80 \\
\hline $137-170$ & 70 \\
\hline $\begin{array}{c}\text { Above 170 or significant } \\
\text { Pedestrian safety risk score }\end{array}$ & 50 \\
\hline
\end{tabular}

Notes: ${ }^{(1)}$ Limited to functional road type Maximum Safer Speed Limit (Table 3)

results of Doecke, et al. (2018), which indicated that speed limits of $100 \mathrm{~km} / \mathrm{h}$ or more would only meet the objectives of the Safe System where all crash types except rear end crashes are exceedingly rare, such as on a high standard divided road with grade separated junctions and a safe roadside design.

\section{Evaluation using crash data}

An integral component within the evaluation criteria will focus on crash data. The current crash investigation process primarily addresses compensation, retribution and fault. Further, there are extensive delays in converting the data analysis into strategic reform and productive interventions. As an initiative, a more analytical approach is to be adopted in the six corridors requiring
Table 3. Maximum safer speed limits for functional road types

\begin{tabular}{|l|c|}
\hline \multicolumn{1}{|c|}{ Functional road types } & $\begin{array}{c}\text { Maximum safer speed } \\
\text { limit }(\mathbf{k m} / \mathbf{h})\end{array}$ \\
\hline Freeways & 110 \\
\hline $\begin{array}{l}\text { Semi-Freeways and divided } \\
\text { multilane highways }\end{array}$ & 100 \\
\hline Undivided main roads & 90 \\
\hline Minor roads & 80 \\
\hline
\end{tabular}

the police investigators to identify primary, secondary and tertiary causes of any serious crashes and then make a recommendation as to how the risk of a crash of this nature can be prevented in the future. An expert review team led by the NRSC will fully analyse the causation factors and ensure the appropriate interventions are actioned. This conceptual approach is centred on current crash investigation reform (Shuey \& Myers, 2021). As an evaluation strategy, it is intended to complement the SSA and address reform and interventions in a timely manner during the life-cycle of this project.

\section{Results}

The procedure described in the previous section for defining safer speed limits was repeated for each road length along the six pilot corridors. Results of SSA-based safer speed limits were compared with the currently posted speed limits based on several indicators. These include 
Table 4. Maximum speed limit by corridor $(\mathrm{km} / \mathrm{h})$

\begin{tabular}{|l|c|c|c|}
\hline \multirow{2}{*}{\multicolumn{1}{c|}{ Corridor }} & Posted speed limit & \multicolumn{2}{|c|}{ Safer Speed Limit (based on SSA framework) } \\
\cline { 3 - 4 } & & $\begin{array}{c}\text { based on the roadway classification } \\
\text { (see Table 3) }\end{array}$ & $\begin{array}{c}\text { based on the current } \\
\text { condition }\end{array}$ \\
\hline Isfahan-Delijan (1) & 110 & 100 & 90 \\
\hline Najaf Abad-Daran (1) & 110 & 100 & 90 \\
\hline Neyshabur-Kahak (1) & 110 & 100 & 90 \\
\hline Chenaran-Faruj (1) & 110 & 100 & 90 \\
\hline Arak-Salafchegan (1) & 110 & 100 & 90 \\
\hline Tehran-Saveh (2) & 120 & 110 & 90 \\
\hline
\end{tabular}

(1) Semi-freeway/divided multilane highway

(2) Freeway

Table 5. Lowest speed limit by corridor $(\mathrm{km} / \mathrm{h})$

\begin{tabular}{|l|c|c|c|c|}
\hline \multirow{2}{*}{ Corridor } & \multicolumn{2}{|c|}{$\begin{array}{c}\text { Forward } \\
\text { direction }\end{array}$} & \multicolumn{2}{c|}{$\begin{array}{c}\text { Reverse } \\
\text { direction }\end{array}$} \\
\cline { 2 - 5 } & $\begin{array}{c}\text { Posted } \\
\text { speed } \\
\text { limit }\end{array}$ & $\begin{array}{c}\text { SSA- } \\
\text { based } \\
\text { speed } \\
\text { limit }\end{array}$ & $\begin{array}{c}\text { Posted } \\
\text { speed } \\
\text { limit }\end{array}$ & $\begin{array}{c}\text { SSA- } \\
\text { based } \\
\text { speed } \\
\text { limit }\end{array}$ \\
\hline Isfahan-Delijan & 40 & 50 & 40 & 50 \\
\hline $\begin{array}{l}\text { Najaf Abad- } \\
\text { Daran }\end{array}$ & 60 & 50 & 40 & 50 \\
\hline Neyshabur-Kahak & 60 & 50 & 40 & 70 \\
\hline Chenaran-Faruj & 30 & 50 & 30 & 50 \\
\hline Arak-Salafchegan & 40 & 50 & 20 & 50 \\
\hline Tehran-Saveh & 40 & 50 & 80 & 50 \\
\hline
\end{tabular}

reduction in maximum speed limits, differences in lowest speed limits, as well as changes in travel times and mean speed. The results of comparisons are discussed in the following subsections.

\section{Reduction in maximum speed limits}

Table 4 presents the maximum values of

1. posted speed limits,

2. safer speed limits based on roadway classification, and

3. safer speed limits based on current conditions.

Five out of six pilot corridors are classified as multi-lane highway, for which the maximum speed limit is currently $110 \mathrm{~km} / \mathrm{h}$. Also, the Tehran-Saveh corridor is classified as freeway, for which, the maximum speed limit is currently $120 \mathrm{~km} / \mathrm{h}$.
Table 6. Number of speed limit changes by corridor (both directions)

\begin{tabular}{|l|c|c|c|}
\hline \multicolumn{1}{|c|}{ Corridor } & $\begin{array}{c}\text { Posted } \\
\text { speed } \\
\text { limit (no.) }\end{array}$ & $\begin{array}{c}\text { SSA- } \\
\text { based } \\
\text { speed } \\
\text { limit } \\
\text { (no.) }\end{array}$ & \% Change \\
\hline Isfahan-Delijan & 51 & 19 & $-63 \%$ \\
\hline Najaf Abad-Daran & 29 & 22 & $-24 \%$ \\
\hline Neyshabur-Kahak & 30 & 33 & $10 \%$ \\
\hline Chenaran-Faruj & 105 & 42 & $-60 \%$ \\
\hline Arak-Salafchegan & 40 & 16 & $-60 \%$ \\
\hline Tehran-Saveh & 17 & 8 & $-53 \%$ \\
\hline All Corridors & 272 & 140 & $-49 \%$ \\
\hline
\end{tabular}

Application of the SSA framework to the functional classifications across the six pilot corridors determined maximum safer speeds of $110 \mathrm{~km} / \mathrm{h}$ for Freeways and 100 $\mathrm{km} / \mathrm{h}$ for Multi-lane highways (Table 3). After further consideration of identified deficiencies in six pilot corridors and current road infrastructure and environmental conditions, the framework determined $90 \mathrm{~km} / \mathrm{h}$ as the maximum safer speed limit for the corridors (third column in Table 5). Thus, if the authorities can improve the safety of the corridors, the maximum safer speed limit can be increased to $110 \mathrm{~km} / \mathrm{h}$ for Tehran-Saveh freeway and 100 $\mathrm{km} / \mathrm{h}$ for the other five multi-lane highways.

\section{Differences in lowest speed limits}

The Safer Speed Limits based on safety risks scores (Table 2) have been applied to determine the safer speed limit zones along each of the pilot corridors with the lowest SSL being $50 \mathrm{~km} / \mathrm{h}$. Further analysis showed considerable 
Table 7. Mean travel speed by corridor $(\mathrm{km} / \mathrm{h})$

\begin{tabular}{|l|l|l|l|l|}
\hline \multirow{2}{*}{ Corridor } & \multicolumn{2}{|l|}{$\begin{array}{l}\text { Forward } \\
\text { direction }\end{array}$} & \multicolumn{2}{l}{$\begin{array}{l}\text { Reverse } \\
\text { direction }\end{array}$} \\
\cline { 2 - 5 } & $\begin{array}{l}\text { Posted } \\
\text { speed } \\
\text { limit }\end{array}$ & $\begin{array}{l}\text { SSA- } \\
\text { based } \\
\text { speed } \\
\text { limit }\end{array}$ & $\begin{array}{l}\text { Posted } \\
\text { speed } \\
\text { limit }\end{array}$ & $\begin{array}{l}\text { SSA- } \\
\text { based } \\
\text { speed } \\
\text { limit }\end{array}$ \\
\hline Isfahan-Delijan & 89 & 88 & 68 & 87 \\
\hline Najaf Abad-Daran & 88 & 87 & 71 & 80 \\
\hline Neyshabur-Kahak & 96 & 88 & 99 & 89 \\
\hline Chenaran-Faruj & 74 & 84 & 79 & 85 \\
\hline Arak-Salafchegan & 76 & 79 & 74 & 81 \\
\hline Tehran-Saveh & 109 & 89 & 109 & 87 \\
\hline
\end{tabular}

variation between the $50 \mathrm{~km} / \mathrm{h}$ lowest safer speed limit zones and the current posted speed zones with the lowest values shown in Table 5.

Comparing the minimum values of posted speed limits along the six pilot corridors indicated that although having similar safety conditions, the lowest values of posted speed limits in these corridors are different and vary from $20 \mathrm{~km} / \mathrm{h}$ to $60 \mathrm{~km} / \mathrm{h}$, illustrating the lack of strict and consistent guidelines for setting speed limits in Iran. This is important because having a clear approach and documented guidelines for setting speed limits will result in more consistent speed limit values for similar conditions along roads all over the country.

\section{Number of speed limit changes}

As seen in Table 6, for each of the pilot corridors, the number of speed limit changes along the six pilot corridors is generally less when based on the SSA-based framework compared to the existing posted speed limits. Following application of the SSA-based framework to define safer speed limit zones, the total number of changes in speed limits across all six pilot corridors have reduced by $49 \%$. As an instance, along the Chenaran-Faruj corridor, the posted speed limit currently changes 105 times, and the lowest speed limit is only $30 \mathrm{~km} / \mathrm{h}$. However, based on the SSA framework, the number of changes in the safer speed limit is decreased to 42 , and the lowest safer speed limit is $50 \mathrm{~km} / \mathrm{h}$.

Reducing the number of changes in the speed limits along a corridor establishes a more credible connection between the safer speed limits and the road infrastructure and environmental conditions. Whether this more credible connection inclines drivers to obey the safer speed limits is a hypothesis that needs to be examined in a separate study.
Table 8. Approximate travel time by corridor (minutes)

\begin{tabular}{|l|c|c|c|c|}
\hline \multirow{2}{*}{ Corridor } & \multicolumn{2}{|c|}{$\begin{array}{c}\text { Forward } \\
\text { direction }\end{array}$} & \multicolumn{2}{c|}{$\begin{array}{c}\text { Reverse } \\
\text { direction }\end{array}$} \\
\cline { 2 - 5 } & $\begin{array}{c}\text { Posted } \\
\text { speed } \\
\text { limit }\end{array}$ & $\begin{array}{c}\text { SSA- } \\
\text { based } \\
\text { speed } \\
\text { limit }\end{array}$ & $\begin{array}{c}\text { Posted } \\
\text { speed } \\
\text { limit }\end{array}$ & $\begin{array}{c}\text { SSA- } \\
\text { based } \\
\text { speed } \\
\text { limit }\end{array}$ \\
\hline Isfahan-Delijan & 98 & 100 & 146 & 114 \\
\hline Najaf Abad-Daran & 61 & 61 & 75 & 67 \\
\hline Neyshabur-Kahak & 111 & 121 & 108 & 121 \\
\hline Chenaran-Faruj & 76 & 67 & 70 & 65 \\
\hline Arak-Salafchegan & 49 & 47 & 53 & 46 \\
\hline Tehran-Saveh & 45 & 55 & 45 & 57 \\
\hline $\begin{array}{l}\text { All Corridors } \\
\text { (Average) }\end{array}$ & 73 & 75 & 83 & 78 \\
\hline
\end{tabular}

\section{Changes in mean speed/travel times}

Another interesting result of the comparison between current posted speed limits and SSA-based safer speed limits is the mean travel speeds and the relevant approximate travel times. The mean travel speeds and the relevant travel times are provided in Tables 7 and 8 , respectively. Intuitively, the introduction of a $90 \mathrm{~km} / \mathrm{h}$ maximum safer speed limit could be expected to decrease the estimated mean travel speed and increase the approximate travel time along the corridors. However, as seen in the Tables 7 and 8, the majority of the SSA-based speed limit mean travel speeds are similar or higher and travel times are similar or lower compared with the current posted speed limits. The reduced numbers of SSA-based speed limit changes (Table 5) are considered to be a factor given the correlation with similar or higher mean travel speeds and similar or lower travel times.

\section{Conclusions}

This study aimed to propose a practical framework, amongst other methodologies, for setting safer speed limits on rural roads based on both the likelihood as well as severity of different potential crash types. This framework has the following benefits:

1. Demonstrates this process as a practical tool for setting safer speed limits by accounting for the potential likelihood and severity of several crash types,

2. Reduces the effect of engineering judgment and unifies the procedure for setting safer speed limits.

The proposed framework was applied to six corridors in Iran and a set of parameters were used to compare the safer 
speed limits with the speed limits currently posted on the six corridors. Results of the comparison showed that the proposed framework can help to provide a more harmonic speed limit profile (i.e., similar speed limits for similar safety conditions), and fewer number of changes in the speed limits along a corridor. Furthermore, comparison results indicated that the safer speed limits have limited impact on reducing the mean travel speed and increase travel time along the study corridors. Also, by applying this framework, evidence has been obtained to legitimise speed limit reductions aimed at saving lives in the interim, while engineering infrastructure treatments can be implemented.

The study demonstrates the potential for SSA-based safer speed limits to reduce the likelihood and severity of several crash types without undue impact on current traffic speeds or travel times. The future potential of the approach is to increase safer speed limits over time as road infrastructure, vehicle and road user initiatives contribute to reduced risk of crash occurrence and injury severity on the continuing path to achieving a Safe System.

Finally, the following notes need further considerations (and perhaps be studied in future research):

1. Speed limit compliance is a crucial challenge especially when it comes to safer speed limits (Doecke et al. 2018). Speed limit compliance may vary due to factors such as perceived reasonableness of safer speed limits, and speed limit enforcement practices (Doecke, et al. 2018). Hence, increasing public awareness and social marketing activities aiming to increase the perceived reasonableness of safer speed limits, as well as more strict law enforcement of speed limit violations are vital for increasing the acceptance of safer speed limits among drivers.

2. Speed limits and infrastructure treatments are the flip sides of a coin. That is, if the infrastructure cannot assure safety at the speeds travelled, the speed limits must be reduced. On the other hand, where the road infrastructure is made safer through engineering treatments, the speed limits can often be raised from basic Safe System levels. Moreover, for a social acceptance perspective, improving road engineering safety standards and raising the safer speed limits on a number of road segments would legitimise lower safer speed limits with lower road engineering safety on other segments. However, this hypothesis needs to be investigated in a separate study.

\section{Limitations}

The focus of this paper was to report the application of Safe System Approach as a robust method to determine safer speed limits. The proposed framework was applied in six pilot zones in Iran. Certainly, the real effect of the proposed safer speed limits and engineering measures on the safety improvement can be demonstrated by comparing safety-related indicators (e.g., average speeds, speed violations, speed variances, crashes and injuries) in the six pilot zones before and after implementing the proposed safer speed limits and engineering measures. In the circumstances, a full evaluation could not be undertaken as the life cycle of the project is to be three years.

Also, regarding the risk scoring system and SSLs, it should be noted that no scoring system is ideal and subjectivity can affect the scores. Moreover, this was the first study in which the safety risk scores were banded and used for determining safer speed limits. The risk score ranges and the relevant safer speed limits were determined for the current case study, and providing a more general risk score and safer speed limit ranges would entail wider use of the framework and comparisons with actual safety performance.

\section{References}

Australian Transport Council (2009), National road safety action plan: 2009 and 2010, ATC, Canberra, ACT.

Australian Transport Council (2011), National road safety strategy 2011-2020, ATC, Canberra, ACT.

Austroads. (2016). Safe System Assessment Framework Research Report AP-R509-16. Austroads.

Department for Transport (2000). Tomorrow's roads: safer for everyone, London, UK

Doecke, S. D., Kloeden, C.N., Dutschke, J. K., Baldock, M. R. J (2018). "Safe speed limits for a safe system: The relationship between speed limit and fatal crash rate for different crash types." Traffic injury prevention 19(4): 404408.

Dua, A., Anderson, C, Cartwright, F, Holmes, J (2013). The NOW 100 speed limit changes in South Australia. Australasian College of Road Safety Conference, 2013, Adelaide, South Australia, Australia.

Elvik, R. (2013). “A re-parameterisation of the Power Model of the relationship between the speed of traffic and the number of accidents and accident victims." Accident Analysis \& Prevention 50: 854-860.

Elvik, R., Christensen, P., Amundsen, A. H. (2004). "Speed and road accidents: an evaluation of the Power Model", Transportøkonomisk Institutt, Report No. 740/2004

Evans, L. (1994). "Driver injury and fatality risk in two-car crashes versus mass ratio inferred using Newtonian mechanics." Accident Analysis \& Prevention 26(5): 609616.

Farmer, C. M. (2017). "Relationship of traffic fatality rates to maximum state speed limits." Traffic injury prevention 18(4): 375-380.

Hughes, B., Anund, A., Falkmer, T. (2015). "System theory and safety models in Swedish, UK, Dutch and Australian road safety strategies." Accident Analysis \& Prevention 74: 271278 . 
Jurewicz, C. and K. Hall (2009). Speed limit setting principles in the Safe System context, Austroads.

Kloeden, C., Ponte, G., McLean, A. J. (1997). “Travelling speed and the risk of crash involvement volume 2-case and reconstruction details." Adelaide: NHMRC Road Accident Research Unit, The University of Adelaide.

Larsson, P., Dekker, S., Tingvall, C.. (2010). "The need for a systems theory approach to road safety." Safety Science 48(9): 1167-1174.

Mackenzie, J., Kloeden, C., Hutchinson, T.P. (2015). "Reduction of speed limit from $110 \mathrm{~km} / \mathrm{h}$ to $100 \mathrm{~km} / \mathrm{h}$ on certain roads in South Australia: a follow up evaluation."

Musicant, O., Bar-Gera, H., Schechtman, E. (2016). "Impact of speed limit change on driving speed and road safety on interurban roads: meta-analysis." Transportation research record 2601(1): 42-49.
OECD (2008). "Towards Zero: Ambitious road safety targets and the Safe System approach.” Transport Research Centre, Paris, France.

Rosen, E., Stigson, H., Sander, U. (2011). "Literature review of pedestrian fatality risk as a function of car impact speed." Accident Analysis \& Prevention 43(1): 25-33.

Shuey, R and Myers D. (2021), "The AAA Approach to Crash Investigation Reform - The Perspective from Road Policing Practitioners." Journal of Road Safety, Vol 32, Issue 4.

Steinmetz, L., Jurewicz, C., Taylor, S. (2015). Safe system in the planning process. Sydney NSW 2000 Australia, Austroads.

World Health Organization, (2018). Global status report on road safety 2018, World Health Organization. https://apps.who. int/iris/handle/10665/276462. 
Appendix 1. Pilot Corridor Base Information

\begin{tabular}{|c|c|c|c|c|c|c|c|c|}
\hline Pilot Corridor & $\begin{array}{l}\text { Length } \\
(\mathbf{k m})\end{array}$ & Segment & $\begin{array}{c}\text { Road } \\
\text { Type }^{(1)}\end{array}$ & Direction & $\underset{(2)}{\mathbf{A A D T}}$ & $\begin{array}{c}\text { Heavy } \\
\text { Vehicles } \\
(\%)\end{array}$ & $\begin{array}{c}\text { Mean } \\
\text { Speed } \\
(\mathrm{km} / \mathrm{h})\end{array}$ & $\begin{array}{c}\text { Speed } \\
\text { Violation } \\
(\%)\end{array}$ \\
\hline \multicolumn{9}{|c|}{ Isfahan Province } \\
\hline \multirow{6}{*}{ Isfahan - Delijan } & \multirow{6}{*}{125} & \multirow{2}{*}{1} & \multirow{2}{*}{ Hwy. ${ }^{1}$} & Forward & 21,905 & 26 & 93 & 19.5 \\
\hline & & & & Reverse & 21,799 & 30 & 93 & 17.2 \\
\hline & & \multirow{2}{*}{2} & \multirow{2}{*}{ Hwy. } & Forward & 12,910 & 45 & 84 & 9.4 \\
\hline & & & & Reverse & 12,656 & 44 & 90 & 10.4 \\
\hline & & \multirow{2}{*}{3} & \multirow{2}{*}{ Hwy. } & Forward & 12,220 & 45 & 83 & 1.7 \\
\hline & & & & Reverse & 12,115 & 41 & 81 & 2.4 \\
\hline \multirow{4}{*}{$\begin{array}{l}\text { Najaf Abad - } \\
\text { Tiran - Daran }\end{array}$} & \multirow{4}{*}{100} & \multirow{2}{*}{1} & \multirow{2}{*}{ Hwy. } & Forward & 22,182 & 11 & 84 & 3.9 \\
\hline & & & & Reverse & 21,526 & 13 & 85 & 8.1 \\
\hline & & \multirow{2}{*}{2} & \multirow{2}{*}{ Hwy. } & Forward & 12,486 & 13 & 82 & 4.9 \\
\hline & & & & Reverse & 13,396 & 13 & 87 & 6.3 \\
\hline \multicolumn{9}{|c|}{ Khorasan Razavi Province } \\
\hline \multirow{4}{*}{$\begin{array}{l}\text { Neyshabur } \\
\text { - Sabzevar - } \\
\text { Kahak }\end{array}$} & \multirow{4}{*}{190} & \multirow{2}{*}{1} & \multirow{2}{*}{ Hwy. } & Forward & 7,680 & 25 & 83 & 0.5 \\
\hline & & & & Reverse & 8,351 & 25 & 80 & 0.6 \\
\hline & & \multirow{2}{*}{2} & \multirow{2}{*}{ Hwy. } & Forward & 7,924 & 28 & 95 & 16 \\
\hline & & & & Reverse & 8,616 & 31 & 87 & 4.8 \\
\hline \multirow{4}{*}{$\begin{array}{l}\text { Chenaran - } \\
\text { Quchan - Faruj }\end{array}$} & \multirow{4}{*}{65} & \multirow{2}{*}{1} & \multirow{2}{*}{ Hwy. } & Forward & 12,883 & 11 & 91 & 7.2 \\
\hline & & & & Reverse & 12,255 & 12 & 91 & 8.3 \\
\hline & & \multirow{2}{*}{2} & \multirow{2}{*}{ Hwy. } & Forward & 12,203 & 8 & 91 & 8.9 \\
\hline & & & & Reverse & 11,365 & 8 & 87 & 2.1 \\
\hline \multicolumn{9}{|c|}{ Markazi Province } \\
\hline \multirow{4}{*}{$\begin{array}{l}\text { Tehran - Saveh } \\
\text { Fwy. }\end{array}$} & \multirow{4}{*}{77} & 1 & FuUu 2 & Forward & 22,750 & 34 & 89 & 3.0 \\
\hline & & 1 & Fwy. & Reverse & 21,036 & 27 & 101 & 10.0 \\
\hline & & & & Forward & 14,613 & 35 & 93 & 10.8 \\
\hline & & 2 & Fwy. & Reverse & 11,314 & 36 & 74 & 2.9 \\
\hline Arak - & 67 & 1 & HUU & Forward & 17,859 & 32 & 97 & 25.6 \\
\hline Salafchegan & $6 /$ & 1 & Hwy. & Reverse & 16,587 & 29 & 98 & 26.3 \\
\hline
\end{tabular}

(1) Hwy. = Highway; Fwy. = Freeway

(2) Annual Average Daily Traffic 


\title{
Silent, unsafe... and underestimated? Exploring the relationships between life stress and safety issues among Spanish drivers
}

\author{
Francisco Alonso $^{1,2}$, Mireia Faus ${ }^{1}$ and Sergio A. Useche ${ }^{1,2}$, \\ ${ }^{1}$ INTRAS (Research Institute on Traffic and Road Safety), University of Valencia, Valencia, Spain \\ ${ }^{2}$ Faculty of Psychology, University of Valencia, 46010 Valencia, Spain
}

Corresponding Author: Sergio A. Useche. Carrer del Serpis 29, Valencia, Spain. sergio.useche@uv.es; ORCID: 0000-0002-5099-4627; (+34) 611317890.

\section{Key Findings}

- Life stress remains an understudied topic compared with other stress-related factors which affect driving performance.

- However, it can be considered relatively common among the Spanish driving population.

- Although stress-related awareness is relatively high, it seems not enough to affect the decision to drive.

\begin{abstract}
Almost all the recent studies addressing road safety from the approach of human factors agree that stress is one of the most considerable (but underestimated) threats for safe driving. However, evidence on the relationship between stressful life events and driver performance remains scarce. Therefore, this study aimed to assess life stress-related perceptions of Spanish drivers, as well as exploring their relationships with self-reported driving performance, decision-making and other road safety-related issues. Methods: This cross-sectional research analysed the information gathered from a nationwide sample of $n=840$ Spanish drivers responding to an electronic survey on psychosocial issues, stress-related factors and driving issues. The results show that a high percentage $(75 \%)$ consider that stress may impair their driving performance, while $76.9 \%$ of drivers report having experienced at least one major stressful life event during the last year. Despite this relatively high awareness of the negative role of stress and its associated factors for driving safety, this study found that drivers tend to 'ignore the alarm signals', as they often reported keeping driving, even when noticing their driving fitness and performance might be impaired by stress-related factors. This study highlights the need to create and apply interventions aimed at informing and training drivers to identify, manage and cope with stress from different spheres, including stressful life events, as a means of potentially improving their driving safety habits and outcomes.
\end{abstract}

\section{Keywords}

Spanish drivers, stress-related factors, life stress, driving performance, road safety

\section{Introduction}

During the last 20 years, new evidence on psychosocial risk factors (especially stress-related ones) suggests not only that they might have a key role to explain negative driving safety outcomes but also that they have been traditionally underestimated by drivers as factors affecting their driving performance (Lane et al. 2020; Legree et al. 2003).
This has been hypothesised to be a negative consequence of many factors, such as overconfidence, repeated practice, lack of information and insufficient risk perception among drivers, a set of facts that could be worsening their road safety outcomes (Alonso et al. 2020a; Spencer et al. 2020). In this context, environmental, social and life-related stressors could be considered as relatively frequent, even though underreporting of their rates remains very high among many sectors of the population (Gustavson et al.

Received: 19/09/2021; Received in revised form: 16/11/2021; Accepted: 13/01/2022; Available online: 09/02/2022

Copyright: (C) The Author(s). 2021 This is an open access article distributed under the terms of the Creative Commons Attribution (CC BY)_license, which permits unrestricted use, distribution, and reproduction in any medium, provided the original author(s) and the source are credited.

Suggested citation: Alonso, F., Faus, M. and Useche, S.A. (2022). "Silent, unsafe... and underestimated? Exploring the relationships between life stress and safety issues among Spanish drivers" Journal of Road Safety, 33(1), 36-48. https://doi.org/10.33492/JRS-D-21-00056 
2018, Weiten et al. 2014). Stress is a feeling of physical or emotional tension that can come from any situation or thought making one feel frustrated, furious or nervous (Koolhaas et al. 2011). Every person has experienced stress symptoms at some point in their life, since, originally, it is a feeling that alerts the subject in case of danger or challenge, being therefore necessary for survival (Soto, Orozco-Fontalvo \& Useche, 2021; Koscinczuk 2014). However, the current social context makes stress increasingly linked to life situations. The body reacts excessively and maladaptively to any demand, having a negative impact on different social spheres of the person's life (Escobar et al. 2010). Life-related stressors are very variable, including health, family, economic and/or financial issues, among others.

The typical symptomatology related to stress includes emotional issues? in the form of anger, irritability and/ or anxiety, but also physical phenomena such as muscular tension, stomach issues and a temporary overexcitement that leads to an increase in blood pressure and heart rates, sweating, palpitations, breathing troubles and/or chest pain (Stults-Kolehmainen \& Sinha 2014). This situation forces the subject to use an important part of their resources to face or mitigate these effects, thus reducing the attention paid to the surrounding environment (García et al., 2019; Myhr et al. 2019).

More specifically, there is considerable empirical evidence of the negative effects of stress on health through direct and indirect mechanisms (Nguyen et al. 2020; Stogner et al. 2020; Useche et al. 2021b). According to recent studies, stress affects and deteriorates cognitive, emotional, and behavioural functions (Pfefferbaum \& Doughty 2001). The research showing the effects of stress on cognitive functioning is based on two basic approaches (Stawski et al. 2006). First, according to the theory of appraisal, when individuals deem life stressful, cognitive resources must be allocated to cope with environmental demands, thus reducing the resources available to perform cognitive functions (Bakker \& Demerouti 2017, Calvo \& GutierrezGarcia 2016). In this sense, several studies of aging have provided similar findings, indicating that individuals who report higher levels of subjective distress exhibit poor episodic memory, fluid intelligence and processing speed performance, as well as an increased risk of cognitive decline (Perrotin et al. 2017; Wilson, et al. 2005). The second method to assess the effects of stress consists of evaluating cognitive interference, intrusive off-task thoughts and images, and the intentional suppression of such intrusions that limit attentional resources used for working memory (Luna et al. 2020; Oberauer et al. 2016; Oberauer 2019; Sepp et al. 2019). Among other adverse effects of stress, the deviation of attention resources from the main task should be emphasised. In other words, the interference with recording, attention, and processing of the information affects aspects that compromise the execution of such tasks (Grover et al. 2017). Specifically, cognitive and emotional processes associated with stress may lead to difficulties experienced in one domain transferring information to another (Rowden et al. 2011; Rowden et al. 2006).

Reducing the cognitive resources destined for certain daily activities is not especially problematic; however, there are some tasks that can be adversely affected. In this sense, some recent evidence has systematically shown how stress (approached from different theoretical models and conceptions) and driving performance are closely related, as safe driving requires balancing external and personal demands and resources, but demands often overcome the latter (Epel et al. 2018, Rowden et al. 2011, Spencer et al. 2020, Useche et al. 2021a). Also, there exists a growing body of scientific evidence endorsing the hypothesis of a relationship between stress and traffic crash rates among drivers (Legree et al. 2003).

Life-related stressors affect driving in many ways. To the previously mentioned cognitive deterioration, must be added an emotional and physical symptomatology that impairs the ability to adequately perform activities. On the one hand, a higher irritability and impatience can lead to aggressive driving. In addition, risk perception could be diminished, which may imply dangerous or inadequate behaviours (Taylor \& Dorn 2006). The driving performance can be altered by muscular tension, fatigue and physical pain derived from stress. Also, other, secondary risks produced by stress (approached from the transactional perspective) must be mentioned as well, such as behavioural strategies to face the stressrelated emotional and cognitive responses caused by, for instance the development of unhealthy lifestyles and the consumption of psychoactive drugs, especially alcohol (Alonso et al., 2017, Chilcoast \& Menard 2003, Emo et al 2016, Marti-Belda et al. 2019, Rowden et al. 2011).

Therefore, the literature overall supports the proposition that assessing driving stress must also imply considering life events, as well as the stress generated by the traffic context itself. In this sense, interaction between the driving environment and the characteristics of the driver may take place, with particularly negative results in terms of driving safety (Rowden et al. 2011; Taylor \& Dorn 2006). Said differently, a prolonged and not intervened imbalance between drivers' own cognitive, emotional and behavioural resources and the demands imposed by both life and traffic contexts can constitute a 'hazardous formula' for drivers, as well as for other road users (Useche et al. 2018). This makes it extremely more likely to observe riskier behaviours such as cognitive lapses, errors, aggressive patterns and conventional traffic violations (Wickens et al. 2008) that, in turn, remain considered by the empirical literature as related to pre-crash situations and crash rates (Lagarde et al. 2004; Legree et al. 2003). 


\section{The underexplored (or undervalued?) role of life stress on driving performance}

Contrary to what has been explained so far, an essential sphere of stress remains markedly underexplored in this context, i.e. the role of stressful life events on driving performance. The scarce scientific literature available in this regard has shown that the probability of being involved in a traffic crash notably increases during the subsequent days and even months after a highly stressful event. More specifically, major events or the cumulative effect of daily hassles have been linked with detrimental road safety outcomes (Rowden et al. 2011) such as family issues (Lagarde et al. 2004), financial difficulties (Norris et al. 2000), occupational stress (Cendales et al. 2017), resulting in adverse situations at the wheel (Scott-Parker et al. 2018). Furthermore, increased exposure to acute life stressors may predict stress-related outcomes of drivers when exposed to certain traffic conditions, such as traffic jams and challenging road conditions, thus increasing their likelihood of involvement in traffic crashes (Hennessy et al. 2000). The few studies in this field confirm the need for research addressing the real influence of stressful events in the driving task, and, consequently, in road safety.

\section{Study objective and hypothesis}

The core aim of this study was to assess life stress-related perceptions of Spanish drivers, as well as exploring their relationships with self-reported driving performance, decision-making and other safety-related issues. On the basis of the aforementioned theoretical and empirical findings, it was hypothesised that $(i)$ as per the general population, life stressful events would be relatively common among drivers, and (ii) as in other stress-related spheres, there might be a low awareness of the potentially impairing effects on driving performance.

\section{Methods}

\section{Sample}

This study analysed the data retrieved from a nationwide sample of $n=840$ Spanish drivers with a mean age of $M=$ $37.6(S D=14.9)$ years, all of them of legal driving age. 466 (56\%) were males, and 374 (44\%) were females. Most drivers had reached high school $(53.7 \%)$, or university $(28.9 \%)$, and $73 \%$ of them were working, while $5.5 \%$ were dedicated to housework.

In relation to driving issues, $27.4 \%$ had driven for between 11 and 20 years, while $24.1 \%$ had driven for between 3 and 10 years. More than half of the drivers acknowledged that they had been involved in at least one crash $(24 \%$ had been involved in one crash, and $34 \%$ in two or more) in the previous 12 months.

The starting (minimum) sample size was initially established as about $n=720$ individuals with an anticipated effect size of .20, and a statistical power level of .80 assumed (Salgado 2018).

The response rate was $\approx 91 \%$, as approximately 925 persons were invited to participate. There were $65(9 \%)$ people who did not wish to participate in the survey or did not complete the questionnaire once it was started.

The sample was obtained through a convenience (non-probabilistic) sampling process, based on accessibility to the population of interest i.e. licensed Spanish drivers. For this purpose, an inter-institutional mailing list of the general population previously utilised in other studies, shared by various Spanish universities and research centers was used. Participants were invited to take part in the study through a personal invitation (e-mail) providing the link to a structured electronic survey.

As data were being received, quotas were used to cover age segments and regions with low representation in the sample. These quotas (without being too rigorous, as they did not pursue the statistical representativeness of a probabilistic design) were guided by the data provided by the national records of the Directorate-General of Traffic (DGT) and information from the Spanish National Institute of Statistics (INS) in terms of age, gender and regional distribution of the Spanish population.

This structured questionnaire was administrated during the second semester of 2019, through electronic surveys, whose duration to complete ranged between 6-22 minutes, depending on the age and literacy profiles of the respondents.

\section{Study setting and measures}

The only selection criteria for participating in this research were $(i)$ owning any type of driving licence for fourwheeled vehicles (i.e. motorcycles were excluded), which ensured all participants were aged over 18; (ii) driving at least once a month), but not being a professional driver, and (iii) currently residing in Spain.

The questionnaire, presented in Spanish, was composed of three sections:

The first section aimed to gather basic data on participants, useful as profiling variables. These variables, mainly focused on socio-demographic features, were: demographic variables: gender, age, and occupation; driving-related variables: driving experience (years since first licensed), type of vehicle most frequently driven, usual time of driving (day/night/both), average driving hours a week, and the main reason for driving (e.g.) commute, work, leisure and/or personal motives; and self-reported road safety records: traffic sanctions (fines) received and crashes in the last 12 months. Also, drivers were asked to what extent did they consider that stress: $(i)$ may affect overall driver performance, and (ii) may increase the 
likelihood of crash involvement, using a Likert-based [0-3] scale, where $0=$ not at all, and $3=$ definitely.

Secondly, and in order to assess stressful life events, the questionnaire included a selection of eight items from the Social Readjustment Rating Scale (SRSS; Holmes \& Rahe 1967), that present a series of life situations likely to represent significant sources of stress among individuals (Fig. 1). Cronbach's Alpha of the SRSS is 0.89 (Scully et al. 2000). It is important to note that under this approach, not all stressful events necessarily are prototypically negative situations, even though the most relevant ones tend to have such characteristics (e.g. sickness, loss of loved ones, financial issues). Instead, theoretically positive events might easily turn into sources of stress, anxiety and psychological issues, as this is the case of (e.g.) weddings, pregnancy/childbirth, or challenging situations such as exam sessions (in the academic context) and job-seeking (Hassanzadeh et al. 2017; Salm Ward 2017).

The third section of the questionnaire was only applied to those drivers who reported they had experienced at least one of the significant stressful life events included in the SRSS during the last year. They were asked about whether: $(i)$ they kept driving during the month after the stressful event(s); and (ii) they perceived that their driving performance had been impaired as a consequence of such event(s). These two questions were structured on the basis of a dichotomic (Yes/No) scale. In order for participants to adequately answer the questionnaire, they were provided with an explanation of what 'stressful life events' are.

\section{Ethics}

This study was conducted in conformity with the Code of Ethics of the World Medical Association (Declaration of Helsinki). The Research Ethics Committee of the University Research Institute on Traffic and Road Safety (INTRAS) of the University of València (Institutional Board) was consulted, certifying that the research subject met the general ethical principles and the study was approved to be carried out in Spain (IRB number: HE000231119).

Each participant signed an informed consent statement and participated voluntarily. All the questionnaires and tests were designed and applied to ensure the anonymity of the participants and the non-existence of wrong or right answers. Data were confidential and participation was anonymous implying no potential risks for the integrity of participants.

\section{Data Processing}

For this study, descriptive analyses (frequencies and central tendency measures) were used to describe and characterise the prevalence of stress and crash-related factors among Spanish drivers.
To explore the association between driver risk levels and life stress events, drivers were firstly classified in accordance with their risk level, as follows: (i) drivers who had been fined at least once over the last year (except for parking tickets) and/or suffered more than one traffic crash were labeled as 'high risk drivers' ( $n=135 ; 16.1 \%)$; (ii) drivers not having suffered crashes or received fines, but having a greater risk exposure (i.e. higher average weekly driving time, that can be understood as 'driving exposure'), were considered as 'medium risk drivers' ( $n=462 ; 55 \%)$; and (iii) drivers not having suffered crashes nor receiving fines, added to a low-risk exposure, were classified as 'low-risk drivers' ( $n=243 ; 28.9 \%)$.

In regard to the statistical tests used in the study: Chi-square $\left(\chi^{2}\right)$ analyses were conducted to establish potential statistical associations between categorical variables. After performing normality tests and testing basic parameters, One-way Analyses of Variance (ANOVA) were used for testing potentially statistically significant outcomes in terms of stress and crash rates, according to dichotomic demographic variables (i.e. gender), and Tukey's Post hoc was used to compare variables with more than two groups, such as driver experience (divided into six levels). Once the data was obtained, the relevant statistical analyses were carried out using IBM SPSS (Statistical Package for Social Sciences), version 26.0 .

\section{Results}

\section{Stress-related perceptions and driving}

The first key outcome was related to the life stress-related perceptions of Spanish drivers. Three out of four (75.4\%) reported believing that stressful life events have a major impact on driving patterns. On the other hand, $21.5 \%$ considered that their effect is limited - although it exists, while $3.2 \%$ perceived that these events have no effect on driving performance. Comparative age and gender-based analyses concerning the appraisal of the negative effects of stress on driving show that neither driver age nor gender had a significant impact on continuing or avoiding driving $(p>.05)$.

Regarding participants' assessments on how much stress may increase the likelihood of crash involvement, measured on a scale ranging between 0 (not at all) and 3 (definitely), found a mean of $M=2.73(\mathrm{SD}=.87)$. Mean comparison tests indicated there were differences between groups of drivers, namely:

1. Reasons for driving, where participants using the vehicle for both commuting or working reasons $(M=$ $1.51 S D=.89$ ) considered that stress increases crash likelihood to a greater extent than participants who use the vehicle for personal reasons or leisure $(M=$ $1.40 ; S D=.79$ ), with $\mathrm{F}_{(1,825)}=3.41 ; p<.050$; (One-way ANOVA between groups). 
2. Drivers' years of experience, where participants with more than 30 years $(M=1.59 ; S D=.90)$ of driving experience considered that stress has a higher impact on driving, compared with drivers with 21-30 years of experience $(M=1.36 ; S D=.78)$, with $\mathrm{F}_{(5,789)}=2.68 ; p<$ .050 (Tukey's Post-hoc significant difference $=.22$ ).

3. Usual driving time (i.e., day, night or both), where average scores were significantly greater among daylight drivers $(M=1.51 ; S D=.75)$, compared to those driving equally during both the day and night $(M=1.33 ; S D=.74)$, with $\mathrm{F}_{(2,796)}=5.15 ; p<.050$ (Tukey's Post-hoc significant difference: $M_{\text {diff }}=.18$ ).

Other variables such as gender, age, risk exposure, type of vehicle, hours of non-stop driving, type of road most frequently used, crash involvement, penalties received over the last three years (excluding parking tickets), working status, occupation or work schedule did not report One way ANOVA-based significant differences among participants.

\section{Life stress and safety outcomes}

Among the 840 participants, over three-quarters (76.9\%) admitted to having experienced at least one of the relevant life stressors listed in the research protocol, which were theoretically likely to trigger stress during the past year.

In brief, more than $40 \%$ experienced a wedding, a birth or a similar positive family-related event. On the other hand, almost $30 \%$ had faced the death or illness of a loved one; around $20 \%$ reported having a significant occupational or academic change; approximately $15 \%$ had reported negative changes on their own health or family/relationship problems; and more than $10 \%$ experienced financial or other problems. The full set of positive and negative cases is presented in Fig. 1.

Categorical (Chi-square) analyses found that statistically significant differences existed for both gender $\left(\chi^{2}=5.03 ; p\right.$ $\leq 0.05)$ and age $\left(\chi^{2}=21.73 ; p \leq 0.01\right)$. As for gender, female drivers were more prone to report having experienced at least one stressful life event (79.9\%), compared with $75 \%$ of male drivers. In terms of age, drivers aged between $18-25(88.5 \%)$ and between 26-35 (83.2\%), were most likely to report experiencing a stressful event. Table 1 shows the frequency and percentage of stressful life events classified by gender and age.

\section{Could riskier driver safety be related to life stress?}

In order to answer this question, driver risk profiles (risk levels) in terms of crashes and fines were analysed against life stress. The results (Fig. 2) show how the relative frequency of drivers reporting having suffered stressful life events is considerably greater among 'high-risk drivers', compared to the other two groups $\left(\chi^{2}=2.890 ; p<\right.$ $.050)$. Although there were no significant gender-based differences in terms of risk levels, Figure 2 depicts the results for the total sample and for male/female drivers.

In other words, there seems to be a relationship between the fact of having experienced relevant stressful life events and road safety-related issues such as traffic crashes and sanctions. Nevertheless, it is worth mentioning that this outcome is merely associative, as no causal inferences could be measured due to the nature of the present data.

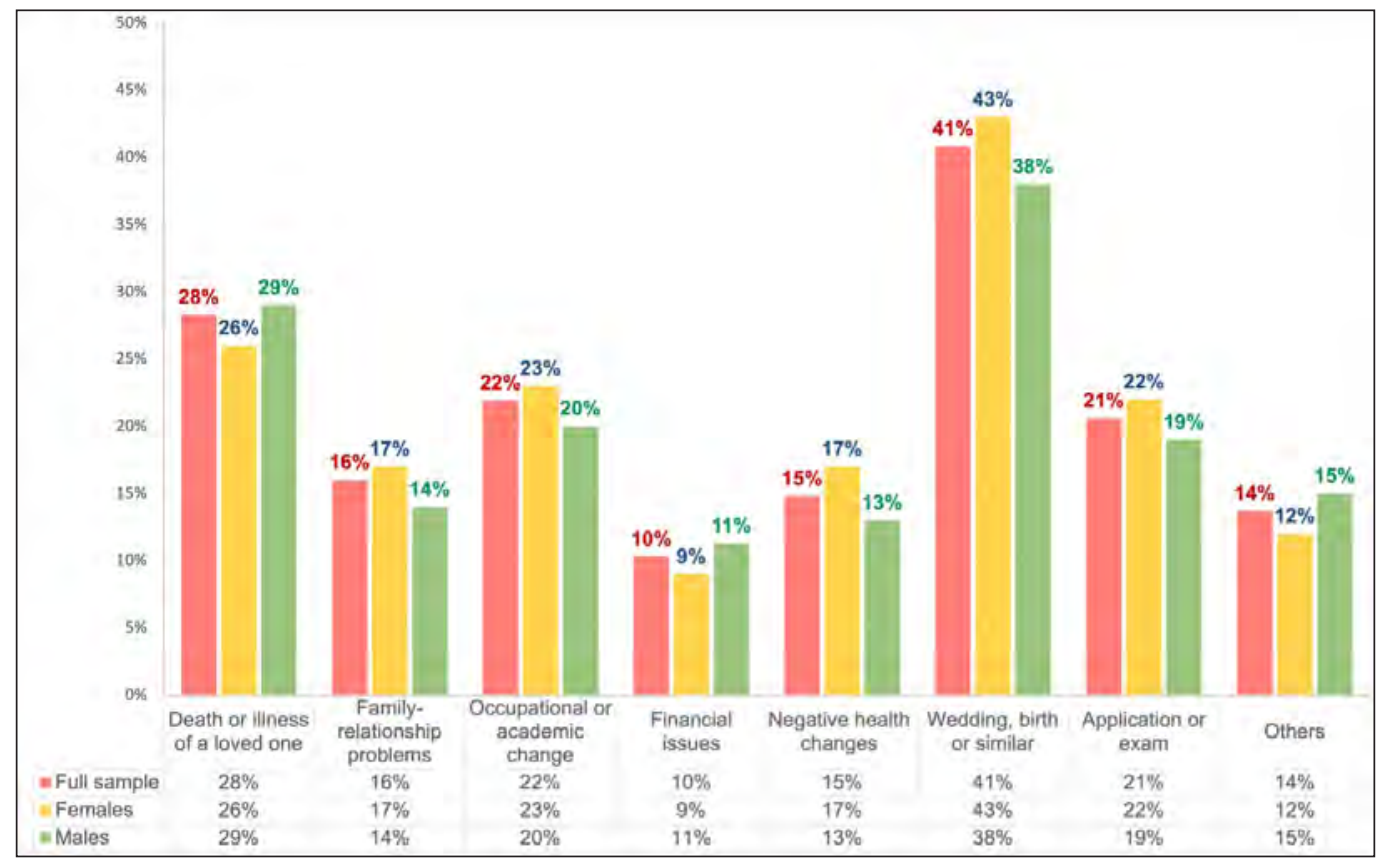

Figure 1. Self-reported stressful life events suffered among Spanish drivers (last 12 months) 
Table 1. Gender and age-based distribution of self-reported stressful life events among Spanish drivers

\begin{tabular}{|c|c|c|c|c|c|c|}
\hline \multirow{2}{*}{ Variable } & \multirow{2}{*}{ Category } & \multirow[b]{2}{*}{$n$} & \multicolumn{2}{|c|}{ Experienced at least one stressful life event } & \multicolumn{2}{|c|}{ Did not experience stressful life events } \\
\hline & & & $\begin{array}{c}\text { Frequency } \\
(n=646)\end{array}$ & $\begin{array}{c}\text { Percentage } \\
(76.9 \%)\end{array}$ & $\begin{array}{c}\text { Frequency } \\
(n=194)\end{array}$ & $\begin{array}{c}\text { Percentage } \\
(23.1 \%)\end{array}$ \\
\hline \multirow{2}{*}{ Gender } & Female & 374 & 299 & $79.9 \%$ & 75 & $20.1 \%$ \\
\hline & Male & 466 & 347 & $74.4 \%$ & 119 & $25.6 \%$ \\
\hline \multirow{6}{*}{$\begin{array}{l}\text { Age } \\
\text { group }\end{array}$} & $18-25$ & 87 & 77 & $88.5 \%$ & 10 & $11.5 \%$ \\
\hline & $26-35$ & 185 & 154 & $83.2 \%$ & 31 & $16.8 \%$ \\
\hline & $36-45$ & 243 & 178 & $73.2 \%$ & 65 & $26.8 \%$ \\
\hline & $46-55$ & 163 & 117 & $71.7 \%$ & 46 & $28.3 \%$ \\
\hline & $56-65$ & 120 & 89 & $74.1 \%$ & 31 & $15.9 \%$ \\
\hline & $>65$ & 42 & 31 & $73.8 \%$ & 11 & $26.2 \%$ \\
\hline
\end{tabular}

\section{Do life stress events affect the decision to drive?}

Another question raised by this study referred to the continuing (or avoiding) driving during the following month after facing a stressful life situation. For this purpose, only those participants who indicated facing at least one significant stressful event in the last year were considered for the analysis. Therefore, a total of 646 drivers ( $76.9 \%$ of the full sample) responded to the following two questions: (i) did you keep driving during the following month after experiencing such stressful situation(s)?, and (ii) do you consider your driving performance was substantially impaired by such event(s)?. The results obtained are presented in Fig. 3.
Overall, 4 out of each 5 (79.6\%) drivers who experienced one or more significant stressful life situations reported they kept driving during the following month after facing such event(s). A similar proportion (77.2\%) considered that their driving performance had been considerably impaired because of these event(s). Finally, Chi-square tests identified a significant relationship between keeping driving after a stressful event and the belief that driving performance was lessened because of such life stress sources $\left(\chi^{2}=8.405 ; p<.001\right)$.

\section{Discussion}

The core aim of this self-report questionnaire study was to assess life stress-related perceptions of Spanish drivers,

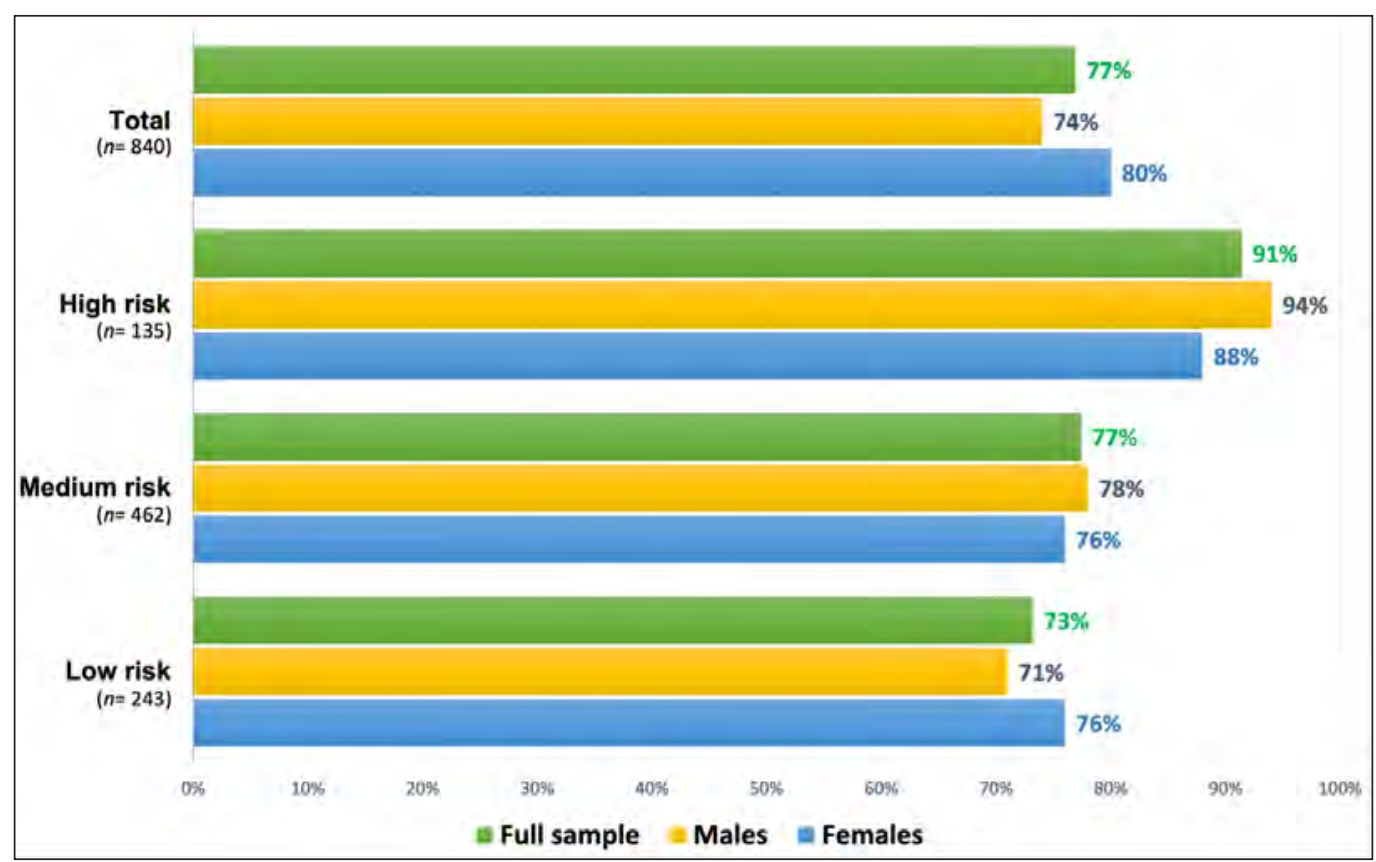

Figure 2. Percentage of drivers having suffered stressful life events according to their risk level 


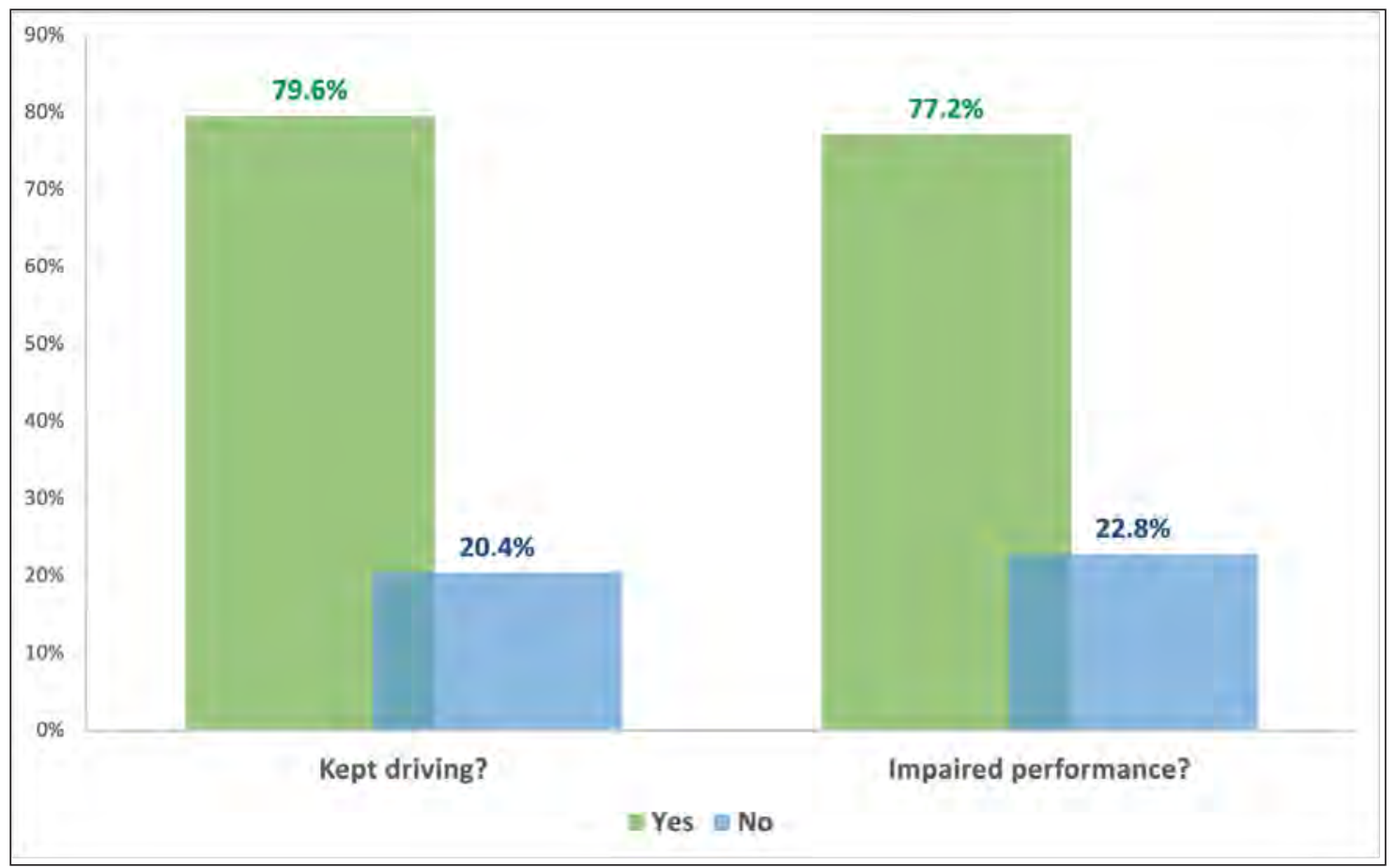

Figure 3. Decision to drive (or not) and perceived driving impairment as a result of stressful life events

as well as to explore their relationships with self-reported driving performance, decision-making and other safetyrelated issues. Overall, the results show how stressful life events are relatively common among the driving population, as $76.9 \%$ of the 840 study participants reported having faced such events at least once during the previous year. More specifically, this percentage was slightly greater among females (79.9\%) if compared with male drivers (74.4\%). This first result is consistent with other similar studies reporting the prevalence of life-related stressful events, even though mostly for the case of general population samples (Grelotti et al. 2018; Salm Ward et al. 2017).

Within these studies ender seems to be a key factor modulating the number and the impacts of these circumstances on individuals. In this case, and although there is not enough evidence to relate it to driving performance, it draws attention to how female drivers tended to report a greater prevalence of stressful life events, in comparison to males. This is consistent with previous studies, most suggesting that women tend to suffer-or at least to self-report- higher levels of stress than males (Andreou et al. 2011, Thwe et al. 2017).

Further, while $38.6 \%$ of women reported having been involved in any crashes during the previous year, in contrast with $60.8 \%$ of men who had at least a slight crash. This is, female drivers report suffering a slightly greater number of stressful situations than males, but have lower crash involvements. At a theoretical level, and far from underestimating stress as a potential source of road risk, it is possible that its value is relative, especially if the large number of variables intervening in driving tasks, including usual road behaviours, that tend to be riskier among males are considered (Peterson et al. 2019, Useche et al. 2021a). Also, it could be considered that women are usually the main caretakers of their families, as well as being responsible for the family economy (Hodgson et al. 2013, Spence et al. 2011), implying, the so-called caretaker load enhances a greater number of demands usually developing in stressful situations, including having less time for oneself, the abandonment of social relationships and behavioural changes, including tasks such as driving (Pinto et al. 2017).

The study results also correlate, to a certain extent, with other studies on stress and crash rates. Different studies performed in Spain point out that young women, as well as people older than 65 , have higher crash rates that men (Lardelli-Claret et al. 2003, Perez et al. 2006). The 'impatient driver' profile outlined in various studies, attributes this role to higher levels of stress and anxiety faced by women (Segura et al. 2009). However, it has been demonstrated that with the same levels of stress, women are usually the most capable of providing emotional support to other people, managing their stress better than their own (Bodenmann et al. 2015). This gives an interesting starting point for the elaboration of programs addressing the management of stressful driving events.

On the other hand, the scientific literature that approaches stress from a generalist perspective offers some key ideas on how certain stressful factors can negatively affect safety in driving (Rowden et al. 2011). There is empirical evidence supporting a positive association between 
problems related to stress (including the different life events) and negative outcomes on the driving task (Bitkina et al. 2019; Norris et al. 2000). Moreover, some evidence (however limited) related stressful life events with (i) risky driving and (ii) involvement in crashes (Lagarde et al. 2004). Most of the evidence assessing the relationships between stress (from different approaches) and driving performance have been developing from the field of professional driving, as people who require a vehicle to perform their job-related tasks (e.g. Boada-Grau et al. 2013 and 2012; Chung \& Wu 2013; Taylor \& Dorn 2006, Useche et al. 2021b and 2017). However, given their considerably longer driving shifts and risk exposure, and all the driving stressors they frequently face, this study did not cover professional drivers.

The present study also found a relationship between having lived stressful life events and issues related to road safety, such as traffic accidents and fines. Therefore, there is an association between risky driving and stress, which is consistent with results from other studies. This evidence (although frequently in a very implicit way) suggests the existence of an interaction between stress and driver performance, which increases the negative emotions from stress such as aggressiveness, impatience or anger (Rowden et al. 2011). Driving under stressrelated conditions has also been linked to detrimental road safety outcomes such as cognitive lapses, errors, intentional traffic violations (Wickens et al. 2008) and an increased likelihood of crash involvement (Lagarde et al. 2004). Therefore, road safety countermeasures aimed at increasing drivers awareness about stress symptomatology, coping and emotional management delivered via behaviour change education type programs could be helpful (Jawi et al. 2017; Miller 2016).

A key finding is that a high percentage of the surveyed drivers who had lived stressful life events during the previous year were still driving at the time of the data collection. This situation is problematic, as it has been proved that symptoms related to stress, such as fatigue or anger, are directly linked to road crashes (Bener et al. 2017, Duan et al. 2019; ,Wang et al. 2019). However, the majority of these drivers were aware that the stress produced by life events was reducing their driving performance. Thus, one must wonder why, if users are aware of this circumstance, they are still making the decision to drive, but (in absence of in-depth interviews or any other type of qualitative data) the authors remain dependent on the previous literature on the matter. In these studies, other factors potentially explaining differences in driver decision-making, such as driver income, social resources available and accessibility to other transport modes are briefly considered (Alonso et al. 2020b). Said differently, if a person, because of economic, safety, time and/or accessibility related reasons, cannot choose to travel in any other way than by car, it will be quite complicated to give it up in case of feeling unwell, being, fatigued or for any other issue (Gabrielli \& Maimone, 2013).
Therefore, even though it would be ideal that people who are not in perfect condition to drive did not do so, the fact that they are aware of their state and capabilities is important. This way, understanding the symptomatology of stress and knowing to what extent it affects driving is essential to identifying when driving should be avoided (Petersen et al. 2019). However, these results contradict those of other studies where about a third of Spanish drivers underestimated the influence of other types of stress on driving performance (Alonso et al., 2021). As a consequence, it seems necessary to promote informative actions on the negative (i.e. physical, cognitive, emotional, social and behavioural) effects of stress in relation to life events and other relevant spheres also potentially affecting driver safety (Rowden et al. 2011; Taylor \& Dorn 2006). Another important element in this field is the advance in fatigue-detection systems for drivers, which prevent drivers from starting the vehicle if they are not in adequate condition (Sikander \& Anwar 2018).

Moreover, this study followed a dynamic transactional approach to life stressful factors, i.e. individuals' interaction with the stressful factor(s), which remain relevant as factors potentially enhancing negative outcomes (Cunningham \& Regan 2016). Therefore, it is possible to state subjective stress appraisals and 'coping' as key factors potentially mediating the link between life stressors and road safety outcomes, as suggested by Calderwood et al. (2019), Rowden et al. (2011), Useche et al. (2021a).

It should be mentioned that studies in this area suggest that a holistic approach is needed to base any intervention when considering road safety as a complex process that should cover a sufficient variety of factors (Rowden et al. 2006). In the case of life stress, several fields and factors can contribute to explaining an eventual imbalance between life demands and personal resources, including driving performance, to potentially explain road safety outcomes (beyond their associations) in an analytic perspective.

Lastly, the data analysed in the present study was gathered just before the COVID-19 pandemic. Therefore, it is possible to hypothesise that the prevalence of stressful life events in many spheres might be substantially higher after the data was collected, that could impair the external validity of the results (Talaee et al. 2020). Therefore, it would be relevant to design communication campaigns directed at drivers, discussing stress symptomatology and raising awareness of its consequences for road safety. In addition, it would be interesting to include in stress-coping programs, advice for drivers to identify and prevent its negative consequences at the wheel. In this sense, future studies should aim at identifying the influence of certain stress coping techniques for vehicle management, in order to determine to what extent they could be useful in this field of study. 


\section{Limitations of the study}

Although this study involved an extensive sample of Spanish drivers from all regions across the country (even though the sample is not fully representative) and the methodology followed was rather prudent and exploratory, there are some crucial study limitations worth acknowledging. First, this was a self-report questionnaire study. In this regard, common method biases (CMBs) could have influenced the outcomes of this research. In other words, given the heightened vulnerability of participants to socially desirable responses or inaccurate memories, the self-report data may also be a limitation (Subar et al. 2015). While efforts were made to reassure participants of the anonymity of their responses, it could not be ensured that all responses were unbiased. Secondly, social norms, prejudices and misunderstandings on the concept of 'stress' would have a certain influence on the study outcomes. Thirdly, at the time of asking participants about if they avoided driving, the authors did not consider nor control their actual needs or contextual circumstances (e.g., force majeure events, the availability of other transport means) but only their unwillingness to drive as a determinant of this behaviour. Finally, and even though a transactional definition of stress (as mentioned in this study) was provided to participants, it cannot be assumed that a total comprehension has been achieved in all cases, given the complexity of the term, which is evident even among academics and researchers.

As for further research, the authors would like to encourage other researchers to perform additional studies on this underexplored (and sometimes undervalued) research problem, involving other tools for assessing stress-related factors (e.g. psychometric measurement questionnaires), driving behaviour and road safety outcomes -and the potentially hypothesised relationships among them-, under optimal methodological assumptions.

\section{Conclusions}

The results of this study highlight that stressful life events can be considered to be relatively prevalent among Spanish drivers. Given their potential negative effects (e.g. cognitive, emotional, social and behavioural) and their relationship to impaired driving performance (as suggested by other studies), road safety countermeasures aimed at increasing the information available for drivers about stress-related awareness, coping and management might contribute to reducing potential crash risk. Furthermore, these outcomes also suggest that there could be key relationships among demographic factors (especially gender and age), life stress and driving-related decisions that remain pending to explore in depth).

Finally, and despite a relatively high awareness of the negative role of stress and its associated factors for driving safety, this study highlights that drivers tend to 'ignore the alarm signals', as they usually keep driving even when noticing their driving fitness and performance might have been impaired by stress-related factors. Therefore, there is a need to provide drivers with information on how to assess stress levels, reduce stress levels, understand the possible road safety implications of stress and implement possible crash risk countermeasures associated with being stressed. As a potential scenario for it, the literature highlights the need of addressing stress-related awareness and coping in driving training processes, so they whether do not drive when stressed, or seek for reasonable sources of information and/or intervention.

\section{Conflicts of interests}

The authors declare that they have no competing interests.

\section{Funding}

This work was supported by a research grant (ACIF/2020/035) from Generalitat Valenciana. Funding entities did not contribute to the study design or data collection, analysis and interpretation or writing of the manuscript.

\section{Acknowledgements}

The authors wish to thank Arash Javadinejad (licensed translator) for professional editing and proofreading of the final version of the manuscript.

\section{References}

Alonso, F., Esteban, C., González-Marín, A., Alfaro, E., \& Useche, S.A. (2020a). Job Stress and Emotional Exhaustion at Work in Spanish workers: Does unhealthy work affect the decision to drive? PLOS ONE, 15(1), e0227328. https://doi. org/10.1371/journal.pone. 0227328

Alonso, F., Esteban, C., Sanmartin, J., \& Useche, S. (2017). Reported prevalence of health conditions that affect drivers. Cogent Medicine, 4(1), 1303920. https://doi.org/10. 1080/2331205X.2017.1303920

Alonso, F., Useche, S. A., Faus, M., \& Esteban, C. (2020b). Does urban security modulate transportation choices and travel behavior of citizens? A national study in the Dominican Republic. Frontiers in Sustainable Cities, 2, 42. https://doi. org/10.3389/frsc. 2020.00042

Andreou, E., Alexopoulos, E. C., Lionis, C., Varvogli, L., Gnardellis, C., Chrousos, G. P., \& Darviri, C. (2011). Perceived stress scale: reliability and validity study in Greece. International journal of environmental research and public health, 8(8), 3287-3298. https://doi.org/10.3390/ ijerph8083287

Bakker, A. B., \& Demerouti, E. (2017). Job demands-resources theory: taking stock and looking forward. Journal of occupational health psychology, 22(3), 273. https://doi. org/10.1037/ocp0000056

Bener, A., Lajunen, T., Özkan, T., Yildirim, E., \& Jadaan, K. S. (2017). The impact of aggressive behaviour, sleeping, 
and fatigue on road traffic crashes as comparison between minibus/van/pick-up and commercial taxi drivers. $J$ Traffic Transp Eng, 5, 21-31. https://doi.org/10.17265/23282142/2017.01.003

Bitkina, O. V., Kim, J., Park, J., Park, J., \& Kim, H. K. (2019). Identifying traffic context using driving stress: A longitudinal preliminary case study. Sensors, 19(9), 2152. https://doi.org/10.3390/s19092152

Boada-Grau, J., Prizmic-Kuzmica, A.-J., González-Recio, S., \& Vigil-Colet, A. (2013). [Occupational stressors in bus drivers (ELBus-21): Factorial structure, reliability and validity]. Universitas Psychologica, 12(1), 249-259. https:// doi.org/10.11144/Javeriana.upsy12-1.elca

Boada-Grau, J., Sánchez-García, J.C., Prizmic-Kuzmica, A.J., \& Vigil-Colet, A. (2012). Health and safety at work in the transport industry (TRANS-18): factorial structure, reliability and validity. Spanish Journal of Psychology, 15(1), 357-366.

Bodenmann, G., Meuwly, N., Germann, J., Nussbeck, F. W., Heinrichs, M., \& Bradbury, T. N. (2015). Effects of stress on the social support provided by men and women in intimate relationships. Psychological science, 26(10), 15841594. https://doi.org/10.1177/0956797615594616

Calderwood, C., \& Ackerman, P. L. (2019). Modeling intraindividual variation in unsafe driving in a naturalistic commuting environment. Journal of occupational health psychology, 24(4), 423-437. https://doi.org/10.1037/ ocp0000127

Calvo, M. G., \& Gutierrez-Garcia, A. (2016). Cognition and stress. In Stress: Concepts, cognition, emotion, and behavior (pp. 139-144). Academic Press. https://doi.org/10.1016/B978-012-800951-2.00016-9

Cendales, B., Useche, S. A., Gómez, V., \& Bocarejo, J. P. (2017). Bus operators' responses to job strain: An experimental test of the job demand-control model. Journal of occupational health psychology, 22(4), 518. https://doi.org/10.1037/ ocp0000040

Chilcoast, H. D., \& Menard, C. (2003). Epidemiological investigations: Comorbidity of posttraumatic stress disorder and substance use disorder.

Chung, Y.-S., \& Wu, H.-L. (2013). Stress, strain, and health outcomes of occupational drivers: An application of the effort reward imbalance model on Taiwanese public transport drivers. Transportation Research Part F: Traffic Psychology and Behaviour, 19, 97-107. https://doi. org/10.1016/j.trf.2013.03.002

Cunningham, M. L., \& Regan, M. A. (2016). The impact of emotion, life stress and mental health issues on driving performance and safety. Road \& Transport Research: A Journal of Australian and New Zealand Research and Practice, 25(3), 40. https://search.informit.org/doi/10.3316/ informit.476816178722935

Driscoll, T., Marsh, S., McNoe, B., Langley, J., Stout, N., Feyer, A. M., \& Williamson, A. (2005). Comparison of fatalities from work related motor vehicle traffic incidents in Australia, New Zealand, and the United States. Injury Prevention, 11(5), 294-299. http://dx.doi.org/10.1136/ ip.2004.008094
Duan, Z., Xu, J., Ru, H., \& Li, M. (2019). Classification of driving fatigue in high-altitude areas. Sustainability, 11(3), 817. https://doi.org/10.3390/su11030817

Emo, A. K., Matthews, G., \& Funke, G. J. (2016). The slow and the furious: Anger, stress and risky passing in simulated traffic congestion. Transportation research part $F$ : traffic psychology and behaviour, 42, 1-14. https://doi. org/10.1016/j.trf.2016.05.002

Epel, E. S., Crosswell, A. D., Mayer, S. E., Prather, A. A., Slavich, G. M., Puterman, E., \& Mendes, W. B. (2018). More than a feeling: A unified view of stress measurement for population science. Frontiers in neuroendocrinology, 49, 146-169. https://doi.org/10.1016/j.yfrne.2018.03.001

Escobar, M., Trianes, M. V., Fernández-Baena, F. J., \& Páez, J. M. (2010). Relaciones entre aceptación sociométrica escolar e inadaptación socioemocional, estrés cotidiano y afrontamiento. Revista latinoamericana de psicología, 42(3), 469-479. https://www.redalyc.org/ pdf/805/80515851010.pdf

Gabrielli, S., \& Maimone, R. (2013, September). Are change strategies affecting users' transportation choices?. In Proceedings of the Biannual Conference of the Italian Chapter of SIGCHI (pp. 1-4). https://doi. org/10.1145/2499149.2499155

García, T., Rodríguez, C., Rodríguez, J., Fernández Suarez, A., Richarte, V., \& Ramos-Quiroga, J., A. (2019). Psychosocial profiles of adults with ADHD: A comparative study of prison and outpatient psychiatric samples. The European Journal of Psychology Applied to Legal Context, 11, 4149. https://doi.org/10.5093/ejpalc2018a14

Gee, G. C., \& Takeuchi, D. T. (2004). Traffic stress, vehicular burden and well-being: a multilevel analysis. Social Science \& Medicine, 59(2), 405-414. https://doi.org/10.1016/j. socscimed.2003.10.027

Grelotti, D. J., Gerbasi, M. E., Eustache, E., Fils-Aimé, J. R., Thérosmé, T., Severe, J., Raviola, G. J., Darghouth, S., Legha, R., Pierre, E. L., Affricot, E., Alcindor, Y., Boyd, K., Becker, A. E., \& Smith Fawzi, M. C. (2018). Prevalence of stressful life events and their association with post-traumatic stress disorder among youth attending secondary school in Haiti. Psychiatry research, 269, 369-375. https://doi. org/10.1016/j.psychres.2018.08.074

Grover, S. L., Teo, S. T., Pick, D., \& Roche, M. (2017). Mindfulness as a personal resource to reduce work stress in the job demands $\square$ resources model. Stress and Health, 33(4), 426-436. https://doi.org/10.1002/smi.2726

Gustavson, K., Knudsen, A. K., Nesvåg, R., Knudsen, G. P., Vollset, S. E., \& Reichborn-Kjennerud, T. (2018). Prevalence and stability of mental disorders among young adults: findings from a longitudinal study. $B M C$ psychiatry, 18(1), 1-15. https://doi.org/10.1186/s12888-018$1647-5$

Hassanzadeh, A., Heidari, Z., Feizi, A., Hassanzadeh Keshteli, A., Roohafza, H., Afshar, H., \& Adibi, P. (2017). Association of Stressful Life Events with Psychological Problems: A Large-Scale Community-Based Study Using Grouped Outcomes Latent Factor Regression with Latent Predictors. Computational and mathematical 
methods in medicine, 2017, 3457103. https://doi. org $/ 10.1155 / 2017 / 3457103$

Hennessy, D.A., Wiesenthal, D.L., Kohn, P.M. (2000). The influence of traffic congestion, daily hassles, and trait stress susceptibility on state driver stress: An interactive perspective. In Journal Applied Biobehavioral Research, 5(2): 162-179. https://doi.org/10.1111/j.1751-9861.2000. tb00072.x

Hodgson, E. J., Collier, C., Hayes, L., Curry, L. A., \& Fraenkel, L. (2013). Family planning and contraceptive decisionmaking by economically disadvantaged, African-American women. Contraception, 88(2), 289-296.

Hoggan, B. L., \& Dollard, M. F. (2007). Effort-reward imbalance at work and driving anger in an Australian community sample: Is there a link between work stress and road rage?. Accident Analysis \& Prevention, 39(6), 1286-1295. https://doi.org/10.1016/j.aap.2007.03.014

Holmes, T. H., \& Rahe, R. H. (1967). The Social Readjustment Rating Scale. Journal of Psychosomatic Research, 11(2): 213-218. https://doi.org/10.1016/0022-3999(67)90010-4

Jawi, Z. M., Deros, B. M., Rashid, A., Isa, M., \& Awang, A. (2017). The Roles and Performance of Professional Driving Instructors in Novice Driver Education. Sultan Qaboos University medical journal, 17(3), e277-e285. https://doi. org/10.18295/squmj.2017.17.03.004

Koolhaas, J. M., Bartolomucci, A., Buwalda, B., de Boer, S. F., Flügge, G., Korte, S. M., ... \& Fuchs, E. (2011). Stress revisited: a critical evaluation of the stress concept. Neuroscience \& Biobehavioral Reviews, 35(5), 1291-1301.

Koscinczuk, P. (2014). Ambiente, adaptación y estrés. Revista veterinaria, 25(1), 67-76. http://www.scielo.org.ar/scielo. php?script=sci_arttext\&pid=S1669-68402014000100015

Lagarde, E., Chastang, J. F., Gueguen, A., Coeuret-Pellicer, M., Chiron, M., \& Lafont, S. (2004). Emotional stress and traffic accidents: the impact of separation and divorce. Epidemiology, 762-766. https://www.jstor.org/ stable/20485986

Lajunen, T., Parker, D. (2001). Are aggressive people aggressive drivers? A study of the relationship between self-reported general aggressiveness, driver anger and aggressive driving. Accident Analysis \& Prevention, 33(1): 243-255. https://doi. org/10.1016/S0001-4575(00)00039-7

Lane, A., McGrath, J., Cleary, E., Guerandel, A., \& Malone, K. M. (2020). Worried, weary and worn out: mixed-method study of stress and well-being in final-year medical students. $B M J$ Open, 10(12), e040245. https://doi.org/10.1136/ bmjopen-2020-040245

Lardelli-Claret, P., Luna-Del-Castillo, J., Jiménez-Moleón, J. J., Rueda-Domínguez, T., García-Martín, M., FemiaMarzo, P., \& Bueno-Cavanillas, A. (2003). Association of main driver-dependent risk factors with the risk of causing a vehicle collision in Spain, 1990-1999. Annals of epidemiology, 13(7), 509-517. https://doi.org/10.1016/ s1047-2797(03)00003-6
Legree, P. J., Heffner, T. S., Psotka, J., Martin, D. E., \& Medsker, G. J. (2003). Traffic crash involvement: Experiential driving knowledge and stressful contextual antecedents. Journal of Applied Psychology, 88(1), 15. https://doi. org/10.1037/0021-9010.88.1.15

Luna, F. G., Telga, M., Vadillo, M. A., \& Lupiáñez, J. (2020). Concurrent working memory load may increase or reduce cognitive interference depending on the attentional set. Journal of Experimental Psychology: Human Perception and Performance, 46(7), 667. https://doi. org/10.1037/xhp0000740

Marti-Belda, A., Pastor, J.C., Montoro, L., Bosó, P., \& Roca, J. (2019). Persistent Traffic Offenders: Alcohol Consumption and Personality as Predictors of Driving Disqualification. The European Journal of Psychology Applied to Legal Context, 11, 81-92. https://doi.org/10.5093/ ejpalc2019a3

Miller, A. (2016). A Resilience Approach to Road Safety Education. School Drug Education and Road Aware (SDERA). Available from: https://www.sdera.wa.edu.au/ media/2345/challenges-choices-year-8-road-intro.pdf

Myhr, P., Hursti, T., Emanuelsson, K., Löfgren, E., \& Hjemdal, O. (2019). Can the attention training technique reduce stress in students? a controlled study of stress appraisals and meta-worry. Frontiers in psychology, 10, 1532. https://doi. org/10.3389/fpsyg.2019.01532

Nguyen, M. C., Gabbe, S. G., Kemper, K. J., Mahan, J. D., Cheavens, J. S., \& Moffatt-Bruce, S. D. (2020). Training on mind-body skills: Feasibility and effects on physician mindfulness, compassion, and associated effects on stress, burnout, and clinical outcomes. The Journal of Positive Psychology, 15(2), 194-207. https://doi.org/10.1080/174397 60.2019 .1578892

Norris, F. H., Matthews, B. A., \& Riad, J. K. (2000). Characterological, situational, and behavioral risk factors for motor vehicle accidents: a prospective examination. Accident Analysis \& Prevention, 32(4), 505515. https://doi.org/10.1016/S0001-4575(99)00068-8

Oberauer, K. (2019). Working memory and attention-A conceptual analysis and review. Journal of Cognition, 2(1). https://doi. org/10.5334/joc. 58

Oberauer, K., Farrell, S., Jarrold, C., \& Lewandowsky, S. (2016). What limits working memory capacity?. Psychological Bulletin, 142(7), 758. https://doi.org/10.1037/bul0000046

Perez, C., Cirera, E., Borrell, C., \& Plasencia, A. (2006). Motor vehicle crash fatalities at 30 days in Spain. Gaceta Sanitaria, 20(2),108-115.

Perrotin, A., La Joie, R., de La Sayette, V., Barré, L., Mézenge, F., Mutlu, J., ... \& Chételat, G. (2017). Subjective cognitive decline in cognitively normal elders from the community or from a memory clinic: differential affective and imaging correlates. Alzheimer's \& Dementia, 13(5), 550-560. https:// doi.org/10.1016/j.jalz.2016.08.011

Petersen, L., Robert, L., Yang, J., \& Tilbury, D. (2019). Situational awareness, driver's trust in automated driving systems and secondary task performance. SAE International Journal of 
Connected and Autonomous Vehicles, 2(2), 129-141. https:// doi.org/10.4271/12-02-02-0009.

Pfefferbaum, B., \& E. Doughty, D. E. (2001). Increased alcohol use in a treatment sample of Oklahoma City bombing victims. Psychiatry: Interpersonal and Biological Processes, 64(4), 296-303. https://doi.org/10.1521/ psyc.64.4.296.18598

Pinto, X. V. T., Moreno, S. C., \& Díaz, L. C. (2017). Factores que influencian la habilidad y sobrecarga del cuidador familiar del enfermo crónico. Salud UIS, 49(2), 330-338. https://doi. org/10.18273/revsal.v49n2-2017006

Rowden, P., Matthews, G., Watson, B., \& Biggs, H. (2011). The relative impact of work-related stress, life stress and driving environment stress on driving outcomes. Accident Analysis \& Prevention, 43(4), 1332-1340. https://doi.org/10.1016/j. aap.2011.02.004

Rowden, P., Watson, B., \& Biggs, H. (2006). The transfer of stress from daily hassles to the driving environment in a fleet sample. In 2006 Australasian Road Safety Research, Policing and Education Conference Proceedings (pp. 1-11). Able Video \& Multimedia Pty Ltd.

Salgado, J. F. (2018). Transforming the area under the normal curve (AUC) into Cohen'sd, Pearson's rpb, odds-ratio, and natural log odds-ratio: Two conversion tables. European Journal of Psychology Applied to Legal Context, 10(1), 35-47.

Salm Ward, T., Kanu, F. A., \& Robb, S. W. (2017). Prevalence of stressful life events during pregnancy and its association with postpartum depressive symptoms. Archives of women's mental health, 20(1), 161-171. https://doi.org/10.1007/ s00737-016-0689-2

Scott-Parker, B., Jones, C. M., Rune, K., \& Tucker, J. (2018). A qualitative exploration of driving stress and driving discourtesy. Accident Analysis \& Prevention, 118, 38-53. https://doi.org/10.1016/j.aap.2018.03.009

Scully, J. A., Tosi, H., \& Banning, K. (2000). Life event checklists: Revisiting the social readjustment rating scale after 30 years. Educational and psychological measurement, 60(6), 864-876. https://doi.org/10.1177/00131640021970952

Segura, M. D., Cortés, D. C., \& Ramírez, C. C. (2009). Patrones de cambio en la conducción de las mujeres. International Journal of Psychological Research, 2(1), 54-66. https:// www.redalyc.org/pdf/2990/299023510007.pdf

Sepp, S., Howard, S. J., Tindall-Ford, S., Agostinho, S., \& Paas, F. (2019). Cognitive load theory and human movement: Towards an integrated model of working memory. Educational Psychology Review, 1-25. https://doi. org/10.1007/s10648-019-09461-9

Sikander, G., \& Anwar, S. (2018). Driver fatigue detection systems: A review. IEEE Transactions on Intelligent Transportation Systems, 20(6), 2339-2352. https://doi. org/10.1109/TITS.2018.2868499.

Soto, J., Orozco-Fontalvo, M., \& Useche, S.A. (2021). Public Transportation and Fear of Crime at BRT Systems: Approaching to the case of Barranquilla (Colombia) through Integrated Choice and Latent Variable models.
Transportation Research Part A: Policy and Practice, 155(10), 142-160. https://doi.org/10.1016/j.tra.2021.11.001

Spence, N. J., Adkins, D. E., \& Dupre, M. E. (2011). Racial differences in depression trajectories among older women: Socioeconomic, family, and health influences. Journal of health and social behavior, 52(4), 444-459. https://doi. org/10.1177/0022146511410432

Spencer, C., Koç, İ. A., Suga, C., Lee, A., Dhareshwar, A. M., Franzén, E., ... \& McKeown, G. (2020). A Comparison of Unimodal and Multimodal Measurements of Driver Stress in Real-World Driving Conditions. https://doi.org/10.31234/ osf.io/en5r3

Stawski, R. S., Sliwinski, M. J., \& Smyth, J. M. (2006). Stressrelated cognitive interference predicts cognitive function in old age. Psychology and Aging, 21(3), 535. https://doi. org/10.1037/0882-7974.21.3.535

Stogner, J., Miller, B. L., \& McLean, K. (2020). Police stress, mental health, and resiliency during the COVID-19 pandemic. American Journal of Criminal Justice, 45(4), 718-730. https://doi.org/10.1007/s12103-020-09548-y

Stults-Kolehmainen, MA \& Sinha, R. (2014). Los efectos del estrés en la actividad física y el ejercicio. Sports Medicine, 44, 81-121. https://doi.org/10.1007/s40279-0130090-5

Subar, A. F., Freedman, L. S., Tooze, J. A., Kirkpatrick, S. I., Boushey, C., Neuhouser, M. L., ... \& Krebs-Smith, S. M. (2015). Addressing current criticism regarding the value of self-report dietary data. The Journal of nutrition, 145(12), 2639-2645. https://doi.org/10.3945/jn.115.219634

Talaee, N., Varahram, M., Jamaati, H., Salimi, A., Attarchi, M., Kazempour Dizaji, M., ... \& Seyedmehdi, S. M. (2020). Stress and burnout in health care workers during COVID-19 pandemic: validation of a questionnaire. Journal of Public Health, 1-6. https://doi.org/10.1007/s10389-020-01313-z

Taylor, A. H., \& Dorn, L. (2006). Stress, fatigue, health, and risk of road traffic accidents among professional drivers: the contribution of physical inactivity. Annual Reveiew Public Health, 27, 371-391. https://doi.org/10.1146/annurev. publhealth.27.021405.102117

Thwe, P. P., Yamamot, T., Sato, H., \& Morikawa, T. (2017). The impact of demographics, driving stress, driving behaviors related to stress, and unsafe driving behaviors on accident involvement among professional drivers in Myanmar. Journal of the Eastern Asia Society for Transportation Studies, 12, 1950-1964. https://doi. org/10.11175/easts. 12.1950

Useche, S. A., Alonso, F., Cendales, B., \& Llamazares, J. (2021a). More than just "stressful"? Testing the mediating role of fatigue on the relationship between job stress and occupational crashes of long-haul truck drivers. Psychology research and behavior management, 14, 1211. https://doi. org/10.2147/PRBM.S305687

Useche, S. A., Alonso, F., Cendales, B., Montoro, L., \& Llamazares, J. (2021b). Measuring job stress in transportation workers: psychometric properties, convergent validity and reliability of the ERI and JCQ among 
professional drivers. BMC Public Health, 21(1), 1-19. https://doi.org/10.1186/s12889-021-11575-1

Useche, S.A., Cendales, B., Montoro, L., \& Esteban, C. (2018). Work stress and health problems of professional drivers: a hazardous formula for their safety outcomes. PeerJ, 6, e6249. https://doi.org/10.7717/peerj.6249

Useche, S. A., Gómez, V., \& Cendales, B. E. (2017). Stress-related psychosocial factors at work, fatigue, and risky driving behavior in bus rapid transport (BRT) drivers. Accident Analysis \& Prevention, 104, 106-114. https://doi. org/10.1016/j.aap.2017.04.023

Wang, Y., Li, L., \& Prato, C. G. (2019). The relation between working conditions, aberrant driving behaviour and crash propensity among taxi drivers in China. Accident Analysis \& Prevention, 126, 17-24.
Weiten, W., Dunn, D. S., \& Hammer, E. Y. (2014). Psychology applied to modern life: Adjustment in the 21st century. Nelson Education.

Wickens, C. M., Toplak, M. E., \& Wiesenthal, D. L. (2008). Cognitive failures as predictors of driving errors, lapses, and violations. Accident Analysis \& Prevention, 40(3), 12231233. https://doi.org/ 10.1016/j.aap.2008.01.006

Wilson, R. S., Bennett, D. A., de Leon, C. F. M., Bienias, J. L., Morris, M. C., \& Evans, D. A. (2005). Distress proneness and cognitive decline in a population of older persons. Psychoneuroendocrinology, 30(1), 11-17. https://doi. org/10.1016/j.psyneuen.2004.04.005 


\title{
Traffic safety climate factors in explaining driving behaviours and traffic crash involvement: comparative study among male and female drivers
}

\author{
Charles Atombo ${ }^{1}$ and Chaozhong $\mathrm{Wu}^{2,3}$ \\ ${ }^{1}$ Department of Mechanical Engineering, Ho Technical University, Ho, Ghana. \\ ${ }^{2}$ Intelligent Transportation Systems Research Centre, Wuhan University of Technology, Wuhan, China \\ ${ }^{3}$ Engineering Research Centre of Transportation Safety, Ministry of Education, Wuhan, China. \\ Corresponding Author: Charles Atombo, Ho Technical University, P.O. Box HP 217, Ho, Ghana, catombo@htu.edu.gh, \\ $+233-243852651$
}

\section{Key Findings}

- $\quad$ Male and female drivers expressed different perceptions about traffic safety climate, driving behaviour and traffic crash;

- $\quad$ External affective demand is positively related to aberrant driving behaviour but negatively related to positive driving behaviour;

- Internal requirement and Functionality are positively related to positive driving behaviour;

- Internal requirement and Functionality are negatively related to aberrant driving behaviour;

\begin{abstract}
The study examined the explanatory power of Traffic Safety Climate factors in driving behaviours and the probability of traffic crash involvement among male and female drivers in China, taking into consideration different clusters of age. A total of 887 license drivers aged between 24 and 64 completed Chinese version of traffic climate scale, driving behaviours scale, and crash involvement. Multivariate regression analyses were conducted. The result established that male driver's, reported high emotional engagement, driving violations and traffic crashes than female drivers. Perceived external affective demand (EAD) was more likely to be related to aberrant driving behaviours (ADB), but less likely to be related to positive driving behaviour (PDB) with young and middle-aged male drivers more affected. Perceived EAD was less likely to be associated with ADB and traffic crash involvement of female older drivers. The perceived internal requirement was positively related to $\mathrm{PDB}$, but negatively related to ADB for both sexes with young females expressing high PDB and low probability of traffic crash involvement than male drivers. Perceived traffic system functionality (FUN) was negatively related to ADB, but positively related to PDB for both sexes with male drivers in all age brackets expressing more PDB. As a remedial measure, traffic authorities have to direct their attention towards the modification of traffic infrastructure designs.
\end{abstract}

\section{Keywords}

Traffic climate safety, aberrant driving behaviours, positive driving behaviour, sex, traffic crashes

\section{Introduction}

Road traffic crashes pose a serious threat to traffic safety and are the $8^{\text {th }}$ leading cause of death for people of all age groups, but the number one cause of death for young adults (World Health Organisation, 2018). According to World Health Organisation report, the number of people that lose their lives through road accidents remains unacceptably high with 1.35 million people dying each year (World Health Organisation, 2018). In the same report, it was revealed that 18.2 persons per 100000 are killed in China Road traffic crashes as against countries like the UK 3.1,

Received: 30/05/2021; Received in revised form: 15/11/2021; Accepted: 13/12/2021; Available online: 09/02/2022

Copyright: (C) The Author(s). 2021 This is an open access article distributed under the terms of the Creative Commons Attribution (CC BY)_license, which permits unrestricted use, distribution, and reproduction in any medium, provided the original author(s) and the source are credited.

Suggested citation: Atombo, C. and Wu, C. (2022). "Traffic safety climate factors in explaining driving behaviours and traffic crash involvement: comparative study among Male and Female drivers" Journal of Road Safety, 33(1), 49-62. https://doi.org/10.33492/JRS-D-21-00036 
Canada 5.8, Austria 5.2, Denmark 4.0, Germany and Italy 4.1, Israel 4.2 and 12.4 persons per 100000 population for the USA.

Although China has introduced several intervention measures such as improvement of transportation infrastructure (Lijun Wang 2019), the use of trains and ships (National Bureau of Statistics of China, 2010), public education programmes and enforcement of legislation to improve road traffic safety, studies have shown that road traffic crashes remain the leading cause of injury and death in China (Wong, 2020; Zhang et al. 2011). In 2018 alone, China recorded 258,532 injuries and 63,194 fatalities in traffic crash across the country (Wong, 2020; Zhang et al 2021). The increasing number of traffic crashes are linked to the drivers' disregard for traffic safety (Chu et al. 2019, Zhang et al. 2018; Yeşim Üzümcüoğlu Zihni, 2018). The condition of a traffic system also guides driving behaviours (Pousette, Larsson \& Törner, 2008), which could contribute to road traffic accidents (Özkan \& Lajunen, 2005b).

Therefore, the perception of Traffic Safety Climate (TSC) could direct behaviours of a road user and a driver's risk of being involved in a traffic crash may be linearly dependent on exposure to different traffic conditions. Besides, in a study that attempts to evaluate the importance of TSC in promoting safe driving, sex is one of the significant factors that has to be considered (Özkan \& Lajunen, 2015). Therefore, the present study mainly aims to examine the explanatory power of perceived TSC factors in driving behaviours and the probability of traffic crash involvement among male and female drivers in China, taking into consideration different clusters of age. The findings from the study would aid in identifying a group of drivers involved in particular driving behaviour and traffic crash in a specific traffic condition for developing appropriate measures directed towards such group.

\section{Traffic Safety Climate (TSC)}

The perception of TSC plays an important role in road safety issues as it guides the behaviours of drivers (Pousette, Larsson \& Törner, 2008). It may include both the amount of driving and the road conditions under which the driving takes place (Laapotti, Keskinen \& Rajalin, 2003). In a recent development, the TSC scale with its definition developed by Özkan \& Lajunen (2011) has attracted researchers' attention. It has been defined as "the driver's perceptions of the traffic in a context at a given point in time which is subjected to change depending on the features of the traffic environment or conditions that can affect the skills, attitude and drivers' behaviour" (Chu et al . 2019).

The Traffic Climate Scale has been translated into German (Gehlert et al., 2014), Chinese (Chu et al. 2019; Zhang et al., 2018) and Lithuanian (Marksaityte et al., 2014). These studies performing exploratory factor analysis confirmed the three-factor structure representing external affective demands, internal requirements and functionality with high reliability and satisfactory internal validity. The external affective demands describe the emotional engagement of road users (e.g., "aggressive," "time consuming," "putting pressure," and "dangerous") when participating in traffic. The internal requirements factor

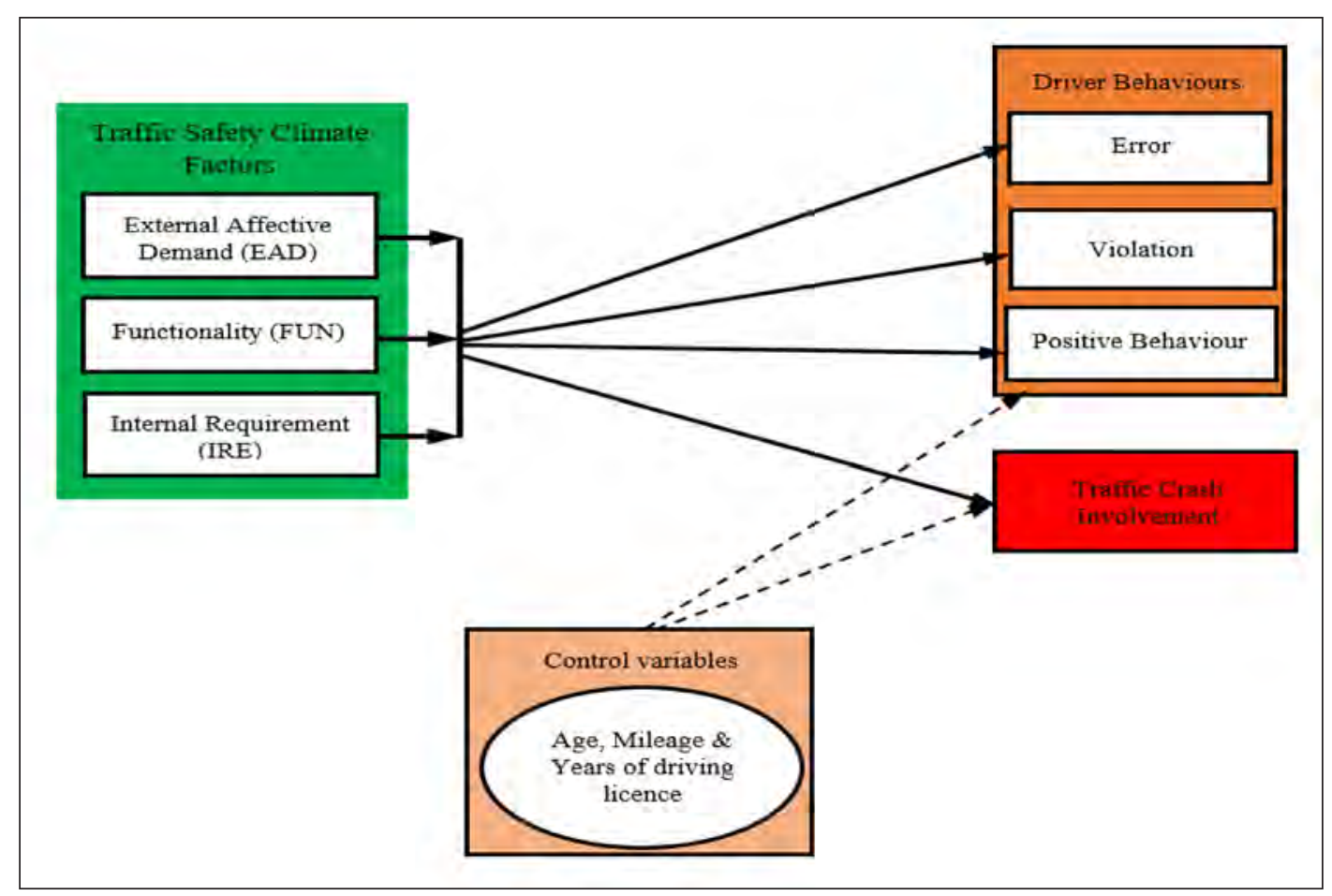

Figure 1. The Conceptual Framework 
refers to cognitive and social requirements describing road users' skills and abilities (e.g., "require experience," "require cautiousness," "require vigilance," "Require patience") to effectively participate in traffic. Functionality factor describes perceived requirements for a functional traffic system that describe the state of the traffic facilities and environment (e.g., "Planned," preventive measures," "dependent on mutual consideration," "Pleasant").

The original structure of Traffic Safety Climate was based on organisational climate, as there are similarities between the two scales. The organisational climate scale comprises affective, cognitive and instrumental components (De Simone, 2014). The development of TSC (external affective demands, internal requirements, and functionality) correspond to the three components of organisational safety climate (Zhang et al 2018).

\section{Driver's Behaviour (DB)}

The analyses of traffic accidents indicate that the component of the traffic system also includes human factors which are the major contributory factors in road traffic accidents (e.g., Sagberg et al 2015; Atombo, Wu, Zhong, \& Zhang, 2016). Human factors in driving can be seen as being composed of two separate components, driving skills and driving style ( Bener et al., 2008). Driving style concerns individual driving habits, i.e., the way a driver chooses to drive. It can be assumed therefore, that male and female drivers should have different driving styles in traffic (Sagberg et al 2015).

One of the most commonly used tools for measuring aberrant driving behaviours is the Driver Behaviour Questionnaire (DBQ) (Reason, Manstead, Stradling, Baxter \& Campbell, 1990). DBQ was extended to cover positive driver behaviours (Özkan \& Lajunen, 2005a). Aberrant and positive behaviour are two sides of driving behaviour (Özkan \& Lajunen, 2005a). They usually occur concurrently in traffic conditions (Shen et al., 2018). The DBQ primarily reflects the difference between errors (example: fail to notice pedestrians are crossing) and violations (example: race away from traffic lights, disregard the speed limit on a residential road).

The driving error was defined as "all those instances in which a planned sequence of a cognitive decision or physical activities fail to achieve its intended outcome" (Reason et al., 1990). Errors may result from activities that are improper in a given circumstance or are appropriate but executed wrongly (Sucha, Sramkova \& Risser, 2014). Errors are unintentional behaviour, separated into slips and lapses according to the potential outcome of the error. Lapses mostly involve failures of memory while slips are associated with attention deficits that do not lead to an increased risk of crash involvement (Stephens \& Fitzharris, 2016).

Violations are intentional aberrations, closely related to personality characteristics, attitudes, and social context which intentionally disobey safe driving practices (Stephens \& Fitzharris, 2016). It is still possible for a driver to commit violations without errors or commit errors without violations. Violations have been categorised into ordinary and aggressive violations, based on the motive for which a driver commits a violation (e.g., Lawton, Parker, Manstead \& Stradling, 1997). In addition, higher scores of violations are associated with increased motor vehicle crash involvement (De Winter \& Dodou, 2010; Nordfjærn, Şimşekoğlu \& Rundmo, 2014). In this present study, it is expected that these violations could be influenced by the conditions or situations in physical traffic environments.

Özkan \& Lajunen (2005a) put forward that, in everyday driving, there are positive behaviours that cannot be classified as errors or violations. Given that, positive behaviour is not based on coded rules and guidelines, or consider safety, rather deal with the situations in traffic and to be well-mannered. These "positive" behaviours can be committed without a violation or an error if the action and the plan were adequate for achieving the intended target. Positive driving behaviour has underlying good intentions, but may sometimes include errors or violations when the intended planned actions are not achieved. In this study, a positive driver's behaviour towards traffic safety climate is defined as the capability of a driver interacting effectively with other road users in the driving environment.

\section{Traffic Safety Climate, Driver Behaviour and Road Traffic Crash}

Traffic safety climate is a "paradigm" for explaining observed road traffic crash and risky driving behaviours" (Ward, Linkenbach, Keller \& Otto, 2010; Özkan \& Lajunen, 2015). In order to achieve a safe driving environment, drivers have to effectively interact with other road users and take one another actions and behaviour into consideration. Drivers use the traffic conditions as a source of information to communicate with the physical driving environments and other road users. However, the condition of traffic might pose difficulties to drivers' performance and attainment of plans. This could generate frustration and induce aberrant behaviours which could increase the risk of crash involvements (Danaf, 2018).

Studies have applied Safety Climate factors in predicting traffic-related behaviours (Wills et al., 2006; AmponsahTawiah and Mensah, 2016). For instance, the study of Wills et al. (2006) found that safety climate factors correlated with safe driving behaviour. In the work of AmponsahTawiah and Mensah, (2016), safety climate predicted safe work-related driving behaviours.

Researchers in the domain of traffic safety have also acknowledged the importance of applying TSC factors in predicting driving-related behaviours (Lee et al., 2016; Schlembach et al., 2016) and crash involvement (Özkan \& Lajunen, 2015) as depicted in Figure 1. However, few 
studies have explored the relationship between traffic safety climate and driving behaviour as well as crash involvement (Chu et al., 2019; Gehlert et al. 2014; Zhang et al., 2018). The work of Gehlert et al. (2014) postulated that the less emotionally and cognitively demanding and the more functional driver's perceived traffic systems to be, the less risky and safer road users feel in traffic. However, the result of the study revealed that traffic violation increases when traffic systems are perceived to be functional and required less skills. The authors also found internal requirements of drivers to be associated with driving style. In another study, Zhang et al. (2018), tested the mediating effect of traffic safety climate between personality and dangerous driving behaviour. They found traffic climate mediating the effect of personality on dangerous driving behaviour.

The study of Chu et al. (2019) found a relationship between TSC, driver behaviour factors and traffic accidents involvement. In particular, their result shows that the external affective demand was positively related to aberrant behaviours and negatively related to positive behaviours whereas functionality and internal requirements were found to be negatively related to aberrant behaviours and positively related to positive behaviours. The same study (Chu et al. 2019), found functionality negatively related to accident involvement whereas external affective demand positively related to accident involvement. The study further indicated that a driver with a positive driving behaviour would interact effectively with drivers and pedestrians in all traffic conditions. These findings are indispensable; however, it does not reveal which sex or age group is more likely to be engaged in a certain driving behaviour and traffic crash involvement. As such, it is imperative to conduct this research.

\section{Sex Characteristic}

Sex (male and female) of drivers is one of the influential factors to be considered in a study that attempts to evaluate traffic safety climate to promote safe driving (Marksaityte et al., 2014; Gehlert et al., 2014). In Traffic safety research, it has been evidenced that the behaviours and the crash risks of male and female drivers are different (Harrison, 2009). However, globally, only a few studies have explored the traffic safety climate in relation to sex characteristics. The study of Marksaityte et al., (2014) found traffic safety climate factors and higher accident risk are related to sex. In that study, it was revealed that men reported a more positive attitude towards traffic safety climate than women. The study further revealed that female drivers who had been involved in at least one traffic accident perceived the traffic system as more functional. In another study, positive behaviours of men are predicted by cycling intensity, knowledge of traffic rules and risk perception (Useche et al., 2018).

Similarly, Alfonsi et al. (2018) revealed that the majority of drivers involved in traffic crashes in every country are virtually male drivers. Apart from males being over-represented in accident statistics, male drivers especially young men are also more inclined to commit more violations in traffic than their female counterparts (Jonah, 1990). Other studies have found sex differences in risky driving behaviours with male drivers found to be engaging in risky driving behaviours more frequently in traffic and are at a higher risk of crashing than female drivers (Harrison, 2009; Rhodes \& Pivik, 2011). The study of Useche et al., (2021) revealed that road users risk perception and misbehaviours are significant predictors of male pedestrians. On the other hand, female drivers, commit more errors than male drivers (Parker, McDonald, Rabbitt \& Sutcliffe, 2000; De Winter et al 2010) especially, when there are distractions in traffic (Useche et al., 2021). However, female drivers psychological distress predicts positive driving behaviours (Useche et al. 2018). Others have also found females being safer drivers with positive driving behaviour characteristics in traffic than males (Özkan \& Lajunen, 2006). Despite these findings on sex characteristics, no study has explored the role of traffic safety climate in explaining driving behaviour-related factors and the probability of traffic crash involvement among male and female drivers in China. Therefore, predicting driver behaviour and crash involvement using traffic climate safety factors have to be tested across male and female drivers in China.

In the study of this nature, it is important to investigate the differences among different age groups of both sex driving behaviours and the probability of crash involvement. This is because, age has been identified as having independent effects on driving behaviour and driving safety (Shinar, 2017). Age has further been recognised as a significant factor to be considered in any attempt to promote safe driving (Shinar, 2017). Studies have previously indicated that younger drivers especially males constitute the age group with the highest rates of aberrant driver behaviours (e.g., de Winter \& Dodou, 2010; Martinussen et al., 2014) and crash involvement in traffic compared to older drivers (Ouimet et al., 2010; Hassan, 2016). This group of drivers tend to overestimate their ability and underestimate traffic hazards (Alfonsi et al. 2018). Rhodes \& Pivik, (2011) also found that teen drivers often engage in risky driving behaviours in traffic than adult drivers.

\section{The rationale for the Study}

The study examining the explanation power of Traffic Safety Climate factors in driving behaviours and the probability of traffic crash involvement among male and female drivers in China is warranted because, there is an increasing population of vehicles and drivers in China. According to statistics, as of September, 2020, China had 365 million motorized vehicles registered for use on roads and a total of 450 million licensed drivers (Ministry of Public Security, 2020). The increase in the number of vehicles on roads could stimulate different driving behaviours and affect 
road crashes. Based on this, authorities have employed traffic rules that are different from what pertains to other countries (Zhang 2018). In addition, the effect of traffic safety climate on driving behaviours and traffic fatalities in China could be different from that of other countries. For instance, studies have shown that traffic environment influences Chinese drivers to exhibit different driving styles which results into high number of crashes than those in the United States and Japan (Atchley et al., 2014; Zhang et al., 2010). In another study, it was reported that Chinese drivers exhibited a lower level of anger in response to driving violations in traffic than drivers in America, New Zealand and Spain Li et al., 2014). Although studies have explored the relationship between TSC factors and driver's behaviour as well as accidents involvement across countries, no research has considered the sex characteristic. In addition, even though, the previous findings are important, but still lack evidence to conclude that drivers with certain sex characteristics are more likely to be involved in a particular driving behaviour and traffic crashes. As such, the association between traffic safety climate and drivers' behaviours as well as crash involvements among male and female drivers is required in order to develop appropriate safety measures directed towards a particular group of drivers.

\section{Methods and Materials}

\section{Procedure and Participants}

A web-based data collection method was used with an assistance of a professional research company in China. The participation was done voluntarily with confidentiality and anonymity assurance. A random sampling technique was used to select 908 drivers covering 27 provinces of China. The random sampling was realised by contacting the participants through the mail and were asked to complete the survey on the Web. After cleaning the data, a total of 887 valid samples were retained, representing approximately $98 \%$ of the total questionnaire administered with a minimum of 29 and a maximum of 35 respondents from each of the selected provinces.

The participants included were drivers who held valid driving licenses at the time of the study. The participants included male $(\mathrm{N}=531)$ and female $(\mathrm{N}=356)$ drivers. The age of the drivers ranges from 24 to 64 and the mileage ranges from 16000 to 1100000 . Furthermore, the year of driving license is between 5 and 36 years and the total number of traffic crashes ranges from 0 to 6 . The mean score and the standard deviation of the characteristics of the whole study samples are presented in Table 1 . In all the characteristics variables, male drivers score higher and had high annual mileage and traffic crashes than their female counterparts.
Table 1. Demographic characteristics of the sample

\begin{tabular}{|c|c|c|c|}
\hline Items & $\begin{array}{c}\text { Total } \\
\text { Sample }\end{array}$ & $\begin{array}{l}\text { Female } \\
\text { Sample }\end{array}$ & $\begin{array}{c}\text { Male } \\
\text { Sample }\end{array}$ \\
\hline $\begin{array}{l}\text { Number of } \\
\text { respondents }\end{array}$ & 887 & 356 & 531 \\
\hline \multicolumn{4}{|l|}{ Age } \\
\hline Mean & 44.58 & 42.93 & 45.70 \\
\hline SD & 7.5 & 5.94 & 8.21 \\
\hline \multicolumn{4}{|l|}{$\begin{array}{l}\text { Total } \\
\text { Mileage } \\
(\times 1000) \\
\end{array}$} \\
\hline Mean & 95.19 & 85.97 & 104.40 \\
\hline SD & 105.47 & 99.85 & 110.94 \\
\hline \multicolumn{4}{|l|}{$\begin{array}{l}\text { Years of } \\
\text { Driving } \\
\text { License }\end{array}$} \\
\hline Mean & 5.72 & 4.81 & 6.61 \\
\hline SD & 4.99 & 3.83 & 5.55 \\
\hline \multicolumn{4}{|l|}{$\begin{array}{l}\text { Road } \\
\text { Traffic } \\
\text { Crashes }\end{array}$} \\
\hline Mean & 1.22 & 1.07 & 1.33 \\
\hline SD & 1.11 & 1.00 & 1.17 \\
\hline
\end{tabular}

\section{Materials}

It is important to note that this study used the validated version of the Chinese Traffic Safety Climate scale and the Driver Behaviour Questionnaire scale that was previously validated on the same sampled population of drivers and published by the authors (refer to Chu et al. 2019 for detail on how the questionnaire tool was validated to adapt to the sociocultural settings in China). In our previous work, we used the forward-and-back translation method to translate the English versions of Traffic Climate Scale (TCS) and Driver Behaviour Scales to Chinese with the support of two different and independent translation teams composed of professors who are bilingual and experts in traffic safety. We used a committee approach to reach a consensus on the translated versions in each phase to avoid the weaknesses of the forward-and-back translation design. We assessed the correctness of the translation by comparing the original and back-translated version. The translated version was then tested on 50 drivers to ensure that the items were clear without any ambiguity. After the testing, the committee made the necessary corrections, changes, and rewording of 9 items of the TCS (item 3, 7, 8, 17, 28, 34, 37, 43 and 44) to resolve any ambiguities based on the feedback from the participants recruited to test the translated version. 


\section{Traffic Safety Climate Scale (TSCS)}

The TCS, which has been used, included 39 items with three dimensions of safety climate. The items in the dimensions contain statements that depict traffic conditions. These dimensions included: 'External affective Demands' (EAD) which describes the emotional engagement required by road users when participating in traffic (e.g., Aggressive, Exciting, Mobile, Dangerous, etc.) 'Functionalities' (FUN) describes the requirements for a functional traffic system (e.g., Including preventive measures, free flowing, travel easily from place to place, etc.) and 'Internal Requirements' (IRE) focuses on road users' skills and abilities to successfully participate in traffic (e.g., Requiring experience, requiring skilfulness, requiring you to obey traffic rules, etc.). Each item was evaluated by drivers on a 6-point Likert type scale (Does not describe it at all $=1$ to Very much describes it $=6$ ). Cronbach's Alpha for internal consistency scores for the EAD (17 items), FUN (12 items) and IRE (10 items) dimensions were $0.94,0.93$ and 0.90 respectively. For more information on how the TCS items were validated, refer to our published article (Chu et al. 2019).

\section{Driver Behaviour Scales}

The DBQ and Positive Driver Behaviour scale were adopted from our validated item conducted in China (Chu et al., 2019) to investigate driver behaviours. The DBQ scale included 31 items of Chinese Translated version with three factors of driver behaviours, such as violations (e.g., Cross a junction when traffic lights have already turned on), errors (e.g., fail to notice pedestrians are crossing), and positive driver behaviour (e.g., Avoid close following not to disturb the car driver in front). According to previous studies (Parker et al., 2000), the items in the lapses are not critical for safety, therefore, it was not used in the present study. Each DBQ and positive driver behaviour item was evaluated by the drivers on a 6-point Likert type scale (never $=1$, to nearly all the time $=6$ ). Cronbach's Alpha internal consistency scores of the violations (6 items), errors (11 items) and positive driver behaviours (14 items) scales for the present study were $0.81,0.90$, and 0.93 , respectively. For more information on how the driver behaviour items were validated, refer to our published article (Chu et al. 2019).

\section{Demographic Variables}

Age, sex (male and female), mileage since getting a license $(\mathrm{km})$, and years of driving license were the important demographic variables included in the study. Finally, participants were asked to indicate the number of traffic crashes (all types of crashes drivers experienced) they were involved in over the last 3 years.

\section{Age Grouping}

According to World Health Organisation (2018), more than half the people killed in traffic crashes are young adults aged between 15 and 44 years. Based on WHO findings, the drivers between the ages of 18 to 29 were categorised as young, 30 to 44 years was grouped as middle age (young adult) and 45 years and above were clustered as older (adult) drivers.

\section{Statistical Analysis and Procedure}

Before the analysis, the distribution of each item was checked for normality. The data was then analysed using descriptive statistics, Pearson's product-moment correlations, and regression analysis. An independent sample t-test was used to examine the significant differences between female and male drivers on the traffic safety climate (TSC) factors, driving behaviours and traffic crash involvement. The correlation analysis was performed to examine the relationship among TSC factors, driving behaviour factors, traffic crash and demographic factors.

Ultimately, Hierarchical Regression Analyses was performed to examine the role of TSC factors in explaining driving behaviours and the probability of traffic crash involvement for female and male drivers. The age group for males and females were further estimated in the Hierarchical Regression Model. The diving behaviour factors and traffic crashes were used as dependent variables in the model and the TSC factors were entered as independent variables. The years of driving license, age and mileage were entered as control variables in the model. All the data were analysed using the SPSS version 24 software.

\section{Results}

\section{Independent-sample t-test (comparing Male and Female Drivers)}

An independent-sample t-test was conducted to compare the TSC factors, driving behaviour factors and probability of crash involvement for female and male drivers. There were notable differences concerning the violation, traffic crashes and traffic system functionality (Table 2 ). The results showed that there is a statistically significant difference between females and males on the violations $(M=2.19, S D=0.79 ; M=2.39, S D=0.86 ; t(885)=3.53$, $p=.000$, two-tailed), traffic crash involvement $(M=2.07$, $S D=2.00 ; M=2.33, S D=2.17 ; t(885)=1.99, p=.023$, two-tailed) and traffic system functionality $(M=3.67$, $S D=0.96 ; M=3.52, S D=0.97 ; t(885)=2.39, p=.017$, two-tailed). Despite reaching statistical significance, the magnitude of the differences in the means was quite small (eta squared). Male and female drivers did not differ significantly on error, positive driving behaviour, perceived external affective demand and internal requirements. However, an inspection of the mean scores indicated that 
Table 2. Difference between male and female drivers (independent sample t-test)

\begin{tabular}{|c|c|c|c|c|c|c|}
\hline Constructs & Sex & $\begin{array}{l}\text { Number of } \\
\text { respondents }\end{array}$ & Mean & Std. Deviation & T-Value & P-Value \\
\hline \multirow{2}{*}{ Error } & Female & 356 & 1.94 & 0.69 & 0.25 & 0.807 \\
\hline & Male & 531 & 1.93 & 0.67 & & \\
\hline \multirow{2}{*}{ Violation } & Female & 356 & 2.19 & 0.79 & 3.53 & 0.000 \\
\hline & Male & 531 & 2.39 & 0.86 & & \\
\hline \multirow{2}{*}{ Positive driving behaviour } & Female & 356 & 4.64 & 0.88 & 1.08 & 0.278 \\
\hline & Male & 531 & 4.58 & 0.89 & & \\
\hline \multirow{2}{*}{ Traffic crash involvement } & Female & 356 & 1.07 & 1.00 & 1.99 & 0.023 \\
\hline & Male & 531 & 1.33 & 1.17 & & \\
\hline \multirow{2}{*}{ External affective demand } & Female & 356 & 3.44 & 0.86 & 1.54 & 0.124 \\
\hline & Male & 531 & 3.53 & 0.88 & & \\
\hline \multirow{2}{*}{ Functionality } & Female & 356 & 3.67 & 0.96 & 2.39 & 0.017 \\
\hline & Male & 531 & 3.52 & 0.97 & & \\
\hline \multirow{2}{*}{ Internal requirements } & Female & 356 & 4.66 & 0.81 & 0.73 & 0.468 \\
\hline & Male & 531 & 4.62 & 0.78 & & \\
\hline
\end{tabular}

males reported slightly higher levels of the violation and traffic crash involvement than females. On the other hand, the mean score of female drivers was slightly higher than male drivers on the functionality factor.

\section{Correlations}

Table 3 shows the results of the correlations between background variables, driving behaviour factors, TSC and traffic crash involvement for female and male drivers. The demographic factors of females had no association with traffic climate factors. Aberrant driving behaviours (errors and violations) were negatively related to functionality and internal requirements. Besides, the positive driving behaviour was positively related to perceived traffic system functionality and internal requirements, but not related to perceived external affective demand.
On the other hand, age and driving license of male drivers had a negative association with functionality with mileage having insignificant relation to TCS factors. Violations, errors and traffic crash involvement had a positive correlation with perceived external affective demand but negatively correlated with perceived traffic system functionality. Positive driving behaviour of male drivers was positively related to traffic system functionality and internal requirements but has no association with the external affective demand.

\section{Hierarchical Regression Analyses (Female Drivers)}

Hierarchical multiple regression was used to assess the explanatory power of TSC factors (Functionality, External

Table 3. Correlation between TCS factors, demographic factors, traffic crash involvement and driving behaviours

\begin{tabular}{|c|c|c|c|c|c|c|c|c|c|c|c|c|c|c|}
\hline \multirow{2}{*}{\begin{tabular}{|l|} 
TSC \\
Factors
\end{tabular}} & \multicolumn{7}{|c|}{ Female } & \multicolumn{7}{|c|}{ Male } \\
\hline & Err & Viol & PB & PTC & Age & Mileage & YDL. & Err & Viol & PB & PTCs & Age & Mileage & YDL \\
\hline FUN & $-0.20^{* * *}$ & $-0.11^{*}$ & $0.23^{* * *}$ & -0.04 & -0.07 & 0.09 & 0.04 & $-0.13^{* *}$ & $-0.25^{* * *}$ & $0.17^{* * * *}$ & -0.03 & $-0.17^{* * *}$ & -0.04 & $-0.14^{* *}$ \\
\hline EAD & $0.13^{*}$ & 0.06 & -0.05 & -0.01 & $0.12^{*}$ & -0.03 & 0.02 & $0.22^{* * * *}$ & $0.31^{* * *}$ & -0.06 & $0.11^{*}$ & -0.07 & -0.04 & 0.02 \\
\hline IRE & $-0.12^{*}$ & $-0.10^{*}$ & $0.34^{* * *}$ & 0.04 & 0.03 & 0.01 & -0.01 & -0.02 & 0.08 & $0.23^{* * * *}$ & 0.04 & -0.01 & 0.02 & 0.01 \\
\hline
\end{tabular}

Note: ${ }^{*} \mathrm{p}<0.05,{ }^{* *} \mathrm{p}<0.01,{ }^{* * *} \mathrm{p}<0.001$

Err - error, Viol- Violation, PDB-positive driving behaviour, PTCs - probability of traffic crashes, FUN- Functionality, EAD- External Affective Demand, IRE-Internal Requirements, YDL - Years of Driving License 
Table 4. Hierarchical regression analysis on female and male driving behaviours and the traffic crash.

\begin{tabular}{|c|c|c|c|c|c|c|c|c|c|c|c|c|}
\hline Variables & & Errors & & & Violatio & & Posi & tive beha & jiours & $\begin{array}{r}\text { Prob } \\
\text { cras }\end{array}$ & $\begin{array}{l}\text { bility of } \\
\text { a involv }\end{array}$ & $\begin{array}{l}\text { traffic } \\
\text { ment }\end{array}$ \\
\hline Female Drivers & $\mathbf{R}^{2}$ & $\mathbf{F}$ & $\boldsymbol{\beta}$ & $\mathbf{R}^{2}$ & $\mathbf{F}$ & $\beta$ & $\mathbf{R}^{2}$ & $\mathbf{F}$ & $\boldsymbol{\beta}$ & $\mathbf{R}^{2}$ & $\mathbf{F}$ & $\beta$ \\
\hline Background Variables & 0.04 & 0.39 & & 0.05 & 0.04 & & 0.03 & 0.11 & & 0.05 & 1.52 & \\
\hline Age & & & -0.07 & & & -0.03 & & & 0.01 & & & -0.08 \\
\hline Mileage & & & 0.04 & & & 0.02 & & & 0.01 & & & -0.04 \\
\hline Years of driving license & & & 0.08 & & & 0.05 & & & 0.04 & & & 0.03 \\
\hline Main effects & 0.12 & $6.52^{* * *}$ & & 0.07 & 2.05 & & 0.22 & $12.84^{* * *}$ & & 0.04 & 1.01 & \\
\hline Functionalities & & & -0.05 & & & -0.03 & & & 0.01 & & & -0.05 \\
\hline External A. Demands & & & $0.27^{* * *}$ & & & $0.15^{*}$ & & & $-0.31^{* * *}$ & & & -0.02 \\
\hline Internal Requirements & & & $-0.34^{* * *}$ & & & $-0.20^{* *}$ & & & $0.46^{* * *}$ & & & 0.03 \\
\hline Total $\mathbf{R}^{2}$ & 0.16 & & & 0.12 & & & 0.25 & & & 0.09 & & \\
\hline Male Drivers & & & & & & & & & & & & \\
\hline Background Variables & 0.05 & 1.08 & & 0.06 & 1.03 & & 0.04 & 0.23 & & 0.08 & $9.11^{* * *}$ & \\
\hline Age & & & -0.06 & & & 0.03 & & & 0.05 & & & -0.08 \\
\hline Mileage & & & 0.04 & & & 0.04 & & & -0.01 & & & $0.19^{* * *}$ \\
\hline Years of driving license & & & 0.05 & & & 0.06 & & & 0.02 & & & 0.05 \\
\hline Main effects & 0.19 & $11.12^{* * *}$ & & 0.21 & $18.02^{* * *}$ & & 0.18 & $11.25^{* * *}$ & & 0.06 & $4.43^{* *}$ & \\
\hline Functionalities & & & -0.04 & & & $-0.16^{* * *}$ & & & $0.16^{* * *}$ & & & -0.03 \\
\hline External A. Demands & & & $0.36^{* * *}$ & & & $0.36^{* * *}$ & & & $-0.14^{*}$ & & & 0.04 \\
\hline Internal Requirements & & & $-0.23^{* * *}$ & & & $-0.10^{*}$ & & & $0.31^{* * *}$ & & & 0.04 \\
\hline Total $\mathbf{R}^{2}$ & 0.24 & & & 0.27 & & & 0.22 & & & 0.14 & & \\
\hline
\end{tabular}

Note: ${ }^{*} \mathrm{p}<0.05,{ }^{* *} \mathrm{p}<0.01,{ }^{* * *} \mathrm{p}<0.001$.

Affective Demand and Internal Requirements) in driving behaviours and the probability of crash involvement, after controlling for the influence of age, mileage and years of driving license. The result in Table 4, demonstrates that the demographic factors were not associated with driving behaviour factors and the probability of crash involvement. Similarly, the TSC factors have no significant association with the probability of traffic crash involvement.

The perceived external affective demand positively related to driving errors $(\beta=0.27 ; p<0.001)$ and violations ( $\beta$ $=0.15 ; \mathrm{p}<0.05)$ but negatively related to positive driving behaviour $(\beta=-0.31 ; p<0.001)$. However, perceived internal requirement was negatively related to errors $(\beta$ $=-0.31 ; \mathrm{p}<0.001)$ and violations $(\beta=-0.31 ; \mathrm{p}<0.001)$, but positively related to positive driving behaviour $(\beta=$ $-0.31 ; p<0.001)$. Perceived functional traffic systems had no significant relation with driving behaviour factors and traffic crash likelihood. The variance explained in the driving behaviour factors and probability of traffic crash involvement are also indicated in Table 4.

\section{Hierarchical Regression Analyses (Male Drivers)}

The result in Table 4 further indicates that control variables (age and years of driving license) were not related to driving behaviour factors and crash involvements. However, mileage was related to the likelihood of traffic crash involvements $(\beta=0.19 ; \mathrm{p}<0.001)$, but not driving behaviours.

The perceived external affective demand was positively related to driving errors $(\beta=0.36 ; \mathrm{p}<0.001)$ and violations $(\beta=0.36 ; p<0.05)$ but negatively associated with positive driving behaviour $(\beta=-0.14 ; \mathrm{p}<0.05)$ whereas perceived 
Table 5. Effect of TSC on driving behaviours and traffic crash for the age groups (females and males)

\begin{tabular}{|c|c|c|c|c|c|c|c|c|c|c|c|c|c|c|c|c|}
\hline \multicolumn{9}{|c|}{ Females } & \multicolumn{8}{|c|}{ Males } \\
\hline \multirow{2}{*}{$\begin{array}{l}\text { TSC Factors/ } \\
\text { Age groups }\end{array}$} & \multicolumn{2}{|c|}{ Err } & \multicolumn{2}{|c|}{ Viol } & \multicolumn{2}{|c|}{ PB } & \multicolumn{2}{|c|}{ PTC } & \multicolumn{2}{|c|}{ Err } & \multicolumn{2}{|c|}{ Viol } & \multicolumn{2}{|c|}{ PB } & \multicolumn{2}{|c|}{ PTC } \\
\hline & $R^{2}$ & $\beta$ & $R^{2}$ & $\beta$ & $R^{2}$ & $\beta$ & $R^{2}$ & $\beta$ & $R^{2}$ & $\beta$ & $R^{2}$ & $\beta$ & $R^{2}$ & $\beta$ & $R^{2}$ & $\beta$ \\
\hline $\begin{array}{l}\text { Young } \\
(18-29)\end{array}$ & 0.23 & & 0.10 & & 0.30 & & 0.16 & & 0.29 & & 0.23 & & 0.26 & & 0.17 & \\
\hline FUN & & -0.04 & & -0.02 & & 0.05 & & -0.09 & & -0.02 & & $-0.13^{*}$ & & $0.17^{*}$ & & -0.07 \\
\hline EAD & & $0.32^{* * *}$ & & $0.20^{*}$ & & $-0.21^{*}$ & & -0.01 & & $0.45^{* * *}$ & & $0.40^{* * *}$ & & $-0.25^{* *}$ & & 0.05 \\
\hline IRE & & $-0.30^{* *}$ & & $-0.12^{*}$ & & $0.46^{* * *}$ & & $-0.33^{* * *}$ & & $-0.26^{* *}$ & & $-0.14^{*}$ & & $0.36^{* * *}$ & & 0.10 \\
\hline $\begin{array}{l}\text { Middle age } \\
(30-44)\end{array}$ & 0.19 & & 0.11 & & 0.26 & & 0.11 & & 0.18 & & 0.20 & & 0.20 & & 0.12 & \\
\hline FUN & & -0.05 & & -0.02 & & 0.02 & & -0.06 & & 0.01 & & $-0.16^{*}$ & & 0.08 & & -0.06 \\
\hline EAD & & $0.21^{* *}$ & & $0.14^{*}$ & & $-0.35^{* * *}$ & & -0.09 & & $0.32^{* * *}$ & & $0.29^{* * *}$ & & $-0.11^{*}$ & & $0.12^{*}$ \\
\hline IRE & & $-0.31^{* * *}$ & & $-0.21^{* *}$ & & $0.41^{* * *}$ & & -0.01 & & $-0.18^{* *}$ & & -0.05 & & $0.32^{* * *}$ & & 0.01 \\
\hline $\begin{array}{l}\text { Older } \\
(45+)\end{array}$ & 0.26 & & 0.24 & & 0.27 & & 0.27 & & 0.20 & & 0.33 & & 0.19 & & 0.14 & \\
\hline FUN & & $-0.35^{* * *}$ & & $-0.23^{* *}$ & & -0.08 & & $-0.14^{*}$ & & $-0.19^{*}$ & & $-0.22^{* *}$ & & $0.18^{*}$ & & $-0.15^{*}$ \\
\hline EAD & & $-0.30^{* *}$ & & $-0.36^{* * *}$ & & $-0.21^{* *}$ & & $-0.36^{* * *}$ & & $0.13^{*}$ & & $0.29^{* *}$ & & 0.06 & & -0.03 \\
\hline IRE & & 0.02 & & 0.02 & & $0.35^{* * *}$ & & $-0.25^{* * *}$ & & $-0.18^{*}$ & & -0.03 & & $0.16^{*}$ & & -0.01 \\
\hline
\end{tabular}

Note: ${ }^{*} \mathrm{p}<0.05,{ }^{* *} \mathrm{p}<0.01,{ }^{* * *} \mathrm{p}<0.001$.

Err -error, Viol- Violation, PB-positive behaviour, PTC- Probability of Traffic crash, FUN- Functionality, EAD- External Affective Demand, IRE-Internal Requirement.

Years of driving license and mileage were used as control variables in the model.

$\mathbf{R}^{2}$ - Variance explained in dependent variable, $\beta$ - Standardised Coefficients.

internal requirement was negatively related to errors $(\beta$ $=-0.23 ; \mathrm{p}<0.001)$ and violations $(\beta=-0.10 ; \mathrm{p}<0.05)$ but positively related to positive driving behaviour $(\beta$ $=0.31 ; \mathrm{p}<0.001)$. The TSC factors have no significant association with probability of traffic crash involvement. It must be noted, however, that, the variance explained in aberrant driving behaviours and the probability of crash involvements by male drivers' model was higher than their female counterparts. However, the variance explained in the positive driving behaviour is high for female drivers compared to males (see Table 4).

\section{Age Grouping for Female and Male Drivers}

The result in Table 5 illustrates that perceived external affective (EAD) demand was positively related to aberrant driving behaviours but negatively related to positive driving behaviour for both young and middle-aged female drivers. On the other hand, the perceived internal requirement (IRE) was negatively related to aberrant driving behaviours but positively related to positive driving behaviour. Again, IRE had a negative relation with the probability of traffic crash involvement for the young and older female drivers. Moreover, the result further showed that, for older female drivers, the perceived traffic system functionality and EAD were negatively related to driving behaviour factors. In addition, the functionality and EAD were negatively associated with probability of traffic crash involvement.

Similar to the findings of female drivers, the result in Table 5 demonstrates that for both young and middle-aged male drivers, the perceived EAD had a positive relation with aberrant driving behaviours, but was negatively related to positive driving behaviour. More so, the result shows that EAD factor was positively related to probability of traffic crash involvement $(\beta=0.12 ; \mathrm{p}<0.05)$ for middleaged drivers. On the other hand, the perceived IRE was negatively associated with aberrant driving behaviours but positively related to positive driving behaviour for young and middle-aged drivers. The result further revealed that for older male drivers, the perceived traffic system functionality was negatively related to aberrant driving behaviours and probability of traffic crash involvement. Besides, functionality was positively associated with positive driving behaviour. The perceived EAD was positively related to errors and violations but has no significant association with positive driving behaviour and 
traffic crash involvement. Perceived IRE had a significant negative relation with errors, but positively related to positive driving behaviour with no significant association with traffic crash involvement for older drivers.

\section{Discussion}

The study aims to examine the explanatory power of Traffic Safety Climate factors (i.e., external affective demand, functionality and internal requirements) in driving behaviours and probability of traffic crash involvement among male and female drivers in China, taking into consideration different age groups.

The result showed that male and female drivers express driving violations and probability of traffic crashes differently, with males reporting high driving violations, emotional engagement and traffic crashes than female drivers. In accordance with a previous study, this result implies that traffic crashes among male drivers happened more as a consequence of traffic rule violations (Parker et al., 1995) and perception that traffic is emotionally demanding (Chu et al. 2019).

The differences in TSC and driver's behaviour factors revealed that there was no significant difference in errors, positive driving behaviour and perceived external affective demand and internal requirements for both sexes. This suggests that males and females held similar perceptions concerning the frequency of committing driving errors and positive driving behaviour as well as emotional engagement and vehicle handling skills in traffic. However, in accordance with a previous study, it appears that females reported more driving errors than male drivers (De Winter et al 2010). Similarly, female drivers demonstrated high positive driving behaviours and perception of vehicle handling skills in traffic compared to male drivers. Most likely, females exhibit more positive driving behaviour because traffic situations that require vehicle handling skills may have forced them to alter driving behaviours.

The correlation analysis revealed that, except for age that had a negative correlation with functional traffic systems for male drivers, mileage and probability of traffic crash involvement show no association with traffic safety climate factors for both male and female drivers. This result means that age is an important factor to be considered in the study that seeks to promote traffic safety. As expected, the perceived functional traffic system and the internal requirement was negatively related to aberrant driving behaviours and positively related to positive driving behaviour for both male and female drivers. This finding is in line with a previous study (Gehlert et al., 2014), revealing that perceived internal requirements and traffic system functionality are related to road safety behaviours. In addition, other researchers have indicated that positive driving behaviour has the capability to reduce aberrant driving behaviours (Özkan \& Lajunen, 2005a). The result suggests that functional traffic systems together with the appropriate driving skills in traffic lead to higher positive driving behaviours and less aberrant driving behaviours (Özkan \& Lajunen, 2005; Chu et al 2019) among male and female drivers. These measures could help individual drivers to interact effectively with different traffic conditions in order to achieve the desired road safety in China. Nonetheless, the result has further demonstrated that male drivers aberrant driving behaviours could be partly linked to the conditions in physical traffic environments (external affective demand). The possible explanation for this result could be that, when male drivers perceived traffic to be more emotionally demanding, they tend to violate the acceptable driving rules whereas females do not (e.g., Harrison, 2009). Female drivers are to some extent safer drivers in traffic than male drivers in China (Wei, Chen \& Wang, 2015). In support of the previous studies, we can therefore claim that traffic system functionality is the most important factor of traffic safety climate tool for explaining observed differences in demographic factors in traffic (Ward et al., 2010).

\section{TSC Factors in explaining DB and Traffic crashes for Male and Female}

In the comparative analysis, it was clear that none of the perceived traffic safety climate factors had a significant association with traffic crash involvements. In line with the previous studies, this indicates that, although an accident is most often an outcome of risky driving behaviours, not all traffic conditions could result in an accident (Özkan $\&$ Lajunen, 2005b). The reasons a driver may engage in particular driving behaviour is dependent on the perceived traffic conditions. On the other hand, a previous study has revealed that TSC is related to accident involvement in an indirect way through proximal factors such as driving behaviours (Chu et al, 2019). In the present study, we explored the direct association between TSC factors and traffic crash involvement. It is possible that TSC factors may be related to traffic crash involvement only when mediated by driving behaviour factors. However, further studies are needed to explore how TSC factors are related to traffic crash involvement for drivers in China.

According to the results, the variance explained in aberrant behaviours variables were higher for male drivers compared to the female drivers whereas the variance explained in positive driving behaviour was higher for female drivers than the male drivers. In accordance with previous findings, it is evident that male drivers overestimate their driving skills and emphasise vehicle handling skills rather than safety (Özkan \& Lajunen, 2005b; Wei, Chen \& Wang, 2015) whereas female drivers are more concerned about safety in traffic. This finding emphasises the fact that when developing measures to reduce risky driving behaviours and enhance traffic safety, both male and female drivers have to be taken into consideration. However, male drivers are of a major concern than female drivers. 


\section{Differences among Age Groups for Male and Female Drivers}

Though the difference between female and male drivers has been established, it could not be established which age (young, middle-aged and older drivers) among these groups are of more concern. Therefore, the characteristics of different ages for males and females were presented. The result demonstrated that perceived external affective demand was positively related to aberrant driving behaviours and negatively related to positive driving behaviour for young and middle aged for both male and female drivers. This result suggests that when the young and middle-aged groups for both male and female drivers perceive traffic systems to be emotionally demanding (e.g., "aggressive," "putting pressure," and "dangerous"), their positive behaviour decreases and tend to commit errors and traffic rules violations. In accordance with a previous study, the result further, explains that regardless of sex characteristics young and middle-aged driver's tendency to involve in risky driving behaviour or underestimate hazards in traffic is related to the situations or conditions in the traffic (Alfonsi et al. 2018). Within the bracket of older drivers, females were less likely than male drivers to engage in perilous driving behaviour and report a high probability of traffic crashes. In general, the results imply that irrespective of age, male drivers as a group are more likely to experience high traffic crashes as per the perception that traffic is emotionally demanding.

The result further evidenced that perceived internal requirement is more likely to enhance positive driving behaviours but prevent aberrant driving behaviours of young and middle-aged drivers of both sexes. Likewise, the perceived internal requirement enhances both male and female older drivers' positive behaviour. This demonstrates that when both sexes perceive traffic conditions to require driving skills/capabilities such as experience, cautious, and vigilance, they tend to promote positive driving behaviour and avoid committing errors as well as violations of driving norms (Chu et al. 2019; Gehlert et al. 2014). Conversely, perceived required driving skills is more likely to increase young female drivers' crash rate than males. This means that female young drivers have defects in their driving skills when the traffic environment is complex and are likely to experience crashes. Consistent with this finding, Drummond and Yeo (1992), also reported that females have a higher causality involvement rate compared to males. However, satisfactory driving skills in traffic is less likely to affect female older drivers' crash rate than that of male drivers. This explains that, when female drivers are young, they are likely to experience more traffic crashes and as they grow old, the rate of traffic crash is likely to decrease.

Further, the result established that perceived functional traffic systems which include; "Planned," preventive measures," "dependent on mutual consideration,", is indisputably associated with violations, but negatively associated with positive behaviour (Chu et al., 2019) of male young and middle-aged drivers. Within the bracket of the older drivers, the perceived traffic system functionality was not associated with aberrant driving behaviour of both sexes, but related to the positive driving behaviour of male older drivers, but not for female drivers. These results imply that drivers can avoid aberrant driving behaviours when the traffic situations meet their physical driving abilities. Besides, when traffic systems are functional it is likely to promote positive driving behaviour of older male drivers but may not motivate female drivers to exhibit positive driving behaviour in traffic. The result further demonstrated that a functional traffic system is likely to be a tool for plummeting traffic crash involvement for both male and female drivers.

In summary, the study suggests that the traffic safety climate factors have an appreciated relationship with driving behaviours and traffic crash involvement among male and female drivers in China. Emotional engagement in traffic is linked to aberrant driving behaviours and traffic crash involvement especially, among male drivers. However, a perceived functional traffic system together with perceived internal requirements such as vehicle handling skills/capabilities in traffic is positively related to positive driving behaviours but negatively related to aberrant driving behaviours as well as traffic crash involvement in China.

\section{Practical Implications}

The traffic condition has a considerable significant association with driving behaviours and traffic crashes in China. Moreover, this problem seems to be growing due to aberrant driving behaviours among drivers. The results of the study consistently indicate that, with functional traffic systems together with appreciable vehicle handling skills, drivers can effectively participate in traffic and can circumvent aberrant driving behaviours and exhibit positive driving behaviours. Therefore, traffic authorities should give special attention to the modification of traffic infrastructure systems designed to facilitate effective interactions and reduce risky driving behaviours in traffic. In addition, there is the need to conduct regular traffic safety exercise tailored towards developing drivers especially, young males driving skills and positive driving behaviour that will limit emotional engagement and crash involvement.

It is also obvious that the basic requirements such as enforcement and education of safe traffic have to be directed towards male drivers, especially young and middle-aged drivers in order to promote positive driving behaviour and reduce aberrant behaviours in China.

When traffic is perceived to be emotionally demanding, young male drivers are likely to incur the majority of crashes and this is likely to remain unchanged in the 
future. The high traffic crash involvement reflects the deficiency of vehicle handling skills that do not meet different traffic conditions. Therefore, it is imperative to identify specific assertiveness associated with young male drivers' risky driving behaviours and discourage such inappropriate behaviour by increasing the booking fine for road traffic offenders. This intervention will promote positive driving behaviours that will limit emotional engagement and optimise driving skills in terms of crash avoidance.

One of the strategies that have been proven to be effective in reducing risk-taking behaviour is the participatory approach (Mason et al., 2013). This will mean engaging the young and middle-aged drivers in empowering ways to define their driving behaviours and crash rates in different traffic conditions and to develop solutions to the challenges they face in traffic. This approach will allow these categories of drivers to find out themselves the need for behavioural change and how the change process should take place.

\section{Conclusion}

Studies have concluded that sex and age of a driver have an independent effect on driving behaviour and driving safety (Parker et al. 1992; Shinar, 2017). The evidence from multiple studies has revealed that sex and age are more important to be considered in a study that attempts to promote driving safety (McCartt et al., 2009; Shinar, 2017). However, in the field of traffic safety study, there is little finding on the impact of traffic safety climate factors on drivers' behaviour and traffic crashes, particularly among male and female drivers hence, the need for this study.

The result demonstrates that male and female drivers in China expressed different perceptions about traffic safety, driving behaviours, and traffic crashes. However, in some instances, there is no significant difference between male and female drivers. Male drivers have a higher emotional engagement, driving violations and crash rates than female drivers. Whereas female drivers exhibited more internal requirements, positive behaviours and driving errors. The decrease in the traffic crash involvement according to age is larger among male than female drivers. The aberrant driving behaviour and traffic crash become regular when traffic is perceived to be emotionally demanding with young and middle-aged drivers experiencing the majority of crashes. Perceived internal requirements and traffic system functionality, on the other hand, promote positive driving behaviour, but reduce aberrant driving behaviours of both sexes with a low traffic crash involvement. In support of previous study, it is, therefore, imperative that the traffic authorities give special attention to the modification of traffic infrastructure designs (Regmi, 2021) to optimise vehicle handle skills which are likely to promote positive driving behaviours and limit emotional engagement as well as aberrant driving behaviours in traffic. It should be noted, however, that, the difference in road traffic injuries and fatalities, as well as driver behaviours among countries, might be influenced by the perceived traffic climate of a country traffic context (Yeşim Üzümcüoğlu Zihni, 2018). Therefore, ways of expressing behaviours in traffic can be expected to vary from country to country.

\section{Limitations}

The results may have limitations related to self-reported data. Although participants were assured of anonymity and confidentiality, their responses may have been biased towards social desirability. Drivers may underreport their view about traffic conditions, driving behaviours and traffic crash involvement. A purposeful underreporting is not a problem as long as that underreporting is true for all groups under study and the focus of interest is not on the absolute but the difference between driver groups (Laapotti 2001). Lajunen and Summala (2003), also concluded that social desirability has a relatively small impact on traffic safety studies. Notwithstanding the limitations, the study has some implications for safety research and traffic safety campaigns in China. The study concludes with a suggestion that there is the need to conduct traffic safety exercise that is tailored towards developing young males driving skills and positive driving behaviour that will limit emotional engagement and crash involvement.

The study focused only on age in the aberrant driving behaviours and traffic crash involvement. However other demographic variables such as educational level, marital status, occupation/income level, among others may influence driving behaviours and traffic crashes. Therefore, further research on these variables is recommended. In addition, the present study explored the direct association between TSC factors and driving behaviours as well as traffic crash involvement. It is possible that driving behaviour variables will mediate the relationship between TSC factors and traffic crash involvement. Therefore, further study can be conducted to test the mediational role of driving behaviours in the relationship between TSC and traffic crash involvement using the Structural Equation Model.

\section{Acknowledgements}

The authors acknowledge the support from the National Nature Science Foundation of China (51775396), the National Nature Science Foundation of Guangxi Province (2019JJB160047), and Ho Technical University, Ghana for their support.

\section{References}

Alfonsi, R., Ammari, A., Usami, D. S. (2018). Lack of driving experience, European Road Safety Decision Support System, developed by the H2020 project Safety Cube. Retrieved from www.road safety-dss.eu on 17/08/ 2020 
Amponsah-Tawiah, K., \& Mensah, J. (2016). The impact of safety climate on safety related driving behaviors. Transportation research part F: traffic psychology and behaviour, 40, 4855.

Atchley, P., Shi, J., \& Yamamoto, T. (2014). Cultural foundations of safety culture: A comparison of traffic safety culture in China, Japan and the United States. Transportation research part F: traffic psychology and behaviour, 26, 317-325.

Bener, A., Özkan, T., \& Lajunen, T. (2008). The driver behaviour questionnaire in Arab gulf countries: Qatar and United Arab Emirates. Accident Analysis \& Prevention, 40(4), 14111417.

Traffic Management Bureau of Ministry of Public Security of China. (2020). Statistics Annals of Road Traffic Accident of People's Republic of China.

Chu, W., Wu, C., Atombo, C., Zhang, H., \& Özkan, T. (2019). Traffic climate, driver behaviour, and accidents involvement in China. Accident Analysis \& Prevention, 122, 119-126.

Danaf, M., Hamdar, S. H., Abou-Zeid, M., \& Kaysi, I. (2018). Comparative assessment of driving behavior at signalized intersections using driving simulators. Journal of Transportation Safety \& Security, 10(1-2), 124-158.

De Simone, S. (2014). The affective component of workplace in organizational behaviour studies. American International Journal of Contemporary Research, 4(9), 38-43.

De Winter, J. C. F., \& Dodou, D. (2010). The Driver Behaviour Questionnaire as a predictor of accidents: A metaanalysis. Journal of safety research, 41(6), 463-470.

Drummond, A. E., \& Yeo, E. Y. (1992). The risk of driver crash involvement as a function of driver age (Vol. 49). Monash University, Accident Research Centre.

Gehlert, T., Hagemeister, C., \& Özkan, T. (2014). Traffic safety climate attitudes of road users in Germany. Transportation research part F: traffic psychology and behaviour, 26, 326336.

Harrison, W. A. (1999). The role of experience in learning to drive: a theoretical discussion and an investigation of the experiences of learner drivers over a two-year period (No. 156).

Harrison, W. A. (2009). Reliability of the Driver Behaviour Questionnaire in a sample of novice drivers: Austroads.

Hassan, H. M. (2016). Investigation of the self-reported aberrant driving behavior of young male Saudi drivers: A surveybased study. Journal of Transportation Safety \& Security, $8(2), 113-128$.

Jonah, B. A. (1990). Age differences in risky driving. Health Education Research, 5(2), 139-149.

Laapotti, S., Keskinen, E., \& Rajalin, S. (2003). Comparison of young male and female drivers' attitude and self-reported traffic behaviour in Finland in 1978 and 2001. Journal of Safety Research, 34(5), 579-587.

Laapotti, S., Keskinen, E., Hatakka, M., \& Katila, A. (2001). Novice drivers' accidents and violations - a failure on higher or lower hierarchical levels of driving behaviour. Accident Analysis \& Prevention, 33(6), 759-769.
Lajunen, T.; Summala, H. (2003). Can we trust self-reports of driving? Effects of impression management on driver behaviour questionnaire responses, Transportation Research Part F: Traffic Psychology and Behaviour. DOI: http:// dx.doi.org/10.1016/S1369-8478(03)00008-1, 6(2): 97-107.

Lee, J., Huang, Y.H., Murphy, L.A., Robertson, M.M., Garabet, A., (2016). Measurement equivalence of a safety climate scale across multiple trucking companies. J. Occup. Organ. Psychol. 89 (2), 352-376. http://dx.doi.org/10.1111/ joop. 12127.

Markšaitytè, R., Žardeckaitė-Matulaitienè, K., Pranckevičienė, A., Šeibokaitè, L., \& Endriulaitienè, A. (2014). Perception of the traffic safety climate: comparison of different groups of Lithuanian drivers. In Transport means-2014: proceedings of the 18th international conference, October 23-24, 2014, Kaunas university of technology, Lithuania. Kaunas: Technologija, 2014,[vol.] 18.

Martinussen, L. M., Møller, M., \& Prato, C. G. (2014). Assessing the relationship between the Driver Behavior Questionnaire and the Driver Skill Inventory: Revealing sub-groups of drivers. Transportation research part F: traffic psychology and behaviour, 26, 82-91.

Mason, M. J., Tanner, J. F., Piacentini, M., Freeman, D., Anastasia, T., Batat, W., ... \& Rangan, P. (2013). Advancing a participatory approach for youth risk behavior: Foundations, distinctions, and research directions. Journal of business research, 66(8), 1235-1241.

McCartt, A. T., D. R. Mayhew, K. A. Braitman, S. A. Ferguson, and H. M. Simpson (2009). Effects of age and experience on young driver crashes: Review of recent literature. Traffic Inj. Prev., 10, 209-219.

National Bureau of Statistics of China. National data [translated from Chinese]. http://data.stats.gov.cn/easyquery. htm?cn=C01 (accessed June 23, 2020).

Ouimet, M. C., Simons-Morton, B. G., Zador, P. L., Lerner, N. D., Freedman, M., Duncan, G. D., \& Wang, J. (2010). Using the US National Household Travel Survey to estimate the impact of passenger characteristics on young drivers' relative risk of fatal crash involvement. Accident Analysis \& Prevention, 42(2), 689-694.

Özkan, T., \& Lajunen, T. (2005a). A new addition to DBQ: Positive driver behaviours scale. Transportation Research Part F: Traffic Psychology and Behaviour, 8(4), 355-368.

Özkan, T., \& Lajunen, T. (2005b). Why are there sex differences in risky driving? The relationship between sex and gender role on aggressive driving, traffic offences, and accident involvement among young Turkish drivers. Aggressive behaviour, 31(6), 547-558.

Özkan, T., \& Lajunen, T. (2006). What causes the differences in driving between young men and women? The effects of gender roles and sex on young drivers' driving behaviour and self-assessment of skills. Transportation Research Part F: Traffic Psychology and Behaviour, 9(4), 269-277.

Özkan, T., \& Lajunen, T. (2011). Person and environment: Traffic culture. Handbook of traffic psychology, 179-192. 
Özkan, T., \& Lajunen, T. (2015). A general traffic (Safety) culture system (G-TraSaCu-S). TraSaCu Project, European Commission, RISE Programme.

Özkan, T., Lajunen, T., \& Summala, H. (2006). Driver Behaviour Questionnaire: A follow-up study. Accident Analysis \& Prevention, 38(2), 386-395.

Parker, D., Manstead, A. S., Stradling, S. G., \& Reason, J. T. (1992). Determinants of intention to commit driving violations. Accident Analysis \& Prevention, 24(2), 117-131.

Parker, D., McDonald, L., Rabbitt, P., \& Sutcliffe, P. (2000). Elderly drivers and their accidents: the Aging Driver Questionnaire. Accident Analysis \& Prevention, 32(6), 751-759.

Parker, D., Reason, J. T., Manstead, A. S., \& Stradling, S. G. (1995). Driving errors, driving violations and accident involvement. Ergonomics, 38(5), 1036-1048.

Pousette, A., Larsson, S., \& Törner, M. (2008). Safety climate cross-validation, strength and prediction of safety behaviour. Safety science, 46(3), 398-404.

Reason, J., Manstead, A., Stradling, S., Baxter, J., \& Campbell, K. (1990). Errors and violations on the roads: a real distinction? Ergonomics, 33(10-11), 1315-1332.

Regmi, M. B. (2021). Road safety policy and practice: What does it take to improve road safety in Asia?. Journal of road safety, 32(4), 29-39.

Rhodes, N., \& Pivik, K. (2011). Age and gender differences in risky driving: The roles of positive affect and risk perception. Accident Analysis \& Prevention, 43(3), 923-931.

Sagberg F., Selpi, Bianchi Piccinini G.F., Engström J. (2015). A review of research on driving styles and road safety, Human Factors, 57, 1248-1275

Samantha Wong, (2020). Number of fatalities in traffic accidents in China from 2008 to 2018, https://www.statista.com/ statistics/276260/number-of-fatalities-in-traffic-accidentsin-china/ (accessed June 23, 2020).

Schlembach, C., Furian, G., Brandstatter, C. (2016). Traffic (safety) culture and alcohol use: cultural patterns in the light of results of the SARTRE 4 study. Eur. Transp. Res. Rev. 8 (1). http://dx.doi.org/10.1007/s12544-016-0194-8.

Shen, B., Qu, W., Ge, Y., Sun, X., \& Zhang, K. (2018). The relationship between personalities and self-report positive driving behavior in a Chinese sample. PLoS one, 13(1), e0190746.

Shinar, D. (Ed.). (2017). Traffic safety and human behavior. Emerald Group Publishing.

Stephens, A., \& Fitzharris, M. (2016). Validation of the Driver Behaviour Questionnaire in a representative sample of drivers in Australia. Accident Analysis \& Prevention, 86, 186-198.
Sucha, M., Sramkova, L., \& Risser, R. (2014). The Manchester driver behaviour questionnaire: self-reports of aberrant behaviour among Czech drivers. European transport research review, 6(4), 493-502.

Useche, S. A., Hezaveh, A. M., Llamazares, F. J., \& Cherry, C. (2021). Not gendered but different from each other? A structural equation model for explaining risky road behaviors of female and male pedestrians. Accident Analysis \& Prevention, 150, 105942.

Useche, S. A., Montoro, L., Alonso, F., \& Tortosa, F. M. (2018). Does gender really matter? A structural equation model to explain risky and positive cycling behaviors. Accident Analysis \& Prevention, 118, 86-95.

Wang, L., Ning, P., Yin, P., Cheng, P., Schwebel, D. C., Liu, J., ... \& Zhou, M. (2019). Road traffic mortality in China: analysis of national surveillance data from 2006 to 2016. The Lancet Public Health, 4(5), e245-e255.

Ward, N. J., Linkenbach, J., Keller, S. N., \& Otto, J. (2010). White paper on traffic safety culture. White Paper(2).

Wei, L., Cen, H., Wang, L. (2015) Analysis of Key Factors Leading to Road Traffic Accidents. Journal of Transport Information and Safety, 33(1), 85-89

Wills, A. R., Watson, B., \& Biggs, H. C. (2006). Comparing safety climate factors as predictors of work-related driving behavior. Journal of safety research, 37(4), 375-383.

World Health Organization. (2018). Global status report on road safety 2018: Summary (No. WHO/NMH/NVI/18.20). World Health Organization.

Zhang, L., Tan, B., Liu, T., \& Li, J. (2021). Research on recognition of dangerous driving behavior based on support vector machine. In Twelfth International Conference on Graphics and Image Processing (ICGIP 2020) (Vol. 11720, p. 117201L). International Society for Optics and Photonics.

Zhang, Q., Ge, Y., Qu, W., Zhang, K., \& Sun, X. (2018). The traffic climate in China: The mediating effect of traffic safety climate between personality and dangerous driving behavior. Accident Analysis \& Prevention, 113, 213-223.

Zhang, W., Tsimhoni, O., Sivak, M., \& Flannagan, M. J. (2010). Road safety in China: analysis of current challenges. Journal of safety research, 41(1), 25-30.

Zhang, X., Xiang, H., Jing, R., \& Tu, Z. (2011). Road traffic injuries in the People's Republic of China, 19512008. Traffic injury prevention, 12(6), 614-620.

Zihni, Yeşim Üzümcüoğlu. (2018). The Relationship between traffic climate and driver behaviors: explicit and implicit measures with Turkish and Chinese samples. Orta Doğu Teknik Üniversitesi, SBE, Danıșman. 


\section{Contributed articles}

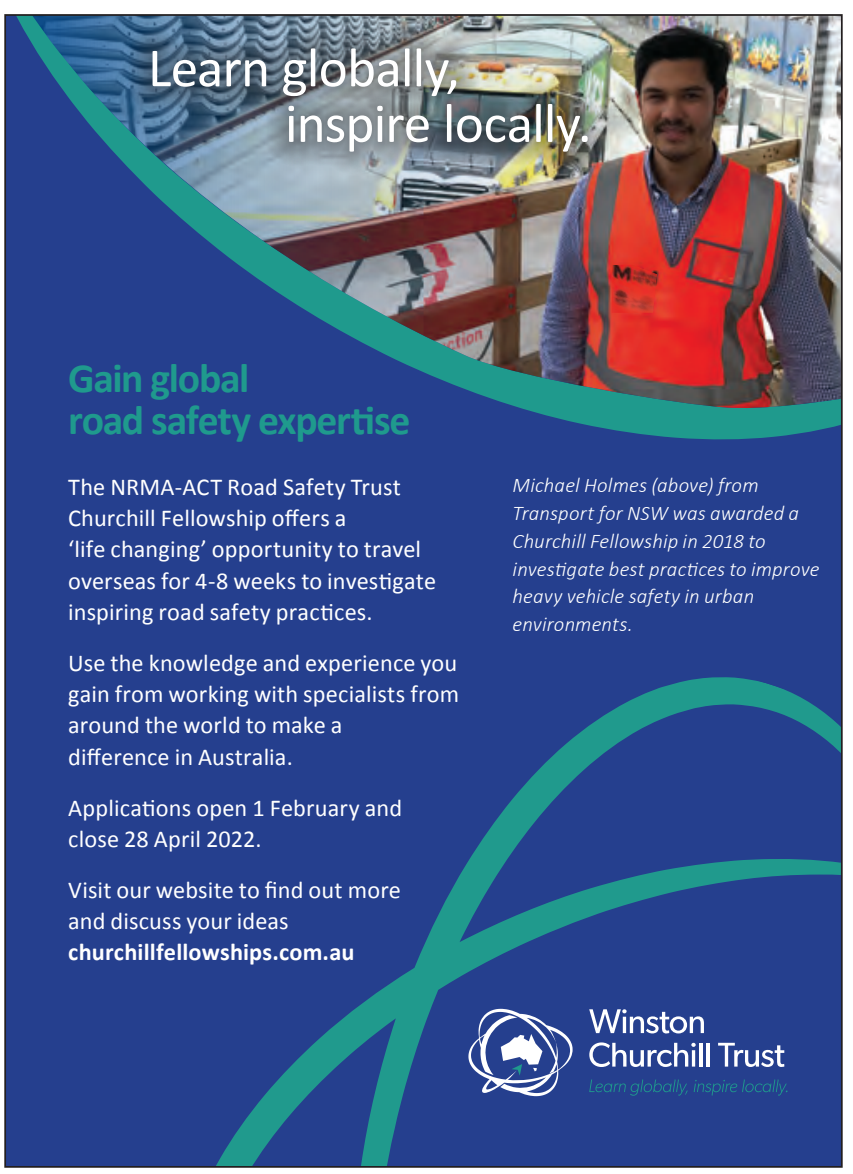




\section{Perspective on Road Safety}

\section{New Deal in Road Safety: Why we need NGOs}

Lotte Brondum ${ }^{1}$, Chika Sakashita ${ }^{1}, \operatorname{Liz~Man}^{1}$ and Valeria Motta ${ }^{1}$

${ }^{1}$ Global Alliance of NGOs for Road Safety, Zurich, Switzerland

Corresponding Author: Lotte Brondum, Erik Eriksens Gade 11, 1th, 2300 Copenhagen S, Denmark, lotte.brondum@roadsafetyngos.org+4529939914.

\section{Key Findings}

- The Global Plan for the Decade of Action for Road Safety 2021-2030 with the target of reducing road traffic deaths and injuries by at least $50 \%$ by 2030 was launched on 28 October 2021.

- A lack of political will to road safety delivery hinders the achievement of the global target.

- NGOs have the power to increase political will through three key roles:

- Advocacy to drive the implementation and financing of evidence-based interventions;

- Holding decision makers accountable for road safety delivery;

- $\quad$ Empowering communities to demand a Safe System.

\section{Keywords}

NGO, advocacy, accountability, political will, Global Alliance of NGOs for Road Safety, road safety financing

\section{Background}

Road safety has been receiving increasing global attention, for example: the inclusion of road safety in the 2030 Agenda for Sustainable Development and the United Nations General Assembly (UNGA) adoption of resolution 74/299 "Improving global road safety"; Stockholm Declaration (2020) reflecting the recommendations of the Academic Expert Group of the $3^{\text {rd }}$ Global Ministerial Conference on Road Safety. Recognising that the target to reduce road deaths and serious injuries by $50 \%$ was not met in the First Decade of Action for Road Safety (Decade of Action) 2011-2020, the UN High-level Political Forum on Sustainable Development made a pledge in September 2019 to make the new decade one of action and delivery. On 28 October 2021, the Global Plan for the Decade of Action for Road Safety 2021-2030 (the Global Plan) was launched to guide Member States in the implementation of key actions to improve road safety with the target to reduce road traffic deaths and injuries by at least $50 \%$ by 2030 (WHO \& UN Regional Commissions, 2021).

The Global Plan calls on governmental agencies as the primary responsibility holder in delivering a safe road transport system and implementing the required road safety actions to achieve the global target of $50 \%$ reduction in deaths and injuries by 2030. The Global Plan also calls on other actors - nongovernment organisations (NGOs), academia, youth, funders, private sector and UN agencies - as important contributors. NGOs are groups organised independently from governments at a local, national or international level to serve a certain cause such as road safety. NGOs exist to drive actions and bring improvements on a societal issue, and, in the field of road safety, NGOs drive road safety actions to protect people from being killed or seriously injured in our ubiquitous use of the road transport system.

The Global Alliance of NGOs for Road Safety (the Alliance) is a member-based organization for NGOs working for road safety around the world and currently represents 288 NGO members in 98 countries. The Alliance was founded in 2011 by NGO members of the United Nations Road Safety Collaboration (UNRSC) under the auspices of the World Health Organization (WHO) with a mission to unite, empower and strengthen civil society to stimulate collaborative advocacy, action and accountability

Received: 20/12/2021; Received in revised form: 11/01/2022; Accepted: 11/01/2022; Available on-Line: 09/02/2022

Copyright: (C) The Author(s). 2021 This is an open access article distributed under the terms of the Creative Commons Attribution (CC BY)_license, which permits unrestricted use, distribution, and reproduction in any medium, provided the original author(s) and the source are credited.

Suggested citation: Brondum, L., Sakashita, C. Man, L. and Motta, V. (2022). "New Deal in Road Safety: Why we need NGOs"

Journal of Road Safety, 33(1), 64-70. https://doi.org/10.33492/JRS-D-21-00070 
for road safety. The Alliance achieves this by providing services to its members in three key areas: networking and sharing, advocacy and accountability, and capacity development.

The aim of this paper is to articulate the NGO response to the calls made in the Global Plan by analysing the current road safety context and what NGOs contribute to the $50 \%$ reduction target by 2030 . The paper employs relevant literature and results of an online survey conducted by the Alliance to substantiate the analyses herein. This online survey was conducted 14 January - 3 February 2021 to collect NGO perspectives of the first Decade of Action in anticipation of the launch of the second Decade of Action (Alliance NGO survey). It was made available to the Alliance member NGOs in English, Spanish, and French. A total of 100 NGOs from 53 countries responded to this survey. Further details are available in the Alliance (2021).

\section{Lack of political will for road safety delivery}

Despite knowing during the first Decade of Action that globally we suffer nearly 1.3 million preventable deaths and an estimated 50 million injuries from road crashes each year (WHO, 2015; WHO, 2018), these unacceptable numbers remained largely unchanged (WHO \& UN Regional Commissions, 2021). Though many countries and organisations have adopted a vision of zero deaths from road crashes, the number of deaths is nowhere near zero. Without serious actions, road crashes are set to cause a further estimated 13-17 million deaths and 500 million injuries during this new decade (WHO \& UN Regional Commissions, 2021; Job, 2019). There are three key factors retarding the progress that we need to urgently make in road safety - all these are indicators of the levels of political will to deliver road safety. They are discussed below.

\section{We know what works but we are not implementing it}

Even though much is known about what works to reduce deaths and injuries from road crashes (evidencebased interventions), these interventions are not being implemented to the scale required to address the actual size of the deaths and injuries occurring from road crashes. We know safe speed limits are required for people to survive in a crash, yet speed limits are left too high on many roads (Power, 2019). We know speed-calming measures save lives and reduce injuries, but they are not commonly implemented across low- and middle-income countries (World Bank, 2020). Universal helmet laws for motorcycle riders work, but they have been repealed in a number of states in the USA (Peng et al., 2017). We know how to build five-, four- and three-star roads, yet $88 \%$ of a 358,000 $\mathrm{km}$ sample of roads across 54 countries found sampled roads were only one- or two-star rated for pedestrians
(iRAP, 2021). Lifesaving vehicle technologies such as Intelligent Speed Assistance (ISA) and Anti-Lock Brakes in Motorcycles (ABS) are available, yet they are resisted by the motor vehicle industry and not mandated to be part of all vehicles manufactured or driven in most countries (Ward, 2020). We know a legal breath alcohol (BAC) limit of .02 is better than .05 or .08 , yet every state of USA has .08 except Utah which adopts .05 (FindLaw, 2021) and only 45 countries have adopted BAC limits of .05 for the general population and .02 for young or novice drivers (WHO, 2018). These are only some of the many examples of measures proven to save lives and injuries not being implemented.

\section{Evidence-based interventions are not financed to the scale required}

Verbal commitments that are not backed with financing to deliver them are not genuine commitments. The lack of funding towards the interventions known to work to save lives and serious injuries is well recognised as the core of the continuing road trauma experienced around the world (Wegman, 2015; Job, 2020). The Global Plan recognises that road safety is underfunded and a call for sustainable financing of road safety was made at the Supporting Event to the High-level Meeting (HLM) of the UNGA on Global Road Safety to be held in 2022 (UNGA, 2021). Some countries may report on the transport infrastructure spending - for example, the European Union reports that transport infrastructure investment represents around 1\% of the GDP (Brendt et al., 2014). However, that does not necessarily mean such funding has road safety impact (i.e. death and injury reductions) because, for example, road surface improvements can generate increased vehicle speed, which directly increases the risks of deaths and serious injuries (Sekhar, et al., 2016).

As highlighted at the Supporting Event by Lotte Brondum, Executive Director of the Alliance, without public reporting of funding for road safety specifically, it is hard to make improvements in road safety investment (UNGA, 2021). In road safety, transparency in exactly what monetary value has been put towards specific interventions to reduce the number of deaths and injuries is lacking compared to other movements such as HIV, malaria, and tuberculosis (e.g. https://data.theglobalfund.org/). This lack of transparency in genuine road safety spending reflects the lack of genuine commitments to road safety.

In addition, funds are often misused on interventions which are not evidence-based, perpetuating the underfunding of evidence-based interventions. For example, evidence shows that school-based and postlicence driver/rider training and education at best make no difference to road safety outcomes and sometimes show worse outcomes, yet they continue to attract funding due to common sense beliefs and popularity rather than scientific evidence (Turner, et al., 2021; Ker et al., 2005; Ivers et al., 2016; Roberts and Kwan, 2001). 


\section{Decision makers evade taking responsibility for road safety}

The Stockholm Declaration (2020) called for political commitment and responsibility at the highest level and governmental agencies to deliver the scale of efforts required at regional, national and sub-national levels to achieve SDG targets. In the Alliance NGO survey, the 'lack of political will', 'lack of accountable focal point in government', 'lack of prioritization of road safety in government' and 'lack of political commitment' were commonly cited by NGOs as hampering road safety delivery. In the Global Plan, governments (national, state and local) are clearly identified as the entity that bears the main responsibility to ensure people's safety and to fund road safety activities. However, governments often evade taking responsibility for road safety and investing in system reforms by presenting the lack of safe road use by the people as the core of the road safety problem. The funding sits with the Heads of States, but, related to the point above, road safety continues to be underfunded often because governments do not take ownership of road safety.

For example, Transport for London (TfL) ran a campaign with the message "See Their Side. See safer roads." It promoted to the community that we all need to play our part in making our streets safer because $71 \%$ of Londoners think road users are not as considerate as they should be (TfL, 2021). This presentation of road safety as a personal responsibility undermines public demand for a Safe
System that protects the road users and therefore political incentives to fund system reforms for road safety. Case studies in Nairobi, Mumbai and Bogota have shown road safety is generally perceived as a personal responsibility rather than something that could be influenced by government action (Overseas Development Institute, 2018). According to the National Highway Traffic Safety Administration (NHTSA), an agency of the US Federal Department of Transportation, 94\% of serious crashes are due to human error (NHTSA, n.d.). These often-quoted statistics mislead people to believe that safety interventions must fix the road users (e.g. via education) and that the responsibility of road safety largely falls on the individuals (Zipper, 2021). In some countries, the blame may even be made to an uncontrollable force such as fatalism (Kayani, et al., 2011) in addition to the road users. A senior official of the Federal Road Safety Corps of Nigeria recently attributed the deaths on the roads in Bauchi state to the handwork of the devil as well as claimed that "all the departments of the Road Corps are working for one goal which is to reduce road crashes, avoid deaths through accidents that are caused by negligence of the road users" (Vanguard, 2021). These claims absolve governments of responsibility for the unsafe road transport systems they provide.

Knowing what works, yet not implementing these interventions, knowing the continuing unacceptable numbers of deaths and injuries, yet not funding the measures that are known to save lives and injuries, and

Table 1. The roles of NGOs in the field of road safety as described in the Global Plan for the Decade of Action for Road Safety 2021-2030 (the Global Plan) and by NGOs (Alliance NGO survey).

\begin{tabular}{|l|l|}
\hline The Global Plan & Alliance NGO survey \\
\hline $\begin{array}{l}\text { "Civil society can help amplify the voice of academia by being } \\
\text { an advocate and acting as an independent voice to influence } \\
\text { social change." }\end{array}$ & $\begin{array}{l}\text { "Ensure evidence-base" } \\
\text { "Bring change" }\end{array}$ \\
\hline $\begin{array}{l}\text { "support the development of policies by augmenting the } \\
\text { comidence base as well as bringing the perspectives of }\end{array}$ & $\begin{array}{l}\text { "participate in decision making" } \\
\text { "data collection, research, monitoring \& evaluation" } \\
\text { "support, empower and include victims in road safety } \\
\text { actions" }\end{array}$ \\
$\begin{array}{l}\text { "help ensure government accountability by empowering } \\
\text { communities on road safety issues and ensuring good } \\
\text { governance" }\end{array}$ & $\begin{array}{l}\text { "hold governments accountable" } \\
\text { "help push for the achievement of the road safety related SDGs" }\end{array}$ \\
\hline $\begin{array}{l}\text { "keeping road safety on the government agenda and uniting } \\
\text { stakeholders with a common goal" }\end{array}$ & $\begin{array}{l}\text { "influence government" } \\
\text { stakeholders" }\end{array}$ \\
\hline $\begin{array}{l}\text { "be an important source of road safety information for the } \\
\text { community and governments" }\end{array}$ & "community \& government education" \\
\hline
\end{tabular}


continuing acceptance that road safety is a personal responsibility rather than a system designer responsibility all reflect the deep lack of political motivation to address the road safety problem. As Viviam Perrone, representative of Asociación Madres del Dolor, highlighted at the Supporting Event to the HLM on Global Road Safety, "we need the political will" (UNGA, 2021).

\section{Power of NGOs in road safety}

Genuine commitments to road safety delivery are demonstrated by funds allocated to and spent on measures that are known to work in saving lives and injuries. NGOs play a key role in highlighting the accountability of decision makers who have the power to determine where funds go and how funds are spent. NGOs also play a key role in amplifying public demand for transparent, dedicated, impactful investments in road safety. Thus, NGOs increase motivation from governments and other critical decision makers to fund evidence-based road safety actions and act as a catalyst to genuine commitments to road safety delivery - that is, NGOs have the power to increase the political will for road safety delivery.

The Alliance has endorsed the Global Plan and is calling on governments to implement the evidence-based actions recommended, commit the resources needed to implement them, and involve NGOs in decision making. Since its launch on 28 October 2021, NGOs have taken the Global Plan to their decision makers at symbolic handover events to ensure that their governments are aware of the Global Plan and feel a pressure to respond by implementing evidence-based measures and accepting accountability to achieve the 2030 target to reduce road deaths and injuries by $50 \%$. As of December 2021, NGOs have completed handovers of the Global Plan to their local decision makers in 35 countries. The Alliance will further support NGOs to follow up with their governments to share their local road safety plans for the new decade.

The important roles NGOs play is also articulated in the Global Plan, which is broadly consistent with the ways the NGOs themselves described them in the Alliance NGO survey (see Table 1). Acknowledging these roles of NGOs, there are many ways the NGOs contribute to the $50 \%$ reduction target by 2030 . These are discussed in turn below.

\section{Advocacy to drive the implementation and financing of evidence-based interventions}

As summarised in Table 1, one of the key NGO roles that the Global Plan outlines is to foster evidence-led advocacy and policy development (e.g. 'amplify the voice of academia by being an advocate', 'support the development of policies by augmenting the evidence base as well as bringing the perspectives of communities'). The NGOs may work more closely and collaborate with academics who empirically identify effective solutions and strategies (evidence-based interventions). The accessibility to the knowledge of evidence-based interventions for real-world implementation will be important for NGOs to readily advocate for such interventions. The Alliance may therefore assist NGOs to prioritise their advocacy for evidence-based interventions by providing a ready list of those which research has shown to reduce deaths and injuries. The Alliance may also support NGOs to follow an advocacy journey towards obtaining genuine commitments from decision makers and actualisation of those commitments (i.e. implementation and financing of evidence-based interventions). The Alliance may also strengthen its research activities. For example, the Alliance helped bring the perspectives of communities and highlight the devastating impacts of road crashes on community members via the People's Survey which received responses from 5,606 people from 132 countries (The Alliance \& Accountability International, 2020). The People's Survey results were used to call on decision makers for urgent actions at the $3^{\text {rd }}$ Global Ministerial Conference on Road Safety in February 2020. The Alliance will conduct a research project funded by the Global Road Safety Facility in partnership with the Milken Institute School of Public Health of the George Washington University and local NGOs in Cameroon, Kenya and Rwanda, to assess the enablers of implementing $30 \mathrm{~km} / \mathrm{h}$ urban speed zones and support advocacy and policy change.

\section{Holding decision makers accountable for road safety delivery}

As summarised in Table 1, another key NGO role the Global Plan outlines is ensuring accountability and governance (e.g. 'help ensure government accountability', 'ensuring good governance', 'keeping road safety on the government agenda', 'help push for the achievement of the road safety related SDGs'). The NGOs may more strongly challenge the communications of road safety as a personal responsibility and instead bring attention to governments' responsibilities in providing a safe road transport system. The NGOs may ask governments to report on the specifics of government spending on road safety and its impact in terms of saving lives and injuries (e.g. funds made available to road infrastructure designed to save lives and injuries rather than simply road maintenance to assist purely travel speed). The NGOs may also ask and track governments to demonstrate genuine commitments by putting finance towards implementation of evidence-based interventions.

The NGOs may play a role in holding other entities to account such as the private sector such as the motor vehicle manufacturers to ensure the vehicles on our roads are safe and clean, as highlighted by David Ward, President of the Towards Zero Foundation at the Supporting Event to the HLM (UNGA, 2021). While there are NGOs who already dedicate their advocacy to the private sector, governments 
still hold the power to legally regulate the private sector via laws and regulations, making holding governments accountable still relevant. In addition, we need to be mindful that holding non-state actors accountable for road safety does not act as another defence mechanism for governments to absolve themselves of responsibility. The Alliance has been supporting NGOs to push their local and national governments to make meaningful and specific commitments and track them via the \#CommitToAct campaign (The Alliance, 2019). This has been developed by the Alliance for its member NGOs to call on their local decision makers to make commitments to act. The Alliance may further assist NGOs to track government activities beyond commitments (i.e. implementation) and reflect evidence, as well as track activities of other vital decision makers through an accountability tool.

\section{Empowering communities to demand a Safe System}

As summarised in Table 1, another key NGO role that the Global Plan outlines is empowering communities (e.g. 'be an important source of road safety information for the community and governments', 'influence social change', 'uniting stakeholders with a common goal'). NGOs work for the people and put the value of human life at the core of road safety. When using the road transport system, we want people to be able to travel without being killed or seriously injured, and therefore not suffer the negative consequences of deaths and serious injuries, such as grief, pain, psychological suffering, loss of livelihoods and other negative impacts on quality of life. A Safe System is a road transport system that allows people to travel without being killed or seriously injured. This peoplecentred advocacy for a Safe System is what makes NGOs call for evidence-based interventions, which research has shown to prevent/reduce deaths and serious injuries. This people-centred advocacy for a safe road system also reminds the governments and the communities that it is the governments' role to supply a Safe System rather than individual community members' responsibility to keep ourselves safe. The NGOs can bring relevant information to inspire and empower communities to demand governments to supply a Safe System for the people (Job and Sakashita, 2012). The community demand creates the political incentives to deliver road safety and NGOs work to bring these community perspectives to the governments. For example, an NGO in India (Patiala Foundation http:// patialafoundation.org/frontend/web/) sought road user data (showing almost half of the population in Patiala walks or cycles to work daily and only $6 \%$ used cars) and brought forward online petitions collected from the local communities to the local authorities - as a result, roads are being reconstructed to include pedestrian facilities in Patiala (The Alliance, 2020). The political incentives may be further increased by NGOs working with the media. For example, an NGO in Tunisia (Les Ambassadeurs de la Sécurité Routière http://www.asr.tn/) worked closely with the media to put pressure on the Ministry of Transport to enforce the national seat belt legislation (The Alliance, 2021).

\section{Need for greater meaningful NGO participation}

According to the 2021 NGO survey, $76.8 \%$ of NGOs are already actively engaging with government authorities. In addition to appropriate knowledge and skills within the NGOs, meaningful participation was identified as the second highest enabler of contributing to the Decade of Action and SDGs in the last decade. Furthermore, other than lack of funding of NGOs (72\% of survey respondents identified this as a factor), a lack of a road safety accountable focal point in government (55\%) and lack of NGO meaningful participation (32\%) were identified as possible factors hampering NGO contributions to the global road safety targets in the new decade.

While advocacy was identified as one of the top areas of NGO capacity growth in the past decade $(89 \%$ of respondents said the Alliance contributed to NGO growth in advocacy), only $67 \%$ of respondents said the Alliance contributed to NGO growth in meaningful participation, and $55 \%$ of respondents said they need capacity development support in meaningful participation to help improve NGO contributions to the global targets in the new decade. In response, the Alliance developed a Good Practice Guide: Meaningful NGO Participation (2021) and held capacity development training on meaningful NGO participation in October 2021.

Meaningful NGO participation occurs when NGOs participate in a decision-making space on behalf of the communities they represent and in a way that leads to actions that result in the reductions (and possibly ultimately elimination) of deaths, serious injuries and related psychological suffering from road crashes (The Alliance, 2021). NGO case studies suggest that NGOs who meaningfully participate in a decision-making space keep their focus on bringing positive outcomes and reduced suffering for the communities, seek and use data and evidence to develop their advocacy messages and strategies, actively seek out opportunities they can leverage to amplify their demands, persist despite obstacles and deliver a track record of effective work, identify and approach relevant stakeholders to work with, and use effective communication strategies (The Alliance, 2021). In order for NGOs to have influence at the decisionmaker levels, governments and other decision makers must also allow NGOs to participate in decision making. These enabling environments for meaningful NGO participation may be created and enhanced with the mutual understanding between decision makers and NGOs of the importance of NGO involvements in decision-making. As a way to help generate research-based guidance on the enabling environment of NGOs, the Alliance in 
partnership with the Milken Institute School of Public Health of the George Washington University and local academic institutions in Ethiopia, Uganda and Zambia, a research project funded by UK Aid via the Global Road Safety Facility, is underway.

\section{Conclusion}

People are being killed or seriously injured in our ubiquitous use of the road transport system around the world. Knowing the continuing unacceptable numbers of deaths and injuries, yet not implementing or funding the measures that are known to save lives and injuries with continuing acceptance that road safety is a personal responsibility rather than a system designer responsibility, all reflect the deep lack of political will to address the road safety problem. Genuine commitments to road safety delivery are demonstrated by funds allocated to and spent on measures that are known to work in saving lives and injuries. Decision makers have the power to determine where funds go and how funds are spent and greater transparency in impactful investments in road safety is needed. NGOs have the power to increase the political will through three key roles: 1) Advocacy to drive the implementation and financing of evidence-based interventions; 2) Holding decision makers accountable for road safety delivery; and 3) Empowering communities to demand a Safe System. In order for NGOs to have influence at the decision-maker levels, governments and other decision makers must also allow NGOs to participate in decision making. NGOs are needed to deliver the target of reducing road traffic deaths and injuries by at least $50 \%$ by 2030 .

\section{Acknowledgement}

We would like to thank all the Alliance member NGOs who participated in the Alliance NGO survey. The Alliance receives funding, including non-earmarked funding, from FedEx, Total Energies, FIA Foundation and Global Road Safety Facility. However, this work was not supported by any specific funder nor were the contents influenced by the funders.

\section{References}

Berndt, M., Muent, G., Revoltella, D., Bending, T., Calthrop, E., Dunnett, G., ... \& Välila, T. (2014). Restoring EU competitiveness. Regional Studies and Roundtables.

FindLaw. (2021). Comparing State DUI Laws. Thomas Reuters. https://www.findlaw.com/dui/laws-resources/comparingstate-dui-laws.html

iRAP. (2021). 3 Star of Better. https://irap.org/3-star-or-better/

Ivers, R. Q., Sakashita, C., Senserrick, T., Elkington, J., Lo, S., Boufous, S., \& De Rome, L. (2016). Does an on-road motorcycle coaching program reduce crashes in novice riders? A randomised control trial. Accident Analysis \& Prevention, 86, 40-46.
Job R.F.S. and Sakashita C. (2012). "Combining safe system principles and road safety education in schools: An opportunity for improved demand on road system operators and a broader understanding of risk and safety." Paper presented to the Australasian Road Safety Research Policing and Education Conference, Wellington, 4-6 October 2012.

Job, RFS (2019). Development of a Safe System Approach: Barriers to be overcome. Invited presentation to - From Silos to Safe System: TRB Road Safety Workshop, January 2019, Washington DC.

Job, RFS (2020). To sustain momentum, we must do better in two vital areas: speed management and funding of road safety. In: Can Vision Zero become a Reality? A Quick Guide to Road Safety. England: PVC Group.

Kayani, A., King, M. J., \& Fleiter, J. J. (2011). Fatalism and road safety in developing countries, with a focus on Pakistan. Journal of the Australasian College of Road Safety, 22(2), 41-47.

Ker, K., Roberts, I., Collier, T., Beyer, F., Bunn, F., \& Frost, C. (2005). Post-licence driver education for the prevention of road traffic crashes: a systematic review of randomised controlled trials. Accident Analysis \& Prevention, 37(2), 305-313.

National Highway Traffic Safety Administration [NHTSA]. (n.d.). Automated Vehicles for Safety. https://www.nhtsa.gov/ technology-innovation/automated-vehicles-safety

Overseas Development Institute. (2018). Securing safe roads. The politics of change. https://cdn.odi.org/media/ documents/12132.pdf

Peng Y., Vaidya N., Finnie R., Reynolds J., Dumitru C., Njie G., Elder R., Ivers R., Sakashita C., Shults R.A., Sleet D.A., Compton R.P. and the Community Preventive Services Task Force. (2017) "Universal Motorcycle Helmet Laws to Reduce Injuries: A Community Guide Systematic Review". American Journal of Preventative Medicine. 52(6):820-832. doi:10.1016/j.amepre.2016.11.030.

Power, J. (2019, 24 February). Cut speed limits to $30 \mathrm{~km} / \mathrm{h}$ and save lives, road safety expert says. The Sydney Morning Herald. https://www.smh.com.au/national/nsw/provenways-to-reduce-road-deaths-and-injuries-20190221-p50zaq. html\#: :text=Speed $\% 20$ limits $\% 20$ should $\% 20$ be $\% 20$ reduced,expert $\% 20$ Emeritus $\% 20$ Professor $\% 20$ Raphael $\% 20$ Grzebieta.

Roberts, I. G. and Kwan, I. (2001). School-based driver education for the prevention of traffic crashes. Cochrane database of systematic reviews, (3).

Sekhar, C. R., Nataraju, J., Velmurugan, S., Kumar, P., \& Sitaramanjaneyulu, K. (2016). Free flow speed analysis of two lane interurban highways. Transportation research procedia, 17, 664-673.

Stockholm Declaration. (2020). Third Global Ministerial Conference on Road Safety: Achieving Global Goals 2030 Stockholm, 19-20 February 2020. https://www.roadsafetysweden.com/contentassets/ b37f0951c837443eb9661668d5be439e/stockholmdeclaration-english.pdf 
The Global Alliance of NGOs for Road Safety [The Alliance] \& Accountability International. (2020). The Day Our World Crumbled: The Human Cost of Inaction on Road Safety. https://www.roadsafetyngos.org/what-we-do/resources/ publications/the-day-our-world-crumbled-the-humanimpact-of-inaction-on-road-safety/

The Global Alliance of NGOs for Road Safety [The Alliance]. (2021). Good Practice Guide: Meaningful NGO Participation. https://www.roadsafetyngos.org/what-we-do/ resources/publications/good-practice-guide-meaningfulngo-participation/

The Global Alliance of NGOs for Road Safety [The Alliance]. (2020, 25 June). Building a Safe, Sustainable City in Patiala. https://www.roadsafetyngos.org/events/building-asafe-sustainable-city-in-patiala/

The Global Alliance of NGOs for Road Safety [The Alliance]. (2019, 26 May). \#SpeakUp doesn't end here: \#CommitToAct. https://www.roadsafetyngos.org/events/ speakup-doesnt-end-committoact/

Transport for London [@Tfl]. (2021, Nov 17).71\% of Londoners think road users are not as considerate of other as they should be, but only 9\% think they themselves could be more considerate. Twitter. https://twitter.com/ttl/ status/1460910696087138307?s=21

Turner, B., Job, S. and Mitra, S. (2021). Guide for Road Safety Interventions: Evidence of What Works and What Does Not Work. Washington, DC., USA: World Bank. https:// www.roadsafetyfacility.org/publications/guide-road-safetyinterventions-evidence-what-works-and-what-does-notwork
United Nations General Assembly. (2021, Dec 3). Supporting Event for the High-Level Meeting on Global Road Safety. 3 December 2021, United Nations Headquarters, New York. https://www.un.org/pga/76/event/high-level-meeting-onglobal-road-safety/

Vanguard. (2021, 4 December). Devil now in charge of Bauchi roads - FRSC https://www.vanguardngr.com/2021/12/devilnow-in-charge-of-bauchi-roads-frsc/

Ward, D. (2020, 30 November). Method not Miracles Bring Safety. http://www.daviddjward.com/method-not-miraclesbring-safety/

Wegman, F. (2015). Catalytic funding for road safety in the post 2015 period: priorities, resources and impact. Proposal to support the work of the High-Level Panel for Road Safety. Paris, FIA.

World Bank. (2020). Guide for Road Safety Opportunities and Challenges: Low and Middle Income Country Profiles.

World Health Organization [WHO]. (2015). Global Status Report on Road Safety 2015. Geneva: World Health Organization.

World Health Organization [WHO]. (2018). Global Status Report on Road Safety 2018. Geneva: World Health Organization.

World Health Organization [WHO] and United Nations Regional Commissions (2021). Global Plan for the Decade of Action for Road Safety 2021-2030. https://www.who.int/ publications/m/item/global-plan-for-the-decade-of-actionfor-road-safety-2021-2030

Zipper, D. (2021, 26 November). The Deadly Myth That Human Error Causes Most Car Crashes. The Atlantic. https://www. theatlantic.com/ideas/archive/2021/11/deadly-myth-humanerror-causes-most-car-crashes/620808/ 


\title{
Letter to the Editor
}

\section{COVID-19 pandemic, driving test and road safety during outbreak}

\author{
Rujittika Mungmngpuntipantip $^{1}$ and Viroj Wiwanitkit ${ }^{2}$ \\ ${ }^{1}$ Private Academic Consultant, Bangkok, Thailand \\ ${ }^{2}$ Dr DY Patil University, Pune, India
}

Corresponding Author: Rujittika Mungmngpuntipantip, Private Academic Consultant, Bangkok, Thailand. rujittika@gmail.com.

\section{Keywords}

COVID-19, pandemic, driving test, safety

\section{Dear Editor,}

We would like to share our ideas regarding the publication entitled "Exemption of behind-the-wheel driving test for novice young drivers: A serious public health concern (Bari et al, 2020)." Bari et al. (2020) stated that "While the decision was made to address the backlog of driving tests created by the COVID-19 pandemic, and also to practice social distancing (Taylor, 2020), many public health experts are now concerned that this decision will have catastrophic consequences on road safety." Research suggests that a driving test that monitors both driver performance and behavior (Lee, 2008) is a good test and one that advances road safety. Whether a driving test can be exempted in some special circumstances is an interesting question.

Wiberg (2006) found that there is no gender difference in practical test performance among those male and female individuals who take their driver's license test. However, Wiberg (2006) did find female test-takers performed better than their male counterparts on the theoretical part of the test. Presently, driving test are mandatory for anyone wanting a driver's license, without any exemptions. Health screening is also recommended for diseases such as eye disorders and neuropsychiatric problems.

During the COVID-19 outbreak, because of social distancing public health requirements, driving tests had to be postponed. Nevertheless driver license testing is necessary. Hence, there needs to be solution to overcome the present COVID-19 outbreak problem. One possible solution is to carry out the test using a closed-circuit television (CCTV) camera system for monitoring the driver from a remote safe distance. Approved CCTV technology can be effective in road safety applications as well as in training and licensing drivers (Satiennam et al., 2020).

We agree with Bari et al. (2020), that a lack of testing might increase the risk of traffic incidences for inexperienced young drivers. Prevention of deaths and serious injuries is important, as is preventing COVID19-related deaths via social distancing. Basic safety control measures, such as alcohol breath testing, have been still possible during the COVID-19 pandemic if appropriate personal protection equipment (PPE) are used, such as face shields, masks and for example by using an extension breathing tube for an alcohol breath test (Mungmunpuntipantip and Wiwanitkit, 2020). It simply requires a appropriate planning and adaptation for maintaining social distancing (Mungmunpuntipantip and Wiwanitkit, 2020) and/or anti-viral protection procedures currently being carried out in COVID-19 testing stations and hospitals.

Traffic safety during the present COVID-outbreak is important. Use of safety protective equipment such as helmets and seatbelts, maintaining legal regulations such as speed control and alcohol breath testing, and driver licensing tests, are all still necessary and required. Furthermore, adolescent driving behavior has not changed post COVID-19 outbreak (Stavrinos et al. 2020) although

Received: 09/03/2021; Received in revised form: 12/04/2021; Accepted: 21/12/2021; Available online: 09/02/2022

Copyright: (C) The Author(s). 2021 This is an open access article distributed under the terms of the Creative Commons Attribution (CC BY)_license, which permits unrestricted use, distribution, and reproduction in any medium, provided the original author(s) and the source are credited.

Suggested citation: Mungmngpuntipantip, R. and Wiwanitkit, V. (2022). "COVID-19 pandemic, driving test and road safety during outbreak" Journal of Road Safety, 33(1), 71-72. https://doi.org/10.33492/JRS-D-21-00014 
there appears to be a decreased number of crash incidents (Morris et al., 2020). However, Inada et al. (2021) found that empty roads in Japan during lockdown triggered an increase in speed-related traffic violations causing fatal motor vehicle collisions. Another interesting example is a case study presented by Fernandes (2021) of a motorcycle rider who wore a simple helmet that covered only his head but not his face. At the time of the incident he was wearing a loose facemask while riding. His facemask slipped upwards in the wind blinding him and he subsequently fell seriously injuring his leg.

Hence, appropriate guidelines for the simultaneous use of traffic safety technologies and infection prevention PPE against COVID-19, along with appropriate public health educational and training programs for safe driving/riding, should be developed and are necessary.

\section{References}

Bari, I., Paichadze, N. and Hyder, A.A. (2020). Exemption of behind-the-wheel driving test for novice young drivers: A serious public health concern. Journal of Road Safety, 31(4), 59-61.

Fernandes, R. (2021). COVID-19, facemask wearing, riding and accident. Case Study and Case Report, 11(1), 4 - 6.
Inada, H., Ashraf, L., Campbell, S. (2021). COVID-19 lockdown and fatal motor vehicle collisions due to speed-related traffic violations in Japan: a time-series study. Injury Prevention, 27(1), 98-100.

Lee, J.D. (2008). Fifty years of driving safety research. Human Factors, 50(3), 521-8.

Morris, D., Rogers, M., Kissmer, N., Du Preez, A., Dufourqa, N. (2020). Impact of lockdown measures implemented during the Covid-19 pandemic on the burden of trauma presentations to a regional emergency department in KwaZulu Natal, South Africa. African Journal of Emergency Medicine, 10(4), 193-196.

Mungmunpuntipantip R, Wiwanitkit V. Breath alcohol test and COVID.19. Med J Dr DY Patil Univ Ahead of print DOI: 10.4103/mjdrdypu.mjdrdypu_240_20

Satiennam, T., Kumphong, J., Satiennam, W., Klungboonkrong, P., Jaensirisak, S., Ratanavaraha, V. (2020) Change in helmet use behavior enforced by CCTV cameras with automatic helmet use detection system on an urban arterial road. Traffic Injury Prevention, 21(7), 494-499.

Stavrinos, D., McManus, B., Mrug, S., He, H., Gresham, B., Albright, M.G., Svancara, A.M., Whittington, C., Underhill A, White, D.M. (2020). Adolescent driving behavior before and during restrictions related to COVID-19. Accidental Analysis and Prevention, 144, 105686.

Wiberg, G. (2006). Gender differences in the Swedish drivinglicense test. Journal of Safety Resesarch, 37(3), 285-291. 


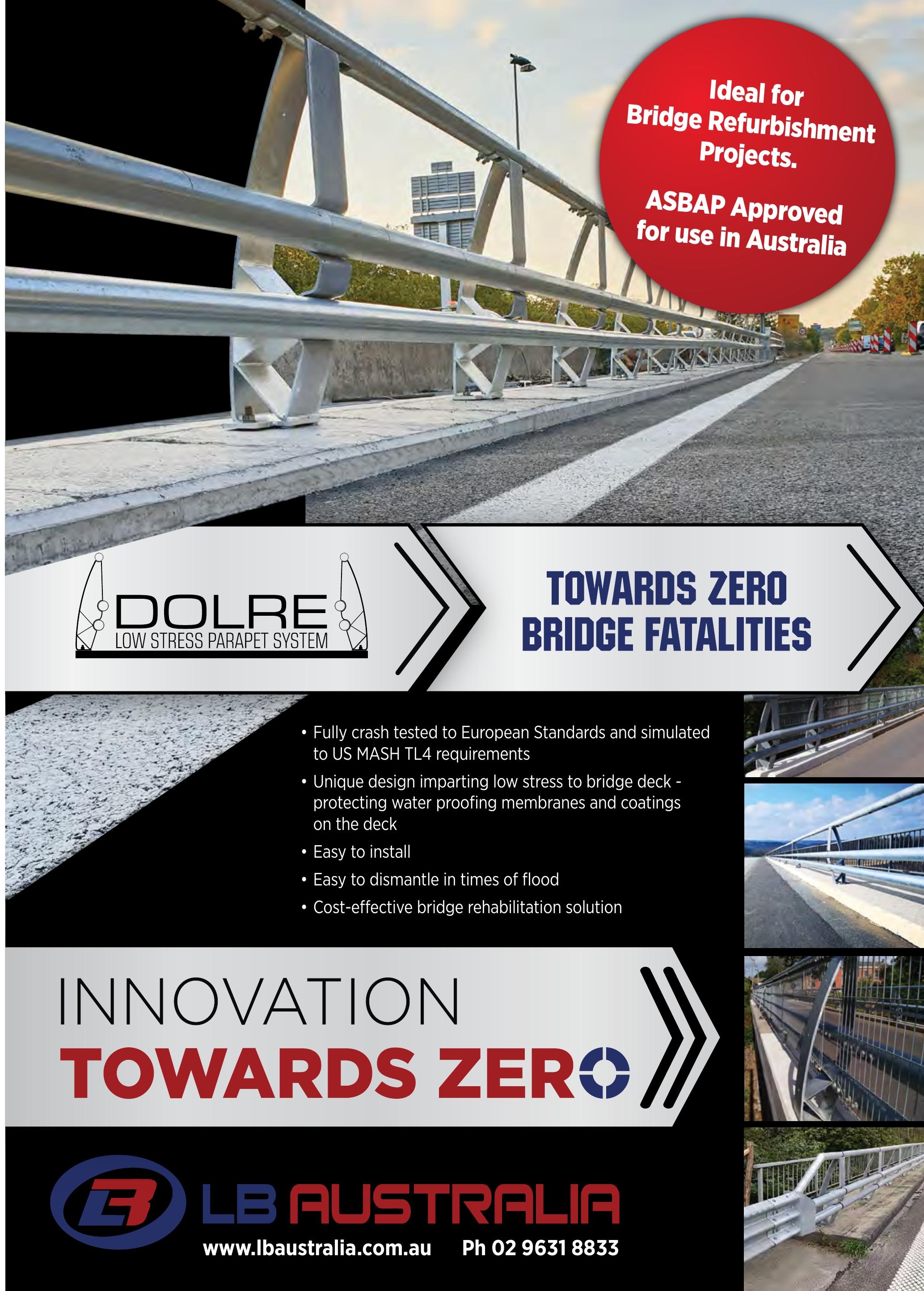




\section{Journal of Road Safety (JRS)}

Visit the JRS website at:

journalofroadsafety.org

Australasian College of Road Safety Inc.

ACRS, PO Box 198, Mawson ACT 2607 Australia

Tel 0262902509

Fax 0262900914

Email ceo@acrs.org.au Head Office

Pearce Centre, Collett Place, Pearce ACT Australia

Visit the College website at www.acrs.org.au

\section{Proudly sponsored by}

LB Australia

Transport for NSW (TfNSW)

and New Zealand Transport Agency

(5) LвคบSTRALIF

NZTRANSPORT

ACENCY

WAKA KOTAH 